\title{
Einleitung
}

\section{RELIGION UND SOZIALISMUS}

Moses Heß wurde am 21. Januar 1812 in Bonn im Rheinland geboren. Diese Provinz hatte in der Zeit der französischen Annektion von 1795 bis 1815 eine tiefgehende ökonomische, soziale und politische Umwälzung erlebt; die Feudalverfassung war beseitigt worden, der Adel hatte Güter und Privilegien verloren, die vermögendsten Bauern wurden zu Großgrundbesitzern, der Entwicklung von Industrie und Handel ward freie Bahn gegeben, die Bourgeoisie begann zur führenden Klasse heranzuwachsen.

In dieser Umwälzung begriffen, wurde das Rheinland auf Grund des Wiener Vertrages (1815) von Frankreich getrennt und zusammen mit Westfalen Preußen angegliedert. Trotz der Befreiung von den militärischen und fiskalischen Lasten, die das Land unter der napoleonischen Herrschaft zu tragen hatte, fand die Angliederung an Preußen nicht den ungeteilten Beifall der Rheinländer, da Preußen die unter Napoleon eingeführten Reformen wieder rückgängig zu machen und das Gebiet den feudalen preußischen Provinzen anzugleichen suchte. Die Rheinprovinz wurde der Mittelpunkt liberaler Bestrebungen und, nachdem infolge der Zollvereinigung die Entwicklung der Industrie und damit auch des Proletariats gefördert wurde, auch ein Mittelpunkt der sozialistischen Bewegung.

Moses Heß entstammt einer strenggläubigen jüdischen Familie. ${ }^{1}$ Seine Vorfahren waren in der Rheinprovinz, in Baden und Hessen beheimatet, über seine Mutter führt auch eine Linie nach Polen. Moses' Vater, David Heß (1790-1851), ein vermögender Kaufmann, war 1816 oder 1817 von Bonn nach Köln übergesiedelt und unterhielt hier zunächst ein Kolonialwarengeschäft, gründete dann, in der ersten Hälfte der 30er Jahre, mit einem Teilhaber, der wieder ausschied, eine Zuckerraffinerie, die bis 1881 bestand. Moses sollte im Geiste seiner Vorfahren erzogen werden, daher ließ man ihn in Bonn bei den Großeltern; sein im Talmud gelehrter Großvater unterzog sich gewissenhaft der Aufgabe und unterwarf das Kind einer strengen jüdisch-religiösen Erziehung. Nach dem Sturz Napoleons und besonders nach dem Wartburgfest (1817) hatten die Juden schwer unter den Maßnahmen der Reaktion zu leiden, durch die ihnen die Bürgerrechte beschnitten wurden, die sie nach der Französischen Revolution erhalten hatten. Auf zweierlei Weise reagierten sie auf den Druck der Reaktion. Einige (wie Eduard Gans und Heinrich Heine) lösten sich von der jüdischen Religion und ließen sich taufen. ${ }^{2}$ Bei anderen provozierte die Judenverfolgung und -ächtung eine Erstarrung in strengem Dogmatismus. Dieses war offenbar der Fall bei dem Großvater von Moses Heß. Indes waren die Juden trotz der Verringerung der ihnen 
unter Napoleon gewährten Rechte auch unter der neuen, preußischen Herrschaft nicht mehr zum Ghettodasein verurteilt, daher auch konnte Heß' Vater sich in Köln als Geschäftsmann etablieren. Die Familie scheint unter den Judenverfolgungen kaum gelitten zu haben; bis Anfang der 40er Jahre war Moses Heß durchaus preußenfreundlich gesinnt. ${ }^{3}$

Eine Schule besuchte Heß nicht, nur in Privatstunden lernte er etwas Deutsch und Französisch..$^{3 a}$

Die unerbittliche jüdisch-religiöse Erziehung, der $\mathrm{HeB}$ anderthalb Jahrzehnte bis auf den Grund seiner Seele ausgesetzt war, hatte zwei sehr verschiedene Folgen, die von großer Tragweite für seinen gesamten geistigen Habitus sein sollten.

Jene versenkte in sein Bewußtsein eine eschatologische Heilserwartung, die ein verborgenes Motiv seiner im Laufe der Zeit wechselnden Vorstellungen von einer Reform der Gesellschaft bildete. Zugleich entband sie eine schwärmerische Phantasie, die weniger durch Gedanken- oder Assoziationsreichtum als durch die Neigung gekennzeichnet war, sich mit Illusionen über nicht bewältigbare Realitäten hinwegzusetzen, und die Heß schon in jungen Jahren die Kompensation persönlichen Unglücks gewährte und ihm immer dann einen Ausgleich bot, wenn seine Gaben ihm die gedankliche Durchdringung eines Sachverhalts verschlossen.

Während Verstand und Seele des jungen Heß nachhaltig von der Geisteshaltung seiner Vorfahren geprägt wurden, zeitigte der gleiche Einfluß eine der eben genannten konträre Wirkung: Heß rebellierte gegen die jüdische Religion und die Pflichten und Opfer, die sie dem Geist und der täglichen Lebensführung auferlegte. Allerdings blieb sein Sträuben gegen den Zwang einer orthodoxen Geistes- und Lebenshaltung eine latente Kraft, unüberwindlich schien die Macht des Großvaters, von dem oder unter dessen Billigung das Kind ,über den Talmud schwarz u[nd] blau“ geschlagen wurde ${ }^{3 b}$, und der zunächst in seine Seele einen blinden Autoritätsglauben pflanzte ; als ,,Kerker“ erschien dem auf seine Kindheit zurückblickenden vierundzwanzigjährigen HeB diese Zeit. ${ }^{3 c}$

Moses war kaum 14 Jahre alt, als seine Mutter starb. Der Vater nahm ihn zu sich nach Köln, um ihn als Kaufmann auszubilden, da er als ältester Sohn dereinst das Geschäft übernehmen sollte (Moses hatte zwei Brüder und zwei Schwestern). Nur dieses äußerlichen Anstoßes der Übersiedlung nach Köln in das Haus des Vaters, dessen geschäftliche Inanspruchnahme eine bisher unbekannte Freiheit für $\mathrm{HeB}$ bedeutete, bedurfte es, um die angestaute Opposition zum Ausbruch kommen zu lassen. Zwar blieb Moses anfangs ,noch ein sehr frommes Judenkind“, denn erst allmählich fand er Zugang zu anderen Bildungsmitteln, aber der Talmud war ihm ,herzlich zuwider".3d Er faßte eine Abneigung gegen die Lehre, deren Härte, durch keine Mutterliebe gemildert, auf ihn eingedrungen war. In sein Aufbegehren, das ihn für revolutionäre Einflüsse empfänglich machte, mischte sich das schmerzliche Empfinden des Entbehrens jeder mütterlichen oder väterlichen Herzlichkeit. Das Verlangen hiernach flocht in sein Wesen eine schwermütige Sehnsucht nach Liebe und Versöhnung, einen Zug, der viele seiner intellektuellen Produktionen beeinträchtigen sollte.

Es ist ersichtlich, daß $\mathrm{HeB}$ der geistigen Atmosphäre seiner Vorfahren keineswegs ungeteilt ergeben war; jene provozierte ihn vielmehr zu einem Auflehnen gegen Verhältnisse, in die er hineingeboren. Um so weniger kann seine jüdische Herkunft in positivem Sinne als Voraussetzung seiner Hinwendung zum Sozialismus gewertet werden, wie dies Heß' erster Biograph Theodor Zlocisti tat, allerdings in Unkenntnis des hier herangezogenen Tagebuchs und lediglich gestützt auf Erinnerungen, die Heß 
in seinem viele Jahre später verfaßten Buch Rom und Jerusalem (1862) eingeflochten hat. $^{3 e}$ Die heute verfügbaren Materialien lassen erkennen, daß diese Rückblicke rosig gefärbt sind, offenbar infolge des zeitlichen Abstandes und Heß' aktueller Situation, die ihn zu einer geistigen Flucht in die Kindheit veranlaßte. ${ }^{4}$

Heß' geistige Entwicklung in dem Jahrzehnt nach seinem Einzug in das Vaterhaus in Köln ist gekennzeichnet durch eine fortschreitende Anpassung der religiösen Heilserwartung an sozialreformerische Zielstellungen, die Heß in dem Maße entwickelte oder sich zu eigen machte, wie er die sozialen Verhältnisse seiner Umwelt bewußt zur Kenntnis nahm und seinen Gesichtskreis durch philosophische, historische und sozialkritische Literatur erweiterte.

Zunächst geriet er, sechzehnjährig, infolge seines Aufbegehrens gegen das orthodoxe Judentum in eine geistige Krisis. ${ }^{4 a}$ Während er dem Vater im Geschäft half ${ }^{4 b}$, hatte er „Musse genug“, sich ,,mit dem Nötigsten und Nützlichsten für's Leben bekannt zu machen“; nachdem er viel ,gelesen und erfahren“ hatte, ,gab's eine ungeheure Revolution“ in seinem „Innern“4c. Seine ,positive Religion“ „fiel zusammen“, „ich war der Elendeste auf der Welt - ich war Attheist". 4d Nach etwa zwei Jahren fand er sein Gleichgewicht wieder in einer auf dem Glauben an die Existenz ,einer höchsten Vernunft"4e beruhenden ,,moralische ( $n$ ) Weltordnung ${ }^{\text {“4f }}$, in der ihm in Anlehnung an Rousseaus Emile das Übel in der Welt als notwendiger Ansporn für die Entfaltung des Guten galt. $^{4 \mathrm{~g}}$

Die vorwiegend moralphilosophische Sicht des achtzehnjährigen Heß bezog auch schon politische Verhältnisse in den Kreis der ,,so vielfältigen Übel ${ }^{\star 4 h}$ ein. Anläßlich der Revolution in Frankreich und Belgien und der Insurrektion in Warschau im Jahre 1830 äußerte $\mathrm{HeB}$, diese Ereignisse seien geeignet, den monarchischen Übermut etwas zu zügeln; bei dieser Gelegenheit läßt er zum ersten Mal einen politischen Standpunkt erkennen: gleich den rheinischen Liberalen bekannte er sich zur konstitutionellen Monarchie. ${ }^{4 i}$ Obwohl Preußen nicht diese Staatsform hatte, scheint HeB zu jener Zeit keineswegs preußenfeindlich gewesen $\mathrm{zu}$ sein..$^{\mathbf{j}}$

Um seinen Trieb nach Wissen und nach Vertiefung seiner Weltanschauung zu befriedigen, beschäftigte $\mathrm{He} B$ sich weiterhin mit philosophischer und historischer Literatur, las u. a. Spinoza und Rousseau und ergänzte recht und schlecht die einseitige Bildung, die er von seinem Großvater erhalten. ${ }^{5}$ Heß' Vater blieb den Interessen seines Sohnes verschlossen; Konflikte konnten nicht ausbleiben. Heimlich verließ Moses $\mathrm{He} B 1833$ das Vaterhaus und ging ins Ausland, von dem Wunsch getrieben, ein unabhängiges Leben zu gewinnen. Dieser Ausbruch war eine erste, noch unbestimmte Revolte gegen eine soziale Organisation, der er sich nicht fügen konnte. Zunächst ging er nach Holland, dann vielleicht auch nach Frankreich, das nach der Revolution von 1830 ein Sammelpunkt vieler Geächteten und Aufständischen war. Heß' Bekanntschaft mit französischen sozialistischen Lehren, von denen die sozialistischen Auffassungen seiner ersten Veröffentlichungen inspiriert sind, könnte hier ihren Anfang genommen haben. Materielle Not veranlaßte ihn, nach Deutschland zurückzukehren. Ein Onkel vermittelte die Versöhnung zwischen Vater und Sohn; Moses versprach, ein ordentlicher Geschäftsmann zu werden, und geriet aufs neue in den Zwiespalt seiner Neigungen und den väterlichen Forderungen. ${ }^{5 a}$

Obwohl er in der Mitte der 30er Jahre als Hospitant einige Vorlesungen (Philosophie und Naturwissenschaften) an der Universität in Bonn besuchen konnte, blieb er doch ein ausgesprochener Autodidakt. In Spinoza fand er das Vorbild für eine Lebensweise, 
die praktische mit theoretischer Tätigkeit vereint. So arbeitete er tagsüber in dem Unternehmen seines Vaters und widmete sich in seiner Freizeit philosophischen Studien, wobei er sich vor allem mit Rousseau und Spinoza befaßte, in welch letzterem er eine Verheißung der Versöhnung zwischen Gott und Welt und den Menschen untereinander zu finden meinte. ${ }^{5 b}$

Im Hinblick auf seine in dieser Zeit beginnende Aufmerksamkeit für soziale Fragen ist hervorzuheben, daß er sich in den Jahren 1835/36 u. a. mit Börne, Heine (Zur Geschichte der Religion und Philosophie in Deutschland, 1835) und Bulwer (Die Herrschaft der Mittelklassen (The monarchy of the middle classes] 1836) beschäftigte und mindestens gelegentlich Menzels Literaturblatt las, das der sozialen Problematik und den französischen sozialistischen Lehren breiten Raum widmete.

Heß' auf persönliche Freiheit gehendes Trachten weitete sich immer mehr zu dem Bestreben nach umfassender Veränderung der menschlichen Gesellschaft aus. Der Aufenthalt im Ausland mochte seinen Blick für die sozialen Verhältnisse seiner Heimat geschärft haben, und seine Erfahrungen auf dem Gebiete des „Schacher's“ haben ihn wohl, ähnlich wie Fourier, zu sozial-reformerischen Überlegungen angeregt. ${ }^{5 c}$

In Spinoza und Rousseau fand $\mathrm{HeB}$ auch die gedanklichen Elemente, die ihm erlaubten, den Begriff der religiösen Harmonisierung in den der sozialen umzuwandeln.

Spinoza ermöglichte es ihm, als er sich noch nicht gänzlich vom Gottesglauben zu lösen vermochte, die von der Religion in das Jenseits verlegte Harmonisierung in das Diesseits zu verlagern. Und Rousseau gab ihm den Ausgangspunkt für ein neues gesellschaftliches Ideal, als dessen Wirklichkeit er eine auf dem Prinzip der sozialen Gleichheit beruhende Gesellschaft ansah. Auf diese Weise säkularisierte sich des vierundzwanzigjährigen Schwärmers Erlösungsvorstellung, er ließ sie mit sozialistischen Zielsetzungen zusammenfallen.

Die noch festgehaltenen religiösen Voraussetzungen bedingen dabei die Forderung sowohl nach Harmonie zwischen Gott und Mensch als auch der Menschen untereinander. Die religiösen Voraussetzungen werden jedoch soweit abgeändert, damit der in der Religion ausgeprochene prinzipielle, in dieser Welt nicht versöhnbare Gegensatz von Gott und Welt einer diesseitigen Versöhnung zugänglich wird: Gott und Welt bleiben zwei reale Wesenheiten, werden aber in Anlehnung an Spinoza innerlich wesensgleich gedacht.

Der Versuch, überkommene religiöse Vorstellungen mit sozialistischen Zielsetzungen in Einklang zu bringen, war charakteristisch für Sozialreformer in der Epoche des Frühkapitalismus. Das Werk eines der bekanntesten Vertreter dieser Vermittlungsversuche, Lamennais' Paroles d'un croyant, (1834 Worte eines Gläubigen), findet sich bezeichnenderweise unter den Schriften, die Heß sich 1835 zu lesen vorgenommen hatte. ${ }^{5 d}$

Es drängte $\mathrm{He} ß$, seine Auffassung auf die Geschichte, von der er kaum die oberflächlichste Kenntnis erworben hatte, anzuwenden und sie der Menschheit zu offenbaren. Im November 1835 begann er Die heilige Geschichte der Menschheit. Von einem Jünger Spinoza's ${ }^{5 e}$ zu schreiben; die Schrift erschien anonym Ende September oder Anfang Oktober 1837 bei Hallberger in Stuttgart. ${ }^{6}$

Die zentrale Idee des Buches bildet die Auffassung des Heils, das durch die Vereinigung des Menschen mit Gott erreicht werden soll. Diese Harmonie von Gott und Mensch habe schon einmal, auf unbewußte Weise, im ,alten Bunde“ geherrscht, in dem HeB die Vorwegnahme der kommenden sozialistischen Gesellschaft sieht. Der 
Harmonie folgte die Trennung zwischen Gott und den Menschen, und Heß erblickt seine ihm von Gott zugedachte Aufgabe darin zu zeigen, wie jene Harmonie wiederhergestellt werden muB, und zwar dieses Mal nicht als das Werk unbewußter, sondern bewußter Tätigkeit. Er fühlt sich als gefügiges Werkzeug Gottes, dem die Berufung zugefallen sei, den Menschen den Weg der Erlösung zu offenbaren. Als erster Verkünder der neuen Lehre habe Spinoza die innere Harmonie von Gott und Welt bewußt gemacht. Es komme nun darauf an, die Einsicht zu verbreiten, auf welche Weise der Wille Gottes, der sich in der Geschichte entfalte, von seiten der Menschen realisiert werden müsse.

So verbindet $\mathrm{He} B$ die ihm durch seine Kindheitserziehung tief eingeprägte religiöse Erlöserkonzeption mit der spinozistischen Auffassung der Identität von Gott und Natur, die seinem Streben nach allgemeiner Befreiung der Menschheit durch die Erlangung göttlicher Harmonie entgegenkommt. Dabei gibt er dem Judentum einen vorwärtsweisenden Charakter, womit er sich zugleich von der strengen jüdischen Orthodoxie löst. Umgekehrt belebt er durch seine Erlöserkonzeption, die ein Entwicklungsmoment einschließt, die spinozistische Auffassung von der Gottwelt als Substanz, die eine Selbstentwicklung ausschließt.

Hatte Hegel Subjekt und Objekt in einer geistigen Einheit verschmolzen, so ererscheinen sie bei $\mathrm{HeB}$ gleich dem Leibnizschen Parallelismus als getrennt. Dieser Parallelismus gilt sowohl für die Beziehungen zwischen Seele und Körper als auch für die zwischen der Entwicklung des allgemeinen Bewußtseins und der Struktur der Gesellschaft. Führe die Bewußtseinsentwicklung notwendig zum Einswerden mit Gott, so werde diesem höchsten Bewußtseinszustand auch ein höchster Gesellschaftszustand entsprechen, in dem die Harmonie unter den Menschen verwirklicht sei. Der inneren Harmonie werde nach außen die soziale Gleichheit entsprechen, die $\mathrm{He} B$ in der Gütergemeinschaft sieht.

So erhält die philosophisch-religiöse Geschichtsauffassung eine sozialistische Richtung, die vor allem an der Rousseauschen Lehre von der sozialen Gleichheit der Menschen orientiert ist. Mit der Verwerfung der bestehenden gesellschaftlichen Verhältnisse legt $\mathrm{He} ß$ das Schwergewicht auf die künftige Entwicklung. Er fordert, daß der Historiker sich nicht mit dem Studium der Vergangenheit und der Gegenwart begnügen dürfe, sondern daß er aus diesem Studium die Gesetze ableiten müsse, deren Kenntnis es ermögliche, die künftige Entwicklung nicht nur zu verstehen, sondern auch, und das ist das entscheidende, $\mathrm{zu}$ bestimmen.

Heß' Auffassung eines gesetzmäßigen Geschichtsprozesses ist religiös fundiert - das Gesetz ist der Wille Gottes - und unbeeinflußt von der Hegelschen Dialektik. ${ }^{7}$ Weil in der Geschichte das Wirken Gottes zum Ausdruck kommt, ist sie heilig.

Die kommunistische Zukunftsaussage versucht $\mathrm{He} B$ aus der Vergangenheit abzuleiten. Entsprechend ist das Werk in zwei Hauptteile gegliedert: 1. Die Vergangenheit als Grund dessen, was geschehen wird, und 2. Die Zukunft als Folge dessen, was geschehen ist. ${ }^{8}$

Der erste Teil umfaßt drei große weltgeschichtliche Abschnitte. Der erste, vor Christus liegende, bildet die Kindheit der Menschheit, in der die unbewußte Vereinigung von Gott und Mensch herrscht, der eine auf Gütergemeinschaft gegründete Harmonie entspricht. Die zweite Periode hebt an mit dem durch Christus vermittelten Bewußtsein dieser Vereinigung und verläuft in der Verunstaltung der ursprünglichen Lehre. Die Verunstaltung erreicht im Mittelalter den Höhepunkt und ver- 
ursacht den Untergang der Harmonie und das Aufkommen des Privateigentums und des Erbrechts. Die dritte und letzte Periode der Vergangenheit bildet die Vorbereitung zur Wiederherstellung der geistigen und sozialen Harmonie. An ihrem Anfang steht Spinoza, der den Menschen wieder auf den Weg der Einheit des Göttlichen und Natürlichen zurückführte; ihr Gipfel ist die Französische Revolution.

Aus diesem der Vergangenheit angehörenden Gang der Geschichte schließt Heß im zweiten Teil auf ihren künftigen Verlauf. Es handelt sich hierbei im wesentlichen um eine teleologische Folgerung, die ihm gestattet, seine religiös-idealistischen Voraussetzungen mit dem sozialistischen Postulat zu verbinden.

Es sei ein historisches Gesetz, vom Keim auszugehen und geläutert und bewußt zum Keim als Frucht zurückzukehren. Im alten Bund, dem Keim, herrschten unbewußt Gleichheit und Freiheit. Die dann eingetretene Spaltung werde durch die Frucht, die künftige kommunistische Gesellschaft, wieder aufgehoben, und Gleichheit und Freiheit werden neuerdings erstehen, dieses $\mathrm{Mal}$ als Resultat bewußter menschlicher Tätigkeit.

Heß' Kritik an der in Gegensätzen zerfallenen Gesellschaft richtet sich vor allem gegen das Erbrecht, das Willkür, Ungerechtigkeit, Sklaverei, Egoismus und Zwietracht zur Folge hatte, die zugleich mit der Gleichheit die ursprüngliche Harmonie zerstören. ${ }^{9}$

Sollte eine von Einsicht getragene Schlichtung verabsäumt werden, so wird die Verschärfung der sozialen Ungleichheit - des Gegensatzes von ständig wachsendem Reichtum auf der einen und zunehmendem Elend des Volkes auf der anderen Seite -, die ihren Höhepunkt in der modernen Gesellschaft erreicht hat, zu einer sozialen Revolution führen, die durch die Abschaffung des Privateigentums und des Erbrechts und durch die Einführung der Gütergemeinschaft Harmonie und Gleichheit wiederherstellen wird.

Der Versuch einer Reform durch Verfassungsgebung oder Änderung der Regierungsform ist deshalb eitel und fruchtlos, weil er den Gegensatz von Armen und Reichen bestehen läßt. Allein die Beseitigung des Privateigentums und des Erbrechts, der Ursachen der sozialen Ungleichheit, vermag zu einer Harmonie unter den Menschen zu führen und das Reich Gottes neu erstehen zu lassen. Dieses wird das Werk von Frankreich und Deutschland sein. Die Vereinigung des Landes der Revolutionen Frankreich - mit dem Land der wahren Religion - Deutschland - verbürgt die Entstehung des ,neuen Jerusalem“. Darin wird es keine Kirche mehr geben, der Staat wird umgewandelt, der Gesetzgeber wird dem Verwalter weichen, und die Gesetze werden allein der Förderung der Humanität und der Eintracht dienen. Die Frau wird emanzipiert und die Jugend durch eine staatliche Erziehung der Willkür der Eltern entzogen sein. In Einigkeit und Freiheit wird die Menschheit in einem Zustand des Glücks und der Freude leben. ${ }^{9 a}$

Dieses erste Werk von $\mathrm{He} B$, in dem sich Religion, Philosophie und Kommunismus unklar vermengen, bringt sozialistische, auf die Befreiung des arbeitenden Volks gerichtete Bestrebungen zum Ausdruck, und zwar durch einen dem Proletariat noch fernstehenden Ideologen. Die gesellschaftskritische Komponente geht vor allem auf Rousseau zurück, aber die Frage ist, unter welchen Einflüssen die sozialistische Erweiterung der Rousseauschen Gesellschaftsauffassung vorgenommen wurde. ${ }^{9 b}$

Es ist behauptet worden, Heß habe auf seiner "Walze“ in der ersten Hälfte der 30er Jahre in Paris deutsche Handwerker kennengelernt, unter denen französische 


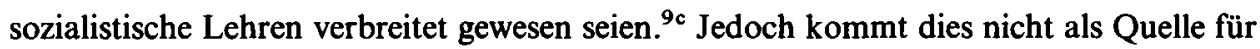
Heß' frühes sozialistisches Theoretisieren in Betracht. Heß hat 1845 öffentlich ausdrücklich erklärt, daß ihm bis 1842 die kommunistischen Handwerker in Paris gänzlich unbekannt gewesen seien. ${ }^{9 \mathrm{~d}}$ Hinsichtlich dieser Fèststellung war er sicherlich keinem Irrtum oder Gedächtnisschwund unterlegen. Im Fall einer erneuten Bekanntschaft in den 40er Jahren wäre ihm gewiß der frühere Kontakt in Erinnerung gerufen worden; und eine beabsichtigte Irreführung erscheint nicht nur unmotiviert, sie ist auch deshalb ausgeschlossen, weil seine Pariser Freunde aus dieser Zeit seine Schriften lasen und ihn ohne weiteres korrigieren konnten.

In dieser Frage sind wohl zunächst die praktischen Verhältnisse ins Auge zu fassen, mit denen $\mathrm{HeB}$ in seinem Vaterhaus und in Köln konfrontiert war. Indem er dem Vater im Kolonialwarengeschäft half, dürfte er Gelegenheit gehabt haben, die soziale Not mancher Käufer zur Kenntnis zu nehmen. Sodann dürfte ihm der speziell in Köln herrschende Pauperismus nicht verborgen geblieben sein. Und als er im Komptoir der väterlichen Zuckerfabrik arbeitete, lernte er die Methoden des kapitalistischen Erwerbs kennen, die ihn abstießen. ${ }^{9 \mathrm{e}}$

Zu diesen praktischen Einflüssen gesellten sich literarische. Die Rolle, die Spinoza und Rousseau in seiner Denkentwicklung spielten, ist erörtert worden. Mit der sozialkritischen und sozialistischen Literatur seiner Zeit war Heß offenbar in größerem Umfang vertraut, als die (in Anm. 7) zitierte Stelle aus seiner Schrift vom Jahre 1840 vermuten läßt. Wenn er dort feststellt, bei Abfassungsbeginn der Heiligen Geschichte Schriften von Heine noch nicht zu Gesicht bekommen zu haben, so entspricht das nicht den Tatsachen: mit Heine hatte er sich bereits 1835 beschäftigt. Die anderen dort genannten Autoren mag er damals im Original noch nicht gelesen haben, aber unzweifelhaft hat er aus zweiter Hand die Ansichten von einigen kennengelernt. So mußte er über Lamennais immerhin soviel vernommen haben, um sich veranlaßt zu fühlen, dessen Paroles d'un croyant auf seinen Leseplan zu setzen. ${ }^{\text {9f }}$ Indirekt belehrt uns $\mathrm{He} ß, \mathrm{da}$ ihm die sozialkritische Literatur und die sozialistischen Bestrebungen nicht ganz unbekannt gewesen sind. In der Heiligen Geschichte schreibt er: „Schon beklagen sich die Bessern und Einsichtsvollern über diese sociale Krankheit."9g „Geistreiche Männer haben schon viel über die ursprüngliche Gleichheit der Menschen gesprochen; [. . .] Man hat endlich behauptet, daß Gütergemeinschaft das Ziel unseres socialen Lebens sey [...] Erkennen wir das Verdienst derjenigen an, die das bedeutende Wort Gütergemeinschaft ausgeprochen haben - es hat uns aufmerksam gemacht auf das letzte Ziel des socialen Lebens. Wir sprechen auch nur darum von Jenen, die uns Gütergemeinschaft anspreisen, um ihnen die gebührende Gerechtigkeit widerfahren zu lassen. “9h $\mathrm{HeB}$ erklärt also selbst, durch andere auf sozialpolitische Zielsetzungen aufmerksam gemacht worden zu sein..$^{9 i}$.Woher wußte nun $H e ß$ von den Bessern und Einsichtsvollern und jenen, die Gütergemeinschaft anpreisen? Eine Antwort hierauf lautet offenbar: Menzels Literaturblatt. Daß Heß es wenigstens gelegentlich las, darf aus einem Briefkonzept an Menzel vom 2. und 18. Januar 1836 geschlossen werden, in dem $\mathrm{He} B$ sich um einen Posten bei dem von Menzel redigierten Blatt bewirbt. ${ }^{9 j}$

Das Literaturblatt hat in jenen Jahren deutsche und französische sozialkritische und sozialistische Schriften eingehend rezensiert und in selbständigen Aufsätzen auf die Bedeutung der sozialen Frage hingewiesen. In seinen Spalten waren St.-Simon, Lamennais und Fourier häufig vorkommende Namen. Alle sozialkritischen Elemente in HeB' 
Erstlingsschrift finden wir auch in dieser Zeitschrift, zumeist in Form von Buchbesprechungen, so die Feststellung der gesellschaftlichen Polarisation, die Kritik der Konkurrenzverhältnisse und der Geldaristokratie, die Erörterung des Verhältnisses von technischem und gesellschaftlichem Fortschritt, die Meinung, daß die soziale Frage aicht allein durch Verfassungsgebung zu regeln sei, das Diskutieren einer revolutionären Iösung und der Forderung nach Gütergleichheit und auch die Verbindung von Religion ind Sozialismus. ${ }^{9 k}$

Wenn $\mathrm{Heß}$ in so überschwenglichem Tone an Menzel schreibt, so läßt sich ungefähr ermessen, welche Anregungen er seinem Blatt verdankte. ${ }^{91}$ Freilich kommt das Literaturblatt nicht als einzige Quelle für Heß' Kenntnis auf diesem Gebiete in Betracht; es wurde hervorgehoben, weil Heß selbst darauf hinweist. ${ }^{9 m}$ Wie ich an anderer Stelle gezeigt habe, wurden in vielen Blättern und selbständigen Schriften die soziale Frage und französische sozialistische Lehren erörtert. ${ }^{9 n}$

Weitere Anregungen und Belehrungen dürfte $\mathrm{Heß}$ dem Werk von H. L. Bulwer über Frankreich verdanken, dessen zweite Abteilung (Die Herrschaft der Mittelklassen) Heß zweimal zitiert.90 Dieses Buch dürfte Heß gewisse Einsichten in ökonomische und soziale Zusammenhänge der bürgerlichen Gesellschaft und mindestens eine flüchtige Kenntnis des französischen Sozialismus vermittelt haben.

Unzweifelhaft hat also $\mathrm{HeB}$ einige Kenntnis der zeitgenössischen sozialkritischen Literatur sowie des französischen Sozialismus gehabt ${ }^{9 p}$, und von beiden Quellen hat er - wenn er sie auch vorwiegend nur aus zweiter Hand kannte - in der Heiligen Geschichte Gebrauch gemacht.

Im Lichte vorstehender Untersuchung bedarf Heß' Rolle als früher deutscher sozialistischer Theoretiker einer Neueinschätzung, wobei von der Liste der ihm zugesprochenen Verdienste einige nicht unwesentliche abzustreichen sind.

Alle Elemente seiner Sozialkritik waren bereits in der deutschen Literatur vertreten, von der westeuropäischen ganz zu schweigen. Und zwar finden wir sie, sowohl was die Beschreibung konkreter gesellschaftlicher Zustände angeht als auch hinsichtlich ökonomischer, sozialer und historischer Aspekte, weit exakter und tiefer formuliert als bei $\mathrm{HeB}$; dies sogar bei bürgerlichen Kritikern, besonders aber bei solchen sozialistischen bzw. radikal-demokratischen Autoren wie Gall und Gerstein. ${ }^{9 q}$

Mit der Feststellung der Bedeutung der sozialen Frage für Deutschland befindet Heß sich in einem großen Kreis gleich oder ähnlich urteilender Schriftsteller.

Nicht haltbar ist die Behauptung, Heß' Schrift habe in Deutschland den Übergang vom Liberalismus zum Sozialismus vorbereitet. ${ }^{9 r}$ Das Buch hatte keinerlei Auswirkungen auf jene Zeit und hat weder bei der Herausbildung der demokratischen und sozialistischen Bewegung noch bei deren Sonderung von einander und von der liberalen irgendeine Rolle gespielt.

Die (eklektische) Zusammenbringung von Spinozismus, Religion und Sozialismus leistete nicht, was sie sollte, nämlich die Ableitung der künftigen sozialistischen Verhältnisse aus dem Gang der Geschichte. Die Zukunft wird nicht kausal aus dem objektiven Geschichtsverlauf abgeleitet, sondern durch die Anwendung einer phantastischen Weltanschauung auf oberflächlich erfaßte gesellschaftliche Verhältnisse teleologisch konstruiert. Jedoch ist es dieser - völlig gescheiterte - Versuch, die sozialistische Umgestaltung der Gesellschaft als historisch-notwendigen Prozeß zu begreifen, der dem Heßschen Werk unter den Dokumenten des frühen sozialistischen Denkens in Deutschland einige Bedeutung verleiht. 
Heß selbst schrieb etwa acht Jahre später: „In dieser Zeit, die nur Noth- und Mißgeburten zur Welt bringen konnte, gab Schreiber dieses, sein erstes, sozialistisches Schriftchen heraus, auch nur eine kleine Noth- und Mißgeburt, die spurlos vorüberging. " 10

\section{DIE BEGRÜNDUNG DES,,WAHREN" SOZIALISMUS}

$$
\text { Die ,,Philosophie der Tat““ }
$$

Nachdem sich für ihn die religiösen Probleme in weltliche, politische und soziale, verwandelt hatten, verfolgte $\mathrm{He} B$ mit Aufmerksamkeit die politischen, literarischen und vor allem die philosophischen Auseinandersetzungen seiner Zeit. Gleichsam eine individuelle Aufklärungsepoche bedeutete für ihn wohl das Studium der Philosophie, dem er sich von Juni 1837 bis einschließlich Wintersemester 1838/39 an der Universität zu Bonn widmete. ${ }^{10 a}$ Mit dem Universitätsstudium begann Heß' stärkere Hinwendung zu dem modernen philosophischen Denken.

Unter der Literatur, mit der Heß sich seit Beginn seines Universitätsstudiums bis 1840, des Zeitraums der Vorarbeiten und der Ausarbeitung seines zweiten Buches, der Europäischen Triarchie, beschäftigte, finden sich vor allem Werke von Hegel sowie solche Schriften, die in den aktuellen Auseinandersetzungen eine Rolle spielten. ${ }^{11}$ Außerdem vertiefte er sich wieder in die Werke Spinozas und Rousseaus. Bestimmend für seine geistige Orientierung wurden jetzt die Hegelsche Philosophie und der Junghegelianismus. Hegel hatte mit der Anpassung des Wissens der Zeit und der bürgerlichen Emanzipationsbestrebungen an die Verhältnisse in Preußen diesem eine gewisse philosophisch-geschichtliche Rechtfertigung gegeben, was erklärt, daß seine Philosophie sich längere Zeit der Gunst der preußischen Regierung erfreute. In seiner Philosophie lagen jedoch wesentliche Elemente der Kritik und einer über sie hinausgehenden Ideologie verborgen.

Diese Elemente wurden von den Junghegelianern nach und nach ans Licht gezogen und polemisch gegen das absolutistische Preußen gewandt. Dies begann bald nach Hegels Tod (1831), unter der Auswirkung der kapitalistischen Entwicklung in Deutschland und der revolutionären Ereignisse in einer Reihe europäischer Länder. Wie die nordamerikanische Revolution ein halbes Jahrhundert zuvor den Anstoß zu revolutionären Erhebungen in Europa gab, gipfelnd in der Französischen Revolution, so waren neuerdings die revolutionären Ereignisse des Jahres 1830 für eine ganze Reihe europäischer Länder der Auftakt zur Entstehung, Wiederentstehung oder Konsolidierung oppositioneller Bewegungen, unter denen jetzt gänzlich neue, die Interessen des ,vierten Standes“ repräsentierende, auftraten.

Dies zeigte sich auch in den deutschen Staaten, namentlich nach Begründung des Zollvereins (1834), der durch die Ankurbelung der Industrie die Bourgeoisie zunehmend in Gegensatz zu den absolutistischen und halbabsolutistischen Regimes brachte und der von Anfang an das Selbstbewußtsein der Bourgeoisie stärkte, denn sie war die erfolgreich treibende Kraft dieser gegen die partikularistischen Interessen der deutschen Fürsten durchgesetzten Vereinbarung.

Parallel zu den ökonomischen, sozialen und politischen Vorgängen ging eịe 
Epoche der Aufklärung, bis gegen Mitte der 40er Jahre hauptsächlich repräsentiert durch das Junge Deutschland und den Junghegelianismus. Hauptmerkmal sowohl des Jungen Deutschland, das auf dem Gebiet der Literatur, wie des Junghegelianismus, der auf dem der Philosophie gegen die politische und geistige Unterdrückung durch den Absolutismus und die mit ihm liierte Kirche kämpften, war die Rezeption der westeuropäischen Aufklärung. Beide Strömungen radikalisierten das deutsche Geistesleben unter Rückgriff auf frühere antireligiöse und antiabsolutistische Bestrebungen in Westeuropa.

Der Junghegelianismus ${ }^{12}$ und die in seiner Nachbarschaft aufkommende materialistische Philosophie Feuerbachs sind eine Wiederaufnahme und Fortführung der deutschen und westeuropäischen Aufklärung und repräsentieren die progressivste geistige Bewegung des deutschen Bürgertums im Vormärz. Sie beginnt bei David Friedrich Strauß mit dem Kampf gegen die Religion und wird mit Bauer, Ruge, Marx, Engels bis zur Forderung nach revolutionärer Etablierung der bürgerlichen Republik radikalisiert.

In seinem den Beginn der junghegelschen Bewegung bezeichnenden Werk Das Leben Jesu ${ }^{12 a}$ anerkennt Strauß Hegels Pantheismus, wendet sich aber gegen den Kompromiß, in dem Hegel Pantheismus und christliche Religion und Philosophie und Glauben zusammengebracht hatte, und beginnt den verborgenen antichristlichen Inhalt der Hegelschen Philosophie manifest zu machen.

Hegel lehrte, die Religion philosophisch bestätigend, daß Religion und Philosophie den gleichen Inhalt, aber verschiedene Formen haben; den nämlichen Gegenstand erfaßt jene in Vorstellungen, diese in Begriffen. Christus war nach Hegel, der die Evangelien nicht auf ihren geschichtlichen Gehalt prüfte, ein Symbol der Verbindung Gottes und der Menschen.

Nach eingehender philosophischer und historischer Untersuchung stellt Strauß dagegen fest, daß die Jesus-Darstellungen der Evangelisten literarisch gefaßte Mythen seien und daß Jesus nicht göttlicher sei als jeder andere Mensch.

Mit diesem Ergebnis wandte Strauß sich gegen jene Hegelanhänger, die besonders auf den Ausbau der religionsverteidigenden Tendenzen Hegels bedacht waren. Aus Hegels Auffassung des Verhältnisses von Religion und Philosophie folgerten sie, daß, wenn wahre Ideen wirklich sind und die religiösen Vorstellungen in den Evangelien wahren Ideen entsprechen, die evangelischen Geschichten wirkliche Geschichte gewesen sein müssen. Diese die christliche Religion bestärkende Gleichsetzung erklärte Strauß für falsch; die Geschichte folge ihren eigenen Gesetzen und könne nicht rückwirkend postuliert werden. Die Wahrheit der Idee werde von der gesamten Weltgeschichte - als Entfaltung des Weltgeistes - produziert. Die Idee der Einheit von Gott und Mensch werde Wirklichkeit, aber nicht in einem Individuum, was auch gar nicht aus den Hegelschen Prämissen folge, sondern in der Menschheit.

Der von Strauß geführte Nachweis des mythischen Charakters der Evangelien nahm Jesus Christus die Göttlichkeit und zerstörte wesentliche Grundlagen der christlichén Religion. Darin liegt Strauß' sowohl aktuell bedeutendes wie bleibendes Verdienst. Seine Kritik stieß auf den größten Beifall bei fortschrittlichen deutschen Intellektuellen. Der Kampf für und wider den Straußschen Standpunkt gab den äußeren Anlaß zur Spaltung der Hegelschen Schule in Althegelianer, welche des Meisters konservative Tendenzen betonten, und Junghegelianer, die dessen progressive Ansichten dem antiklerikalen und antiabsolutistischen Kampf dienstbar machten. Die Junghegelianer und eine wachsende Zahl von Lesern ihrer Publikationen - fühlten sich befreit aus der 
Enge eines religiösen Dogmas und forderten nun allgemein Freiheit des Denkens, der Wissenschaft, des Publizierens. ${ }^{12 b}$

Die zwei Zentren, in denen die neuen Bestrebungen zusammenliefen und von denen aus sie in viele Richtungen strahlten, waren Berlin und Leipzig. In Berlin, der einstigen langjährigen Wirkungsstätte Hegels, interpretierte der von Saint-Simon beeinflußte Eduard Gans die Hegelsche Philosophie in liberalem Geist, und hier fand sich eine Anzahl jüngerer oppositioneller Intellektueller zu Debatten über die neuen Ideen zusammen. In Leipzig erschienen von Januar 1838 bis Januar 1843 die von Arnold Ruge und Theodor Echtermeyer, später von ersterem allein herausgegebenen $\mathrm{Hal}$ lischen, ab Juli 1841 Deutschen Jahrbücher ${ }^{13}$, eıne Zeitschrift, die über mehrere Jahre hinweg nachhaltig den Geist der Opposition in Deutschland verbreitete und eine bedeutende Bresche schlug zugunsten der Schaffung einer über den Kreis der Universitäten und der schöngeistigen Literatur hinausgehenden öffentlichën Meinung.

Für die Bestrebungen der Mehrzahl der Junghelianer lassen sich zwei Wesenszüge feststellen.

1. Mit Hegel fassen sie die Weltgeschichte als Prozeß der Befreiung des Menschen auf, aber anders als Hegel beanspruchen sie die unbegrenzte Weltentwicklung und lehnen die Erstarrung des Entwicklungsgedankens ab.

2. Die progressive Auflösung der Hegelschen Philosophie geschieht bei ihnen, anders als bei StrauB, nicht in der pantheistischen, sondern der subjektivistischen, der Fichteschen Philosophie sich annähernden Richtung. Sie berufen sich nicht auf Hegels Weltgeist, dem kein aktivierendes Moment abzugewinnen war, sondern auf das menschliche Selbstbewußtsein, das sie als geschichtsbildende Kraft ansehen. Dank Hegel sei es mit sich ins reine gekommen und müsse nun in das Leben und das Volksbewußtsein eindringen, gemäß dem Hegelschen Satz, daß alles Vernünftige wirklich sein müsse. Oberste Forderung des Selbstbewußtseins sei die freie Betätigung und die Beseitigung kirchlicher Bevormundung.

Den Junghegelianismus generell als philosophischen Ausdruck des deutschen oder preußischen Liberalismus interpretieren zu wollen, würde seinem tatsächlichen Charakter nicht gerecht werden. Nach der rein religionskritischen Phase mit Strauß repräsentiert er sich uns als philosophisch begründete Bewegung für geistige und politische Freiheit, beginnend mit religiös-aufklärerischen und Preußen wohlgesonnenen Reformvorstellungen (1838-39), übergehend zu konstitutionell-monarchischen, d. h. liberalen Bestrebungen (Ende 1839-40) und schließlich einmündend in eine von atheistischen Ansichten begleitete Agitation zugunsten einer auf Volkssouveränität beruhenden Republik (seit Ende 1840) In dem Maße, wie seine politischen Bestrebungen radikaler wurden, radikalisierte er auch seine theoretische Grundlage, die Philosophie Hegels. Er bezog dessen Dialektik auch auf die Gegenwart und die Zukunft, machte unter Hintansetzung des Weltgeistes und unter Subjektivierung der Hegelschen objektiven Dialektik das Selbstbewußtsein zum Träger der Geschichte und zu einem revolutionären Element, das kritisch gegen die reaktionären Verhältnisse gewendet wurde; und in seiner progressivsten Phase sah er die Republik als Realisierung der Hegelschen Staatsidee an. Charakteristisch für den Junghegelianismus ist die unerhörte Revolutionierung der Hegelschen Philosophie, jedoch auf dem Boden dieser Philosophie, und die durch die idealistische Grundhaltung bedingte falsche Problemstellung, die wir $\mathbf{u}$. a. auch beim jungen Marx wiederfinden werden : der erwünschte gesellschaftliche und politische Fortschritt wird nicht aus der ökonomischen Bewegung und den daraus resultierenden 
Klassengegensätzen und -kämpfen abgeleitet; vielmehr handelt es sich darum, eine abstrakte Wahrheit (Freiheit, republikanischer Staat etc.), die das Selbstbewußtsein auf seiner höchsten Entwicklungsstufe gewonnen hat, Wirklichkeit werden zu lassen.

Am schärfsten wurde die Forderung einer über die Gegenwart hinausgehenden Geschichtsentwicklung zunächst von August von Cieszkowski (1814-1894) zum Ausdruck gebracht. In seinen Prolegomena zur Historiosophie ${ }^{13 a}$, deren Hauptgedanken wir in Heß' Europäischer Triarchie wiederfinden werden, unternimmt er den Versuch, Hegels Philosophie aus einer Wissenschaft des Erkennens in eine Wissenschaft des Veränderns des Bestehenden zu verwandeln. Unter dieser Voraussetzung wendet er sich sowohl gegen die Erstarrung der dialektischen Geschichtsbewegung als auch gegen Hegels absoluten Idealismus.

Hegel spricht er das eminente Verdienst zu, das Entwicklungsgesetz der Vergangenheit erkannt zu haben; er habe sich aber mit deren Erklärung begnügt und eine künftige Entwicklung ausgeschlossen. Indes biete die durch ihn vermittelte, auf die Vergangenheit bezogene Erkenntnis die Möglichkeit, auf die allgemeinen Züge der künftigen Entwicklung zu schlußfolgern.

Die Erkenntnis des Zukünftigen sei jedoch nicht theoretischer Selbstzweck, sondern Voraussetzung für des Menschen freie und bewußte praktische Veränderung der bestehenden staatlichen und sozialen Verhältnisse. Hierauf kommt es Cieszkowski an. Seine Forderung nach wirklichkeitsverändernder Tätigkeit des Menschen und die in Anlehnung an Hegel festgehaltene Annahme objektiver Geschichtsgesetzlichkeit läßt ihn auf die entscheidende geschichtsphilosophische Frage nach dem Verhältnis von freier menschlicher Aktivität zu eben dieser objektiven Geschichtsgesetzlichkeit stoßen. Er meint, dank der Einsicht in den notwendigen Gang der Geschichte sei der Mensch imstande, in freier Aktivität den göttlichen Plan der Vorsehung zu realisieren.

In diesem Tun realisiere sich die Einheit von Denken und Sein. Hegel habe zwar auch die Identität von Denken und Sein betont, aber im Sinne seines absoluten Idealismus nur als Denken; wobei er dem Sein die selbständige Existenz nahm und die Entwicklung als abgeschlossen darstellen konnte, wenn das Denken zur Einsicht seiner Identität mit dem Sein gekommen. Tatsächlich aber - so wendet Cieszkowski unter Berufung auf den Pantheismus Spinozas gegen Hegel ein - seien Sein und Denken zwei reale Wesenheiten. Wenn daher das Bewußtsein in der Philosophie den höchsten Grad seiner Entwicklung erlange und die Identität von Denken und Sein erfaßt habe, so höre die Weltgeschichte damit keineswegs auf, wie Hegel meinte, vielmehr komme es dann darauf an, die Identität von Denken und Sein zu realisieren, d. $h$. die Verhältnisse des Menschen dem Bewußtsein adäquat zu gestalten. Aus einer Erkenntnis des Bestehenden werde die Philosophie zu einem anleitenden Instrument für die Wirklichkeitsveränderung, sie werde eine ,Philosophie der Praxis“13b, und die Bestimmung des Geistes werde, das Denken in Sein zu übersetzen. Instrument der Umsetzung sei der Wille. Der Wille falle aber nicht außerhalb der geschichtlichen Kausalität. Wenn das Bewußtsein den notwendigen Gang der künftigen Entwicklung antizipiere, so setze der Wille es in die Tat um. Dabei falle die Teleologie der Weltgeistentwicklung mit der individuellen Zwecksetzung zusammen. Der Mensch werde ein freier Vollstrecker der Geschichte, indem er zum Objekt seines Willens macht, was die notwendige Entwicklung des Weltgeistes ist.

Nachdem das Denken die inneren Widersprüche überwunden habe, müssen nun da Denken und Sein analogen Bestimmungen unterliegen - die Widersprüche im 
Sein, im Staat und im sozialen Leben, überwunden werden. Ein Anzeichen dafür, daß deren Überwindung auf der Tagesordnung stehe, sei das Auftreten Fouriers. Wenn sein System auch utopisch sei, so werde jedoch die darin repräsentierte Tendenz bestimmend für die künftige Gestaltung der menschlichen Verhältnisse sein.

Cieszkowskis Forderung, an die Stelle der Philosophie die Praxis zu setzen, ist keine Vorwegnahme des späteren Praxis-Begriffs von Marx, wie dies behauptet wurde. ${ }^{13 \mathrm{c}}$ Marx' Praxis-Begriff beinhaltet, daß die Geschichte der Menschheit bestimmt ist von der praktischen, ihrer Reproduktion dienenden Tätigkeit der Menschen - und hiervon ist bei Cieszkowski keineswegs die Rede. Cieszkowskis Philosophie der Praxis zielt zwar auf tatsächliche Veränderung der praktischen Verhältnisse, aber diese Forderung wird auf dem Boden einer idealistischen Philosophie erhoben. Die Weltgeschichte ist für Cieszkowski im Anschluß an Hegel der „Entwicklungsprocess des Geistes der Menschheit", der in seiner Notwendigkeit, Zufälligkeit und Freiheit zu verstehen sei. ${ }^{13 d}$ Nicht aus den wirklichen gesellschaftlichen Verhältnissen werden die Grundzüge des zukünftigen Geschehens kausal abgeleitet, sondern teleologisch aus der Weltgeistentwicklung.

Abgesehen von dem gesicherten Einfluß auf $\mathrm{He} B$ und einem möglichen Einfluß auf Marx läßt sich nicht mit Gewißheit sagen, in welchem Maße Cieszkowski den Charakter der junghegelschen Bewegung bestimmt hat. Wenn auch fast alle ihre Hauptmomente im Keim bei ihm vorhanden sind, so muß nicht in jedem Falle ein eindeutiger Einfluß vorliegen. Denn die junghegelsche Bewegung war nicht Erfindung eines einzelnen, sie entstand als Opposition eines größeren Kreises von Intellektuellen, die unter Rückgriff auf revolutionäre Elemente der Hegelschen Philosophie gegen die herrschenden ideologischen, dann politischen Verhältnisse Front machten. In ihrer Grundanschauung lag - anders als bei Cieszkowski - der Akzent nicht auf der Philosophie der Tat, sondern auf der Philosophie des Selbstbewußtseins, das sich kritisch gegen die Welt wendet.

Führender Kopf dieser Philosophie des Selbstbewußtseins war Bruno Bauer (1809 bis 1882 ), der die Religionskritik von Strauß fortsetzte. ${ }^{13 e}$ An die Stelle des objektiven Weltgeistes setzte er das ,,allgemeine Selbstbewußtsein“, und die Geschichte führte er auf die fortschreitende Entwicklung dieses Selbstbewußtseins zurück. Die christliche Religion wurde zu einer bloßen Etappe der stufenweisen Verwirklichung des Selbstbewußtseins, womit ihr auch der göttliche Inhalt abgesprochen wurde, den Strauß ihr noch belassen hat. Sobald das Selbstbewußtsein sich in einer bestimmten Form, in einer Substanz verwirklicht habe, werde diese zu einem Hemmnis seiner weiteren Entwicklung; sie müsse darum aufgehoben und durch eine höhere ersetzt werden. Diesen Fortgang solle die Kritik bewerkstelligen, deren Aufgabe es sei, das Unvernünftige in den bestehenden Verhältnissen aufzudecken und auszumerzen, um den Weg für eine vernunftmäßige Entwicklung zu bahnen. Das nächste Ziel der Kritik sei die Aufhebung der christlichen Religion, die der Feind der Vernunft und der Wissenschaft und somit des allgemeinen Selbstbewußtseins geworden sei.

Die Hegelsche Philosophie und die Anschauungen der Junghegelianer gaben $\mathrm{He} B$ neue Bausteine für seine Theorienbildung. Die Aufnahme der modernen Geistesbildung führte ihn dazu, die religiöse Grundlage seiner Auffassungen durch eine philosophischidealistische zu ersetzen. Ungeachtet der Aufnahme Hegelscher und junghegelscher Gedankenelemente ist $\mathrm{He}$ jedoch kein Junghegelianer geworden. Mit seinem zweiten 
Werk, Die europäische Triarchie (1841), griff er in die politische Agitation der junghegelschen Bewegung ein. Bereits im Januar 1839 hatte er einige Stücke eines geplanten Werkes, das ursprünglich den Titel Staat tragen sollte, an seinen Freund Berthold Auerbach gesandt mit dem Bemerken, daß er diese Aufsätze zu einer Broschüre mit dem Titel Staat $u[n d]$ Kirche, aus dem spekulativen Gesichtspunkte, von einem Jünger S[pinoza]'s verarbeitet habe. ${ }^{14}$ Ihr Inhalt bezog sich auf den Konflikt, der zwischen der preußischen Regierung und der katholischen Kirche in der Frage der Mischehen entstanden war. Im „Kölner Bischofsstreit“ hatte der Erzbischof Clemens Droste zu Vischering auf die Durchführung einer päpstlichen Bulle bestanden, derzufolge Ehen, in denen nur ein Partner katholisch war, nur dann kirchlich geweiht werden sollten, wenn die Eltern die Kinder katholisch erziehen würden. Der Erzbischof wurde in Haft genommen und erst unter der Regierung Friedrich Wilhelms IV. wieder auf freien Fuß gesetzt.

Gleich den Junghegelianern nahm $\mathrm{HeB}$ in diesem Manuskript Stellung gegen die Forderung der katholischen Kirche; er vertrat das Prinzip, daß der Staat als Verkörperung des Weltgeistes nicht der Kirche untergeordnet werden dürfe. Ihren endgültigen Platz fanden diese Abhandlungen in der Europäischen Triarchie, wo sie im 3. Kapitel eingearbeitet sind. ${ }^{15}$

Der Orientkonflikt ${ }^{16}$ veranlaßte $\mathrm{HeB}$ zu einer Erweiterung des Themas. Der Konflikt führte in Deutschland zu heftigen Auseinandersetzungen zwischen liberalen und reaktionären Kräften. Jenen war die sich herausbildende Mächtegruppierung, bei der Deutschland und Frankreich einander feindlich gegenüberstanden, sehr zuwider. Frankreich galt ihnen als Hort des Liberalismus, von einer Annäherung beider Länder versprachen sie sich einen günstigen Einfluß auf die politische Entwicklung in Deutschland.

Die reaktionären Bestrebungen fanden den stärksten literarischen Ausdruck in Eduard Goldmanns Europäischer Pentarchie ${ }^{17}$ und Menzels Europa ${ }^{17 a}$. In seiner anonym erschienenen Schrift schlug Goldmann zur Sicherung der monarchischen Regimes und zur Abwehr bürgerlich-liberaler Ansprüche die Schaffung einer Vereinbarung der fünf Mächte Preußen, Österreich, Rußland, England und Frankreich vor. Die europäischen Staaten sollten in fünf Assoziationen zusammengefaßt und dem Schutz, d. h. der Herrschaft je einer der genannten Mächte unterstellt werden. Die deutschen Staaten, ausgenommen Preußen, sollten hiernach unter die Schirmherrschaft Rußlands gelangen. Die vorgeschlagene „Pentarchie“ stellte eine Art Fortsetzung der Heiligen Allianz dar, und ihre Verwirklichung hätte dem mächtigsten reaktionären europäischen Staat, Rußland, ein bedeutendes Einflußgebiet in Mitteleuropa gesichert.

Diese Ereignisse sowie den Kampf der fortschrittlichen Geister gegen die Reaktion wollte $\mathrm{He}$ vom Standpunkt seiner neuen Geschichts- und Staatsphilosophie aus beleuchten; zugleich wollte er die allgemeinen Entwicklungstendenzen des modernen Europa bewußt machen. Dem entsprach, daß er zunächst seinem Werk den Titel Europäische Wiedergeburt geben wollte. Auf Anraten eines Freundes nannte er es schließlich Europäische Triarchie, womit bereits im Titel die polemische Haltung gegen die von Goldmann empfohlene reaktionäre Politik ausgedrückt wurde. ${ }^{18}$

Sowohl der Bischofsstreit als der Orientkonflikt gaben ihm Gelegenheit, seine Ansichten über die gegenwärtige und künftige Entwicklung in Europa im allgemeinen und in Deutschland im besonderen darzulegen. Anläßlich dieser Ereignisse erneuerte er seine bereits in der Heiligen Geschichte behauptete These von der Notwendigkeit eines Bündnisses zwischen Frankreich und Deutschland, die ihre unterschiedlichen Kräfte für 
die Beförderung der Befreiung der Menschheit vereinigen sollten. ${ }^{18 a}$ Einen gewissen Vorläufer hatte diese Auffassung in dem Werk von Heine Zur Geschichte der Religion und Philosophie in Deutschland (1835). Heß' These ging aber weit über Heines Absicht hinaus, das Verständnis der beiden Nationen füreinander zu fördern, und schlußfolgerte auf unmittelbare politische und soziale Konsequenzen, die eine totale Umwälzung der europäischen Verhältnisse beinhalteten.

Sein Hauptanliegen bestand darin, die Philosophie der Tat zu vertiefen und aus ihr die historische Notwendigkeit einer sozialen Umwälzung der Gesellschaft abzuleiten.

Die moderne europäische Geschichte faßte $\mathrm{He} B$ als eine Befreiungsbewegung, deren Ziel die geistige und politische Freiheit und die soziale Gleichheit sei. Die Verwirklichung von Gleichheit und Freiheit sei das Werk der drei größten Länder Westeuropas: Deutschlands, Frankreichs und Englands. Durch die Reformation, die in die deutsche Philosophie mündete, habe Deutschland sich die geistige Freiheit erobert; mit der Französischen Revolution habe die politische Freiheit begonnen. Eine dritte, soziale, Revolution werde nun hinzutreten; sie werde in England ausbrechen, wo der Gegensatz von „Pauperismus“ und „Geldaristokratie“ am ausgeprägtesten sei. Deutschland, das Land der philosophisch-religiösen Befreiung, Frankreich, das der politischsittlichen Tat, und England, das Land der politisch-sozialen Praxis, müssen sich zu einer Triarchie zusammenschließen, denn diese wäre stark genug, um gegen den Widerstand geistiger und politischer Mächte die menschliche Emanzipation sicherzustellen. Nachdem die Emanzipation bereits auf dem Gebiet des Geistes, der Sitten und der Politik erreicht sei, werde sie durch eine soziale Revolution in England vollendet werden.

Wenn Heß im Falle Englands dahin tendiert, aus dem Gegensatz von „Pauperismus" und „Geldaristokratie“ eine revolutionäre Kraft abzuleiten, so verläßt er dieses ökonomisch-soziale Erklärungsprinzip bei der Darstellung der vorbürgerlichen englischen und außerenglischen Geschichte. Die augenscheinlich verschieden geartete gesellschaftliche Lage Deutschlands, Frankreichs und Englands sind ihm nicht verschiedene Stufen der bürgerlichen Gesellschaft, nicht verschiedene Stufen eines gleichartig determinierten Geschichtsprozesses, sondern Ausdruck des verschiedenen Wesens der drei Länder. Den Kampf der französischen Bourgeoisie gegen den Absolutismus interpretiert er als einen Kampf um politische Freiheit; die Auseinandersetzung zwischen Arbeiterklasse und Bourgeoisie in England als einen Kampf um soziale Gleichheit, und die Reformation und die moderne deutsche Philosophie als einen Kampf um geistige Freiheit. Statt in der Gegenwart Englands die Zukunft Frankreichs und in der Gegenwart Frankreichs die Zukunft Deutschlands zu sehen, hat er es mit einer Eigenschaftsmetaphysik zu tun, nach der jedes der drei Länder auf eine ihm gemäße Weise zu der allgemeinen Emanzipation der Menschheit beitrage. ${ }^{19}$

Auf die Kölner Ereignisse anspielend, betonte $\mathrm{HeB} \mathrm{-} \mathrm{in} \mathrm{Anlehnung} \mathrm{an} \mathrm{den}$ Gedanken Spinozas von der Vorherrschaft der Staatsmacht über die kirchliche Autorität wie auch an die junghegelsche Staatsauffassung - , daß die Anordnungen der Staatsorgane nicht von separaten konfessionellen Interessen diktiert sein dürften. In Abwandlung der Hegelschen Auffassung fordert $\mathrm{Heß}$, daß der Staat die friedliche Einheit der in ihrer Isoliertheit feindlichen Interessen sein solle. Nach Abschaffung der kirchlichen Herrschaft und nach grundlegender Umwandlung des Staates werden Freiheit und Harmonie herrschen. Die christliche Religion werde einer Religion der Liebe weichen, die das wahre Bündnis unter den Menschen sein werde. 
Die Europäische Triarchie bezeugt einen sichtbaren Fortschritt in der allgemeinen Bildung wie in der Theorienbildung von HeB. Er hat sich in beträchtlichem Maße aus dem bornierten Gesichtskreis seines Kinderglaubens herausgearbeitet und AnschluB gefunden an die moderne Geistesbildung und an die in jener Zeit progressivste philosophische Bewegung in Deutschland, den Junghegelianismus. Er greift in den literarischen Kampf der Junghegelianer ein und versucht nach deren Vorbild, die Hegelsche Philosophie politisch zu aktivieren. Die Kenntnisnahme Hegels und der Junghegelianer führt eine entscheidende Veränderung in seinen Grundanschauungen herbei; seine religiöse Einstellung wird von einer objektiv-idealistischen philosophischen verdrängt. An die Stelle der für die Heilige Geschichte charakteristischen Kombination von Religion, Spinozismus und sozialistischen Vorstellungen tritt eine Kombination von Hegelianismus, Spinozismus, Junghegelianismus und sozialistischen Vorstellungen.

Von entscheidendem Einfluß auf seine Hegelrezeption und seine neue philosophische Grundhaltung sind die Prolegomena von Cieszkowski. Freilich, die Frage einer sozialistischen Umgestaltung der Gesellschaft durch die bewußte Aktivität der Menschen und in Übereinstimmung mit einem objektiven Gesetz hatte ihn bereits in der Heiligen Geschichte beschäftigt. Aber die Behandlung dieser Frage auf der Ebene der Hegelschen Philosophie und deren Revolutionierung durch die Philosophie der Praxis übernimmt er fix und fertig von Cieszkowski. Die Übernahme Cieszkowskischer Grundgedanken wird ihm noch insofern erleichtert, als Cieszkowski - gleich ihm von einer spinozistischen Einstellung ausgeht.

Ganz und gar Cieszkowski folgend, versucht $\mathrm{HeB}$, das Hegelsche Ideal des im Bewußtsein der Notwendigkeit frei seienden Menschen umzuwandeln in eine auf die Veränderung der Gesellschaft bezogene Lehre des frei handelnden Menschen. Dies geschieht in einer spinozistisch-pantheistischen Korrektur des Hegelschen Idealismus und in einer Befreiung des Hegelschen Entwicklungsgedankens aus der Gegenwartsbegrenzung.

Die Mängel der Hegelschen Philosophie - ihre Kontemplativität, die Erstarrung des Entwicklungsgedankens und die mit ihr erreichte nur ideale Versöhnung - führt Heß wie Cieszkowski auf ihren einseitigen idealistischen Standpunkt zurück. Demgegenüber macht Heß geltend, daß ebenso wie der Geist auch die Natur eine reale Wesenheit sei und $\mathrm{daß}$ die Geschichte des menschlichen Bewußtseins in der Geschichte der gesellschaftlichen Verhältnisse ein Pendant habe.

Von Hegel übernimmt Heß den Gedanken des gesetzmäßigen Werdens. Der Gedanke der Entwicklung, in der Heiligen Geschichte eine naive Selbstverständlichkeit, wird jetzt bewußtes theoretisches Grundelement seiner Anschauungen. Ferner übernimmt er von Hegel das humanistische Ideal einer allgemeinen Weltversöhnung. Was Hegel bloß als Idee erfaßte, verlegt $\mathrm{HeB}$ als einen noch zu realisierenden Zustand in die Zukunft und identifiziert jene Versöhnung mit der sozialistischen Gesellschaft.

$\mathrm{He} ß$ bleibt indes weit davon entfernt, aus wirklichen gesellschaftlichen Prozessen Gesetzlichkeiten zu abstrahieren, diese sind ihm vielmehr in der Existenz des Weltgeistes verbürgt. Entsprechend beruht die sozialistische Forderung nicht auf einer kausalen Geschichtsableitung, sondern auf einer teleologischen Konstruktion, in der der Entwicklung des Weltgeistes die sozialistische Gesellschaft als Ziel zugewiesen wird.

Die auf dieser idealistischen Konstruktion aufbauende Philosophie der Tat bzw. der Praxis hat ebenso wie die von Cieszkowski nichts mit der späteren Praxisauffassung von Marx zu tun. ${ }^{20}$ 
Die Gesellschaft den im Bewußtsein errungenen Ideen der Harmonie, der Versöhnung, der Liebe adäquat zu machen, ist für $\mathrm{HeB}$ gleichbedeutend mit der Errichtung der sozialistischen Gesellschaft. Die Religion der Liebe ist ihm sowohl Hebel zu deren Herstellung als auch deren tragendes Fundament, nachdem sie hergestellt. Die für den späteren ,wahren" Sozialismus charakteristische Liebesutopie konzipiert Heß also noch vor der Rezeption des Feuerbachschen Humanismus. Dies unter Verwertung religiöser Elemente, von Spinozas Auffassung der intellektualen Liebe (bedeutend die Harmonie zwischen Gott und Mensch und der Menschen untereinander) sowie des Hegelschen Versöhnungsideals.

HeB' Aktivierung der Hegelschen Philosophie geschieht mithin völlig unter idealistischem Vorzeichen. Dies bedingt die nur teilweise Verwertung der Hegelschen Dialektik, von der er sich nur des Entwicklungsgedankens bemächtigt. Hegels tiefgehende Aufschlüsse über das Verhältnis von Arbeit und Gesellschaft sowie seine Widerspruchsdialektik bleiben ihm verschlossen. Seine Geschichtsphilosophie enthebt HeB der Nötigung, von der ,Zerrissenheit“ der Gesellschaft aus vorzudringen zur Erkenntnis ihrer ökonomischen Widersprüche; daher entbehrt er auch des Anlasses, sich eingehend mit der Hegelschen Widerspruchslehre auseinanderzusetzen.

Wo $\mathrm{He} B$ indessen die idealistische Grundlage gelegentlich verläßt, kommt er zu interessanten Einsichten; so spricht er z. B., eine Bemerkung des Aristoteles aufgreifend, von der Bedingtheit der antiken Sklaverei durch den damaligen Stand der materiellen Produktion. ${ }^{21}$

Soweit Heß sonst ökonomische Sachverhalte berührt, geschieht dies in oberflächlicher Weise. In der gesteigerten Produktion sieht er nur ein Mittel, das der Versöhnung die realen Möglichkeiten bietet. Und die Feststellung von dem zunehmenden Gegensatz von Pauperismus und Geldaristokratie wird nicht bestimmend für seine Theorie. Seiner Sozialkritik fehlt das konkrete Eingehen auf sozialökonomische Verhältnisse und beschränkt sich wie zuvor in der Heiligen Geschichte wesentlich auf eben diese Konstatierung des wachsenden Gegensatzes von arm und reich. Aus dem Fehlen des theoretischen Eindringens in die ökonomische Struktur der bürgerlichen Gesellschaft erklärt sich sein inkonsequentes und uneinheitliches Geschichtsbild. Den Weg der Revolution läßt er für England gelten; 1ə Deutschland soll die soziale Harmonie als Frucht der Philosophie der Tat entstehen.

Heß' Verhältnis zum Junghegelianismus ist kompliziert wie die junghegelsche Bewegung selbst. Er selber hält sich nicht für einen Junghegelianer. Deren subjektivistische und atheistische Tendenzen fallen seiner Kritik anheim und machen auch in der Tat die entscheidende Differenz zwischen seinen und den junghegelschen Anschauungen aus. Mit seiner noch religiös gefärbten Weltgeistkonzeption steht er unter dem Niveau der junghegelschen Religionskritik. ${ }^{22}$ Ferner unterscheidet er sich von den meisten Junghegelianern durch seinen spinozistischen Standpunkt. Am nächsten steht er Cieszkowski, aber auch von diesem trennen ihn seine noch nicht gänzlich abgelegten religiösen Reminiszenzen.

Gemeinsam ist ihm und den Junghegelianern die Einstellung zum preußischen Staat. Heß übernimmt von den Junghegelianern die recht verschwommene Annahme, der preußische Staat würde als Erbe des freiheitlichen Prinzips der Reformation die Freiheit in allen Bereichen des Lebens einführen, worunter $\mathrm{HeB}$ jedoch -- anders als die Junghegelianer - auch die Etablierung sozialistischer Verhältnisse versteht. Hier stellt sich ein gewisser Anachronismus heraus; gerade zu der Zeit, als Heß' 
Triarchie erschien, warf die Mehrheit der Junghegelianer die preußenfreundliche Ansicht über Bord und ging auf demokratisch-republikanische Positionen über. Mit seiner sozialistischen Zielsetzung geht $\mathrm{He} B$ über die Bestrebungen der Junghegelianer hinaus; aber wie in puncto Religion bleibt er auch in bezug auf die Einstellung gegenüber dem preußischen Staat hinter dem von den Junghegelianern bereits erreichten Stand zurück. Es war weder eine Laune des Augenblicks noch Opportunismus, wiewohl Mangel an politischer Reife, wenn $\mathrm{He}$ nach Abfassung der Triarchie eine neue Melodie auf das franzosenfeindliche Rheinland von Nikolaus Becker komponierte, während Vertreter der bürgerlichen Opposition die saftigsten Persiflagen auf das Lied in Umlauf setzten. ${ }^{23}$

Heß' Staatsauffassung entbehrt ebenso wie seine Sozialkritik jeden konkreten Eingehens auf wirkliche Verhältnisse und jeder Überlegung, wie denn der Staat praktisch umgewandelt oder wie er in Übereinstimmung mit dem Begriff des Staates gebracht werden könne.

Die größte Übereinstimmung zwischen $\mathrm{He} B$ und den Junghegelianern besteht in der Radikalisierung der Hegelschen Philosophie und in manchen rechtsphilosophischen Ansichten; und die größte Divergenz in sozialpolitischer und religiöser Hinsicht. ${ }^{23 a}$ Heß erklärte etwa 20 Jahre später, er hätte mit dem Buch den Versuch unternommen, ,den Sozialismus auf geschichtsphilosophischem Wege und durch den Junghegelianismus in die Literatur einzuführen“.23b Indes hat das Buch in dieser Richtung nicht gewirkt.

Mit der Europäischen Triarchie begann Heß' Wirksamkeit als politischer Schriftsteller. Anklang fand das Werk in führenden liberalen und in Kreisen der Junghegelianer. ${ }^{23 \mathrm{c}}$ Aus diesen stammen einige lobende Rezensionen, in denen HeB' Anonymität gewahrt wird, obgleich den Rezensenten wohl seine Verfasserschaft bekannt war. Hierfür dürften Heß' rheinische Freunde und auch Wigand gesorgt haben, in dessen Verlagshaus die Fäden der Opposition aus ganz Deutschland zusammenliefen. ${ }^{23 d}$

Die Besprechungen lassen erkennen, daß von den Hauptideen des Buches, Triarchie, Philosophie der Tat und sozialistische Umgestaltung der Gesellschaft, die letzte den geringsten Widerhall gefunden hat. In seiner von lebhafter Zustimmung getragenen Rezension, erschienen in dem von ihm redigierten Athenäum ${ }^{24}$, dem Berliner Organ der Junghegelianer, erklärt Karl Riedel, die Bedeutung des Buches bestehe vor allem in der Forderung nach Schaffung einer europäischen Triarchie. ${ }^{25}$ Die sozialistische Tendenz wird von ihm kritiklos gestreift. Hierbei ergänzt der Rezensent interessanterweise $\mathrm{HeB}$ ' bloße Konstatierung des Gegensatzes von Pauperismus und Geldaristokratie durch den Hinweis auf praktische Bestrebungen, nämlich die von Owen und den Chartisten. ${ }^{25 a}$ Riedel läßt die Philosophie der Tat nur als rein geistige Tätigkeit gelten und wendet sich gegen den von $\mathrm{He} B$ vertretenen spinozistischen Standpunkt einer Gleichwertigkeit von Natur und Geist. Die Natur sei nur eine untergeordnete Stufe, über die der Geist sich erheben müsse, andernfalls wäre das Ende der Entwicklung des Geistes erreicht. Er zählt $\mathrm{Heß}$ ungeachtet seiner spinozistischen Voraussetzungen und der von ihm deutlich ausgesprochenen Distanzierung von den Junghegelianern zur ,linken Seite“ der Hegelianer.

In seiner im Hamburger Telegraph erschienenen Rezension hebt Adolf Bock lobend HeB' Bestreben hervor, die Philosophie zur Tat werden und sie in das politische, sittliche und religiöse Leben eindringen zu lassen. ${ }^{26}$ Bock bedauert, daß die Vorherrschaft der Reaktion vorläufig noch dazu zwänge, „Gedanken als Thaten gelten“ zu lassen. ${ }^{26 a}$ 
Eine andere, ebenfalls zustimmende Besprechung erschien in dem Deutschen Courier. Der Rezensent bemängelt zwar die Darstellungsweise des Verfassers, preist aber seinen heiligen Zweck, ,die welthistorische Bedeutung und Richtung der Nationen in harmonische Wechselwirkung zu bringen". $26 \mathrm{~b}$

Nicht minder lobend äußert sich ein anonymer Rezensent in den Blättern für literarische Unterhaltung. Die Triarchie werde viele Sympathien hervorrufen, und wenn dem Verfasser auch nicht in allen seinen Folgerungen beigestimmt werden könne, so müsse „doch dem tiefen Ernste seiner Speculation“" Anerkennung gezollt werden. ${ }^{26 c}$

Am deutlichsten wurde die sozialistische Tendenz des Werkes von einem offenbar dem reaktionären Lager angehörenden Rezensenten bemerkt. ${ }^{26 d}$ In dem Buch gebe es ,viele Ausgeburten des seichtesten Rationalismus, ja Materialismus, und des extremsten Revolutionismus, eingehüllt in ein schimmerndes Gewand hochtönender Phrasen, scheinbar in einem andern, höhern Sinne gefaßt, der ihre Gefährlichkeit vor ihm und Andern verbirgt, der aber nicht verhindern kann, daß nicht die Massen sich eben das Schlimme daraus nehmen, was in Wahrheit den Kern davon bildet, während der vermeintlich höhere Sinn nur in hohlem Gerede besteht. ${ }^{26 e}$ Allenfalls anzuerkennen sei, daß der Verfasser ,mit mehr Ehrlichkeit und Offenheit" auftrete als die übrigen Junghegelianer ${ }^{26 f}$. In scharfen Worten geißelt der Rezensent die formalen und inhaltlichen Schwächen des Werkes. ${ }^{26 g}$ Des Verfassers Schluß auf die Zukunft aus der Erkenntnis des Vergangenen und Gegenwärtigen sei haltlos; ,da seine Kenntniß jener beiden Momente, sehr schwach ist, so gelingen seine Versuche noch weniger, als die seiner Vorgänger". 26h

So treffend der Rezensent die in der Tat oberflächliche Abstraktheit bei Heß kritisierte, so grundlos war indes seine Sorge über die Gefährlichkeit des Buches. Eine revolutionierende Wirkung scheint es nicht gehabt zu haben. Der Konfident Dr. Singer berichtete am 20. Februar 1841 aus Leipzig: „Bei Otto Wigand ist nun auch eine ,Triarchie' erschienen, die deutsche, französische und englische Freiheit haben will. Sie soll von einem Hegelianer in Halle seyn. Sie macht wenig Aufsehen."26i Dies einige Wochen nach Erscheinen des Buches gefällte Urteil kann freilich nicht viel besagen. In den Polizei- und Zensurakten des ehemaligen Geheimen Preußischen Staatsarchivs scheint die Schrift keine Spuren hinterlassen zu haben; ihren Titel findet man auch nicht in den Bücherverbotslisten der sächsischen Behörden. ${ }^{26 j}$

$\mathrm{He} B$ selbst scheint sein Werk einige Zeit hoch geschätzt zu haben. Bis 1843 hat er verschiedene seiner Artikel „Vom Verfasser der ,europäischen Triarchie“" gezeichnet, das erste Mal mit Voransetzung seines Namens in einem im Oktober 1841 im Athenäum erschienenen Aufsatz. ${ }^{26 k}$ Kritisch dagegen urteilte er 1844 von seinem Werk; er schrieb, ,dessen einziges Verdienst“ habe darin bestanden, ,daß es einen Gedanken, den man in der Kürze und mit Bestimmtheit noch nicht aussprechen durfte, in ein weites, faltenreiches, mystisches Gewand hüllte und so dem Publikum präsentierte: wir meinen den Gedanken des Sozialismus". ${ }^{261}$

Ungeachtet der Tatsache, daß Heß die Grenzen der Utopie nicht überschritt, stellte er sich mit seinem Bemühen, die erstrebte sozialistische Gesellschaft als eine historische Notwendigkeit nachzuweisen, in die erste Reihe der theoretisch-sozialistischen Bewegung in Deutschland.

Die Europäische Triarchie erschien zu einer Zeit, als in Deutschland durch das Anwachsen des Proletariats der Boden für die Aufnahme der aus Frankreich hereindringenden sozialistischen und kommunistischen Ideen vorbereitet war. In der Schweiz 
und in Frankreich hatten sich in den dreißiger Jahren wandernde deutsche Handwerker und Emigranten in Organisationen zusammengeschlossen. Mit dem 1838 in Frankreich begründeten „Bund der Gerechten“ war der erste Ansatz einer selbständigen deutschen Arbeiterbewegung gegeben. Aus diesem trat im gleichen Jahr Wilhelm Weitling mit seinem ersten Werk, Die Menschheit, wie sie ist und wie sie sein sollte, hervor, das insgeheim auch in Deutschland verbreitet wurde, wo sich revolutionäre Zirkel zu bilden begannen. Parallel zu dieser Arbeiterbewegung entwickelte sich nun eine philosophisch gefärbte sozialistische Strömung, getragen von fortschrittlichen, dem Bürgertum entstammenden Intellektuellen, zu denen auch Moses Heß gehörte.

Die größte Wirkung der Triarchie hat wohl darin bestanden, daß sie die politischen Ziele von Liberalen und Junghegelianern bestärkte, daß ihr Verfasser in eben diesen Kreisen als geistreicher Schriftsteller bekannt und von ihnen als Kräftezuwachs im Lager der Opposition begrüßt wurde. Hierin ist gewiß eine der wesentlichsten Voraussetzungen zu sehen für die. Rolle, die $\mathrm{Heß}$ beim Zustandekommen der Rheinischen Zeitung spielen konnte.

Deren künftiger Hauptbegründer, Georg Jung (1814-1886), Sohn eines vermögenden Kaufmanns und 1841 Assessor am Kölner Landgericht, war ein enger Bekannter von $\mathrm{HeB}$ in Köln. ${ }^{26 m}$ Als einer der ersten hat Jung junghegelsche Ansichten im Rheingebiet verbreitet und in dieser Richtung wohl auch auf $\mathrm{HeB}$ gewirkt. Jung hatte die Entstehung dieser Bewegung gleichsam an der Quelle beobachtet, nämlich in Berlin, wo er 1835-36 Jura studierte und Vorlesungen bei Savigny, Rudorff, Ritter, Heffter, Homeyer und Gans hörte. Jung stand mit Ruge in Verbindung und schrieb für dessen Jahrbücher. Im Frühjahr 1841 empfahl er Ruge einen Aufsatz von seinem ,Freunde $\mathrm{He}^{\prime \prime}$ zur Aufnahme in den Jahrbüchern. ${ }^{26 n}$ In seinem Brief an Auerbach vom 10. März 1841 betont $\mathrm{Heß}$ selbst, wie sehr „moderne Gespräche“ seinen Arbeiten ,förderlich" seien, und er teilt mit, daß er jetzt daran arbeite, ,eine bessere Schrift, eine ,Philosophie der Tat' zu schreiben“. Zu diesem Zweck studierte er abermals Fichte und Hegel. Im gleichen Brief erklärt er - im Gegensatz zu der preußenfreundlichen Haltung in der zwei Monate zuvor erschienenen Triarchie -, daß er ,täglich mehr Preußenfeind“" werde und erkenne, daß , alles Schlechte, innerlich Faule, Scheinheilige, preußisch zu nennen" sei. ${ }^{27}$

\section{Erste Feuerbach-Rezeption}

Das Erscheinungsdatum der Europäischen Triarchie fällt etwa mit jenem Zeitpunkt zusammen, da „die kapitalbesitzende und industrielle Klasse“ Deutschlands ,zu einem Zustand“ herangereift war, ,,der ihr nicht länger gestattete, den Druck eines halbfeudalen, halbbürokratischen monarchischen Regimes apathisch und passiv hinzunehmen “. ${ }^{27 a}$ „Das Jahr 1840“, so schrieben Marx und Engels. „bildete einen Wendepunkt in der deutschen Geschichte. Auf der einen Seite hatte die kritische Anwendung der Hegelschen Philosophie auf die Theologie und Politik die Wissenschaft revolutioniert, auf der anderen Seite begann seit der Thronbesteigung Friedrich Wilhelms IV. die Bewegung des Bürgertums“. ${ }^{27 b}$ Gerade als das Bürgertum begann, in verstärktem Maße politische Ansprüche zu erheben, erschien Ludwig Feuerbachs Wesen des Christenthums, das in bisher unerreichter Gründlichkeit und Radikalität die mächtigste ideologische Stütze des Absolutismus attackierte und zugleich ein humanistisches 
Gesellschaftsideal bot, das sich sowohl in demokratischem wie sozialistischem Sinne auslegen ließ. Der Inhalt und die historische Situation bei seinem Erscheinen erklären die unerhörte ideologische und politische Bedeutung des Werkes sowie die Tatsache, daß die Feuerbachsche Ideologie den Bestrebungen derjenigen Oppositionellen eine theoretische Grundlage gab, die vom Demokratismus zum Sozialismus vorstießen.

Unter dem Einfluß von Feuerbach und zeitweilig der Junghegelianer formte Heß von 1841-44 seine sozialistischen Ansichten neu. Zur Bezeichnung jener von Heß und in gewissem Maße auch von Marx und Engels entwickelten sozialistischen Theorie, die sich nicht auf historisch-materialistische Einsichten, sondern auf die deutsche, namentlich die Feuerbachsche Philosophie gründete, ist der Name ,philosophischer“ Sozialismus (oder Kommunismus) gebräuchlich geworden.

Für den ,philosophischen“ Sozialismus, der sich nach dem Weberaufstand (1844) in Gestalt der ,wahr"-sozialistischen Literatur in Deutschland verbreitete, ist charakteristisch, daß der Sozialismus nicht aus einer Analyse der gesellschaftlichen und ökonomischen Verhältnisse, sondern aus einer metaphysischen Wesensbestimmung des Menschen abgeleitet wird.

Heß' Feuerbach-Rezeption weist einige Phasen auf: nach einer ersten Hinwendung zu Feuerbach (1841 - 42) folgt ein Rekurs auf Fichte und die junghegelsche Philosophie des Selbstbewußtseins bei gleichzeitigem Zurücktreten Feuerbachscher Einflüsse (1843) und endlich (seit 1844) die volle Berufung auf Feuerbachsche Anschauungen, die dann bestimmend für HeB" ,wahren“ Sozialismus werden.

Das seinem Inhalt, seiner Methode und seiner Wirkung nach epochemachende Werk Feuerbachs, Das Wesen des Christenthums, erschien Sommeranfang $1841 .^{27 \mathrm{c}}$

Feuerbach geht davon aus, daß die materielle Welt unmittelbar positive Realität darstelle. Der Mensch sei wie Pflanze und Tier ein Naturprodukt, aber anders als Pflanze und Tier zugleich Kulturprodukt. Er sei sowohl Erzeugnis der Natur als auch Erzeugnis des Menschen selbst. Während das Tier mit seinem Bedürfnis zusammenfalle und nicht zum Bewußtsein seiner selbst gelange, komme der Mensçh, weil er als kollektives Wesen existiere, zum Bewußtsein seiner Gattung, er komme zum Selbstbewußtsein, indem er seine Wesenheit zum Gegenstand seines Bewußtseins mache. Gegenüber dem Tier habe der Mensch völlig neue Qualitäten, die nur der Gattung Mensch eigen seien. Es seien dies Vernunft, Wille, Sprache, Denken Lebensakte, die nur als gesellschaftliche, als ,Gattungsfunctionen“ existierten. ${ }^{28}$ Diese Qualitäten seien die sein Wesen begründenden Elemente. Der Mensch sei also, so stellt Feuerbach polemisch gegen den mechanischen Materialismus gewandt fest, nicht gleich Tier plus Selbstbewußtsein, sondern ein gegenüber dem Tier qualitativ völlig neues Wesen. Sowohl seine ursprünglich tierischen Sinne als auch seine menschlichen Sinne (wie Denken, Sprache etc.) seien von dem Gattungsleben bedingte und bestimmte Sinne. Die Bestimmtheit eines jeden individuellen Wesens rühre von dem kollektiven Sein der Gattung her. Die Wirklichkeit des Besonderen, des einmaligen Individuums, existiere nur durch die Wirklichkeit des Allgemeinen, der gattungsmäßigen Wesensgleichheit der sich unterscheidenden Individuen.

Auf dieser materialistischen Grundanschauung basiert Feuerbach die Kritik an der Religion. Die Religion sei historisch das erste Selbstbewußtsein des Menschen. In der Religion vergegenständliche der Mensch sein Wesen, in ihr schaue er sein Wesen an, aber als ein anderes Wesen. Indes sei der Mensch sich dieser Tatsache nicht bewußt. Es frage sich aber dann, wie dieser Zwiespalt des Menschen mit seinem eigenen 
Wesen zustande komme? Der Grund hierfür sei das Vorhandensein eines Mangels. „Gott entspringt aus dem Gefühl eines Mangels; was der Mensch vermißt - sei dieses nun ein bestimmtes, bewußtes oder unbestimmtes Vermissen - das ist Gott."28a Der Mangel sei physischer, psychischer, intellektueller und auch sozialer Art. Was der Mensch als Begrenzung oder Schranke an sich wahrnehme, treibe sein Wunschdenken zur Erfindung eines über alle Grenzen erhabenen Wesens, Gott, an dessen übernatürlichen Qualitäten der Mensch als ein Geschöpf dieses Gottes teilhabe.

Das Wesen der Religion erweise sich als das entäußerte Wesen des Menschen. Die Religion, ein Produkt menschlichen Wunschdenkens und Kompensationsbedürfnisses, habe nun nicht nur die Folge, daß sie dem Menschen in seinem Mangel Trost gebe, sondern auch die, daß sie ihn im Zustand des Mangels erhalte und diesen sogar verschärfe. Indem der Mensch ein über seine Gattung stehendes Wesen schaffe, es verehre und sich ihm unterwerfe, setzte er das tatsächliche Gattungsleben, das im Gebrauch seiner Wesenskräfte bestehe, hintan. Das Individuum genieße sich in der Religion, seine Unvollkommenheit ergötze sich an der Vollkommenheit Gottes, dessen Geschöpf es sei, seine Aufopferung in Gott werde eine versteckte Form seiner Selbstanbetung, Selbstliebe, seines Egoismus. Es komme dazu, daß sich die Religion dem Menschlichen entgegensetzt.

Liebe, Sitte, Gesetz, Recht, die ursprünglich ihren Grund in sich hätten, würden religiös verehrt und dann von der Religion abgeleitet. Die Religion, die ohnehin ein Verhältnis der Subordination schaffe, werde zur Grundlage moralischer, rechtlicher Verhältnisse gemacht. Sie werde zu einer willkürlichen Basis, von der alles Mögliche abgeleitet werden könne. So werde die Religion, zunächst primitives Selbstbewußtsein und kompensatorischer Ersatz für wirklichen oder eingebildeten Mangel, zum Instrument unmoralischer, unrechtlicher Bestrebungen. Die Aufhebung der Religion sei daher der ,nothwendige Wendepunkt der Geschichte“.28b Die Verbindlichkeit des Menschen gegen den Menschen dürfe nıcht einer religiösen Verbindlichkeit aufgeopfert bleiben. Die Notwendigkeit und Möglichkeit der Verbindlichkeit des Menschen gegen den Menschen beruhe auf der Tatsache, daß der Mensch seinem Wesen nach ein Gattungswesen sei, daß alle seine Qualitäten durch die Gattung gesetzt seien und er sich nur wahrhaft betätigen könne innerhalb der Gattung.

In diese allgemeine gesellschaftliche Verbindlichkeit schließt Feuerbach endlich noch einen sozialen Aspekt ein.

Der Mensch sei ein menschlich gewordenes Naturwesen. Er erhebe sich über die Natur, indem er sıch aus Naturgegenständen Mittel seines Lebens schaffe, und dieser Mittel beraubt zu sein bedeutet, der Mittel zum wahren Menschsein beraubt zu sein.

Was die Verwertung Feuerbachscher Einsichten und Ansichten angeht, so sind u. a. zwei gegensätzliche Tendenzen zu beobachten. Heß und seine „wahr" -sozialistischen Gesinnungsfreunde sollten an die theoretisch schwächste Seite der Feuerbachschen Philosophie anknüpfen, den utopischen Humanismus, und diesen zur Grundlage ihrer sozıologischen und sozialistischen Doktrin machen. Marx dagegen sollte zwar auch nicht von Feuerbachs Humanismus unbeeindruckt bleiben, sich aber sehr rasch wieder diesem Einfluß entziehen und an die tatsächlich entwicklungsfähigen Bestandteile der Philosophie Feuerbachs anknüpfen : die gesellschaftliche Bedingtheit des Menschen und materıalıstische Fassung des Verhältnisses von Sein und Bewußtsein. Von hier aus eröffnete sich ihm die Anwendung des Materialismus auch auf die Gesellschaft, indem 
er diese Elemente in den wirklichen Geschichtsprozeß einbettete, schuf er die materialistische Geschichtstheorie und mit ihr die Basis des wissenschaftlichen Sozialismus. Diese Art der Rezeption Feuerbachs sollte Heß verschlossen bleiben.

Marx war Vertreter der Philosophie des Selbstbewußtseins, als Heß ihn, wohl im August 1841, kennenlernte, wahrscheinlich während einer seiner Reisen, auf denen er für die geplante Rheinische Zeitung um Aktienzeichnungen warb. Vielleicht hat Jung, der anscheinend eine Art Bindeglied zwischen rheinischen Oppositionellen und dem Kreis um Ruge war, die Bekanntschaft vermittelt. Gleich im Beginn ihrer Bekanntschaft sehen wir $\mathrm{HeB}$ in der Rolle des Bewundernden, Lernenden, Abhängigen. Kaum mit Marx bekannt geworden, empfand er, der Sozialist, den Wunsch, der Schüler von Marx, des demokratischen Republikaners, zu werden. Er glaubte voraussehen zu können, daß mit Marx eine völlig neue Ära der Philosophie und der politischen

Wissenschaft anbrechen werde. Dies schrieb er am 2. September 1841 aus Köln an seinen Freund Auerbach:

„Du wirst Dich freuen, hier einen Mann kennenzulernen, der jetzt auch zu unsern Freunden gehört, obgleich er in Bonn lebt, wo er bald dozieren wird. [. . .] Es ist dies eine Erscheinung, die auf mich, obgleich ich gerade in demselben Felde mich bewege, einen imposanten Eindruck machte; kurz, Du kannst Dich darauf gefaßt machen, den größten, vielleicht den einzigen jetzt lebenden eigentlichen Philosophen kennen zu lernen, der nächstens, wo er öffentlich auftreten wird (in Schriften sowohl als auf dem Katheder) die Augen Deutschlands auf sich ziehen wird. Er geht, sowohl seiner Tendenz, als seiner philosophischen Geistesbildung nach, nicht nur über Strauß, sondern auch über Feuerbach heraus, und letztres will viel heißen! Könnte ich in Bonn sein, wenn er Logik liest, ich würde sein fleißigster Zuhörer sein. Einen solchen Mann habe ich mir immer als Lehrer in der Philosophie gewünscht. Jetzt fühle ich erst, welch' ein Stümper ich in der eigentlichen Philosophie bin. Aber Geduld! Ich werde jetzt auch noch etwas lernen!

Dr. Marx, so heißt mein Abgott, ist noch ein ganz junger Mann (etwa 24 Jahre höchstens alt), der der mittelalterlichen Religion und Politik den letzten Stoß versetzen wird; er verbindet mit dem tiefsten philosophischen Ernst den schneidendsten Witz; denke Dir Rousseau, Voltaire, Holbach, Lessing, Heine und Hegel in einer Person vereinigt, ich sage vereinigt, nicht zusammengeschmissen - so hast Du Dr. Marx."29

Wie Heß damals auf Marx wirkte, ist nicht überliefert. Irgendeine geistige Beeinflussung durch $\mathrm{HeB}$ ist in keiner der nächsten Schriften von Marx zu erkennen. Dagegen sprechen einige Indizien für eine in umgekehrter Richtung gehende Beeinflussung.

Heß wünschte von Marx Logik zu lernen, das konnte sich nur auf die Hegelsche Dialektik beziehen. Von ihr war Marx in höchstem Maße beeindruckt. Einige Jahre später versuchte er, Proudhon mit der Hegelschen Dialektik vertraut zu machen ${ }^{30}$, um wieviel mehr dürfte ihm zu dieser Zeit daran gelegen gewesen sein, unter seinen Bekannten die Hegelsche Dialektik zur Anerkennung zu bringen, da er noch unter dem unmittelbaren Eindruck seines Hegelstudiums stand. Er schätzte in Hegel den ,,riesenhaften Denker"31 und wertete die junghegelsche Bewegung als strengere Konsequenz der Hegelschen Philosophie, eine Konsequenz, die sich auf den Gedanken des Werdens und des aus dem Zwang des Weltgeistes befreiten Selbstbewußtseins berief. Und Heß scheint auch sogleich von Marx gelernt zu haben. Ein von ihm im Oktober 1841 
veröffentlichter Aufsatz ${ }^{31 a}$ enthält einige neue Gedanken und Gesichtspunkte, die Heß wohl unter dem Einfluß von Marx formulierte.

In dem Aufsatz verteidigt Heß die kritısche Philosophie der Junghegelianer gegen die Angriffe der Reaktion. Die junghegelsche Philosophie sei eine notwendige und logische Folge der Hegelschen Lehre. Die neuere, von Ruge, Feuerbach, Bauer repräsentierte Richtung habe die gleiche ideale Grundlage wie die Hegelsche Philosophie. Aber jene Männer leiteten aus dieser Konsequenzen $a b$, die der Meister nicht zu ziehen geneigt war. Sie blieben nicht beim Denken stehen, sondern seien am Werke, das Leben dem errungenen Selbstbewußtsein gemäß zu gestalten. Indem die Philosophie der Praxis den bedeutendsten Hegelschen Begriff, den des Werdens, auf das Leben anwende, lege sie notwendigerweise das Schwergewicht auf die Kritik des Bestehenden und die Entschleierung seiner Vergänglichkeit.

$\mathrm{He} ß$ erörtert die Frage, warum Hegel oft nur die positive Seite des Bestehenden hervorgekehrt habe, während die neueren Philosophen vielfach nur auf deren negative Seite hinwiesen. Der Grund hierfür sei die veränderte Stellung der Philosophie im Leben. Hegel habe es nur mit der Philosophie zu tun gehabt. Als Philosoph habe er jede Kollision mit dem Leben vermeiden müssen, die ihn hätte hindern können, seine Philosophie zum Abschluß zu bringen. Es sei jedoch nicht anzunehmen, daß Hegel diese Kollision absichtlich vermieden habe, obgleich auch dann, wenn er das Bewußtsein seiner Stellung ebenso klar gehabt hätte als jene, die auf seinen Schultern stehen, $1 \mathrm{hm}$ keinesweges hieraus ein Vorwurf gemacht werden könnte. Hegel hätte genug zu kämpfen und zu ringen gehabt, um den Geist sıch selber adäquat zu machen; das weitere, das Leben dem Geiste adäquat zu gestalten, hätte er anderen überlassen müssen. Vielleicht habe ihm die Schöpferkraft gefehlt, auf das Leben zu wirken, und hieraus mag sich seine Scheu vor dem Bestehenden erklären, welche ihm mit Unrecht oft zum Vorwurf gemacht worden sei. Aber sich auf ihn stützend, könnten die Jüngeren, sich der Zukunft zuwendend, die Kritik gegen das Vergangene richten.

Die ,Krisis“ der deutschen Philosophie sieht Heß in dem Übergang von der Theorie zur Praxis.

Heß' abschließende Polemik gegen die Vertreter der reaktionären Ideologie, die der kritischen Philosophie den Vorwurf des Atheismus machten, während sie selbst das Christentum zu einer schmutzigen, die Entwürdigung des Menschen rechtfertigenden Praxis herabgesetzt hätten, zeigt einen ersten spürbaren Einfluß Feuerbachscher Auffassungen. Wie Feuerbach lehnt Heß nun die christliche Gottesvorstellung als Anthropomorphismus ab.

Auffallend neu oder abweichend gegenüber der Europäischen Triarchie ist das entschiedene Zurücktreten der Weltgeist-Religion, die für jenes Werk charakteristisch ist, sowie eine veränderte Einstellung gegen Hegel und die Junghegelianer. Im einzelnen handelt es sich um folgendes:

1. In seiner Interpretation der Hegelschen Philosophie folgt $\mathrm{HeB}$ ganz der junghegelschen Auflösung der Hegelschen Lehre in eıne Philosophie des Selbstbewußtseins.

2. Die Darstellung der Rolle des Selbstbewußtseins, das sich gegen seine historisch gewordenen Gestaltungen wendet, weist in die Richtung der Marxschen Auffassung.

3. Die Hervorhebung der Kritik als des wesentlichen Elements der jüngeren Philosophie tst neu, und die positive Bewertung der negierenden Kritık weicht ab von der Beurteilung n der Europäischen Triarchie.

4. Heß hält auch Feuerbach für die strengere Konsequenz der Hegelschen Philosophie 
- eine einige Zeit nach Erscheinen des Wesens des Christenthums unter den Junghegelianern verbreitete Fehleinschätzung.

5. Besonders ins Auge fallend ist Heß' Versuch, Hegels positive Einstellung zum Bestehenden zu entschuldigen. Während er gerade dies in der Europäischen Triarchie einer scharfen Kritik unterworfen hatte, meint er jetzt, daß ihm hierin zu Unrecht Vorwürfe gemacht worden seien.

$\mathrm{He} \mathrm{B}^{\prime}$ distanzierte Haltung gegen die Religion ist wohl eine Folge seiner Lektüre des Wesen des Christenthums. Dagegen dürfte seıne Einschätzung des Werkes als strengere Konsequenz der Hegelschen Philosophie sowie die veränderte Haltung gegen Hegel und die Junghegelianer auf Marx' Einfluß zurückzuführen sein. Von entscheidender Bedeutung für die Umgestaltung seiner Weltanschauung wurde für $\mathrm{Heß}$ Feuerbach. Dieser verhalf $\mathrm{ihm}$ dazu, die Weltgeist-Religion zu überwinden. Nicht mehr auf diese, sondern auf den Feuerbachschen Begriff der Gattung stützte Heß nun seine sozialistische Theorie. Eine Verbindung von Feuerbachs Anthropologie mit sozialistischen Vorstellungen finden wir zunächst in Heß' Artikeln in der Rheinischen Zeitung.

\section{Die ,,Rheinische Zeitung““}

Die Rheinische Zeitung, die in Köln, dem wirtschaftlichen Mittelpunkt des Rheinlandes, erschien, verdankte ihr Entstehen dem Bedürfnis der rheinischen Bourgeoisie nach einem Organ, das ihren Handels- und Gewerbeinteressen Ausdruck verleihen konnte. ${ }^{31 b}$ Gegenüber der in Köln seit 1794 erscheinenden Kölnischen Zeitung waren die Blätter der übrigen rheinischen Städte reine Lokalzeitungen ohne größeren EinfluB. Der Besitzer der Kölnischen, DuMont-Schauberg, hatte sich 1839 durch Ankauf des Kölner Welt- und Staatsbothen das Kölner Zeitungsmonopol gesichert, an dessen Beseitigung liberal orientierte Industrielle ein Interesse hatten, da die Kölnische Zeitung, die sich auf breite Kreise einer katholischen Leserschaft stützte, ihre wirtschaftlichen und politischen Belange nur unzureichend vertrat.

Die von dem ehemalıgen Redakteur des Welt- und Staatsbothen, Dr. Bernhard Rave, zusammen mit Dr. Franz Schulte 1840 begründete Rheinische Allgemeine Zeitung vermochte nicht, gegen die Kölnische aufzukommen, und ihr baldiges Eingehen war abzusehen. Das enttäuschte auch die Regierung, die mit der Konzessionierung der Rheinischen die Erwartung verbunden hatte, sie würde das Monopol der Kölnischen brechen, deren ultramontane Tendenzen sie nicht billigen mochte. Noch mehr bedauerten die rheinischen Industriellen den Niedergang der Zeitung, zumal ihnen während der Verhandlungen des 6 . Rheinischen Landtags (1841) die Notwendigkeit eines großen politischen und Wirtschafts-Blattes klarer als je bewußt geworden war. ${ }^{32}$ Die auf eine Fortführung der Rheinischen Allgemeinen Zeitung sich richtenden Bemühungen begannen im Sommer 1841.

Die mißliche Lage seines Blattes veranlaßte wohl Rave, finanzielle Hilfe ber dem vermögenden Assessor Georg Jung zu suchen. Jung scheint anfangs daran gedacht zu haben, das Blatt aufzukaufen, unterleß es aber wegen des Geldrisikos. ${ }^{32 a}$ Sodann wurde erwogen, durch Gründung einer Aktıengesellschaft der Zeitung eine sichere materielle Grundlage zu geben. Jung stımmte dem Projekt zu, unter der Bedingung, daß Heß Redakteur würde. ${ }^{33}$ Angesichts der bekannten Abneigung der preußischen Regierung gegen Aktiengesellschaften plante man dann, eine Kommandit-Aktienge- 
sellschaft zu schaffen ${ }^{33}$, wobei nach rheinischem Recht keine besondere königliche Genehmigung erforderlich war; allerdings mußten die Geranten des Blattes mit ihrem gesamten Vermögen haften. Jung nahm sich mit Energie der Sache an; er darf als Hauptbegründer des neuen Blattes bezeichnet werden. ${ }^{33 b}$,Den Hauptanstoß zur Gründung des Blattes gab Georg Jung “, heißt es in einem Konfidentenbericht. ${ }^{33 c}$

Wahrscheinlich auf Grund einer Vermittlung von Jung, der seinen künftigen Mitarbeiter auf die neuen Aufgaben vorbereiten wollte, leitete $\mathrm{HeB}$, etwa vom 13. bis 22. Juni die Redaktion des literarischen Beiblattes der Rheinischen Allgemeinen Zeiliang. ${ }^{34} \mathrm{HeB}$ ' Haltung war indes schwankend; der Mitarbeiter an dem neuzugründenden oppositionellen Blatt zog er die an der konservativen Augsburger Allgemeinen Zeitung vor. Am 22. Juni legte er die Redaktion des Beiblattes der Rheinischen Allgemeinen Zeitung, nieder, und am folgenden Tage bewarb er sich um eine freigewordene Mitredakteurstelle bei der Allgememen Letlung. " Erst als seine Bewerbung von Cotta, dem Inhaber der Zeitung, unbeantwortet blieb, widmete er sich vornehmlich den Plänen Jungs. ${ }^{36}$ Anfang August schrieb Jung an Ruge: „Heß will Redakteur werden."“36a Jedoch gingen Heß' Pläne jetzt weiter. Er erwartete, als Gerant gewählt zu werden ${ }^{36 b}$, was bei seiner Vermögenslage recht aussichtslos war. ${ }^{36 c}$ Heß' rastloser Eifer, Aktionäre, Mitarbeiter und Korrespondenten zu gewinnen ${ }^{37}$, erweckte bei dem damals in Berlın weilenden Eduard Flottwell, Sohn des derzeitigen Oberpräsidenten der Provinz Sachsen und späteren Korrespondenten der Zeitung, den Eindruck, jener sei ,die Seele des Ganzen". 38

Am 15. November wurde zwischen einem provisorischen Komitee und dem Verleger Joseph Engelbert Renard ein Vertrag über die Herausgabe der Rheinischen Zeitung für Politik, Handel und Gewerbe abgeschlossen. ${ }^{39}$ Außer Renard unterzeichneten den Vertrag Dagobert Oppenheim ${ }^{39 a}$, Heß, Jung, Gerhard Fay ${ }^{39 b}$ und Peter Joseph Mülhens. ${ }^{39 c}$ Der Vertrag beinhaltete die Übergabe der Verzichtsleistung des Herausgebers und Druckers der Rheinischen Allgemeinen Zeitung auf ihre Konzession und bestimmte Renard zum Geschäftsführer der Kommanditgesellschaft und zum gegenüber der Regierung allein verantwortlichen Konzessionar.

Bis zur Abwicklung der noch erforderlichen Formalitäten bestand die Rheinische Allgemeine Zeitung noch weiter (die letzte Nummer erschien am 8. Dezember 1841). Jung berichtete am 18. Oktober an Ruge, daß das neue Blatt ab 1. Januar 1842 erscheinen und die Rheinische Allgemeine Zeitung schon jetzt unter Leitung von Heß für Rechnung der Kommanditäre bis dahin fortgesetzt werde. ${ }^{39 d} \mathrm{Zu}$ dieser Zeit scheint für die auf Grund ihrer Kapitaleinlagen bestimmenden Männer des Unternehmens bereits festgestanden zu haben, daß Heß nicht für den Posten des Chefredakteurs in Frage komme. Die Abneigung gegen seme sozialistischen Tendenzen dürften hierbei ebenso eine Rolle gespielt haben wie die Tatsache, daß er weder Geld noch Erfahrungen zu dem Geschäft mitbrachte. Die Leitung des Blattes wurde dem berühmten liberalen Nationalökonomen Friedrich List angetragen ${ }^{40}$, der eben in seinem Hauptwerk, Das nationale System der politischen Ökonomie (1841) die Bestrebungen der deutschen Bourgeoisie zum Ausdruck gebracht und ein Schutzzollsystem vorgeschlagen hatte, das sie befähigen sollte, gegenüber der englischen Konkurrenz zu bestehen. Aus Krankheitsgründen mußte List das Anerbieten ablehnen. In seinem Antwortschreiben brachte er die Gewißheit zum Ausdruck, daß dem patriotischen Unternehmen dank der geographischen Lage Kölns und der Teilnahme eines so bedeutenden Talents wie Herrn Heß das Gedeihen verbürgt sei. ${ }^{41}$ Auch nach der Absage Lists dachte man nicht 
daran, auf Heß zurückzugreifen. „Heß soll zweiter Redakteur werden, weil er noch gar keine Übung hat", schrieb Jung am 29. November 1841 an Ruge. ${ }^{42}$

Am 6., 8. und 10. Dezember 1841 fanden im Casino zu Köln die Generalversammlungen der Aktionäre statt, auf denen die Gesellschaft gebildet und die Statuten beraten und angenommen wurden. ${ }^{43}$

Auf der Generalversammlung am 8. Dezember 1841 kam es zu ernsthaften Differenzen zwischen $\mathrm{Heß}$ und maßgeblichen Aktionären der Gesellschaft. Der Aktionär Rudolf Schramm ${ }^{44}$ machte sich zum Fürsprecher seines Freundes Heß. Im Protokoll lesen wir: „Herr Ref[erendar] Schramm stellt den Antrag, als Zusatzartikel zu den Statuten aufzunehmen, daß Herr $\mathrm{He}$, der Begründer des Unternehmens, bei der Zeitung der Gesellschaft als Redakteur angestellt werde. - Nachdem die Herrn Jung $u[$ [nd] Fay erklärt hatten, daß Herr $\mathrm{Heß}$ in Anerkennung seiner Verdienste um das Unternehmen von den Geranten als Redakteur angestellt werden würde, es aber unthunlich sei, dieß im Statut aufzunehmen, und Herr Heß hierauf erwiderte, das Unternehmen nicht in der Absicht begründet zu haben, um in eine abhängige Stellung zu bestimmten Personen zu treten; er wolle gerne seine Thätigkeıt dem Urthelle einer Generalversammlung, aber nicht der subjektiven Meinung einzelner Personen unterwerfen, auch nicht von diesen als Gnade hinnehmen, was er als Recht ansprechen könne - wurde nach Anhörung einiger Herren die Debatte vertagt." ${ }^{\text {45 }}$ Auf der folgenden Sitzung am 10. Dezember fiel dann eine weitere Entscheidung gegen Heß. Bei der Wahl der Cogeranten zogen Oppenheim und Jung 45 bzw. 41 Stimmen auf sich, während $\mathrm{HeB}$ mit 2 Stimmen durchfiel. ${ }^{45 a}$ In einem Brief an Auerbach gab Heß seiner Empörung Ausdruck: ,ich kann mit den Geldaristokraten und ihrem Anhange nicht harmonieren, es wird mir kaum möglich sein, eine Redakteurstelle unter ihrer Herrschaft anzunehmen. [. . .] Zum Teufel mit diesen Hunden! Sie müssen alle aufgeknüpft werden, sie haben nichts als Geld und Hochmut. [. . .] Man muB erst den Reichtum verachten, um die Reichen verachten zu können. [...] ich denke, die Herren sollen erfahren, mit wem sie zu tun haben; sie haben schon manche bittre Pille von mir herunterschlucken müssen. [. . .] Jung wäre gut, wenn er nicht reich wäre. Diese Menschen glauben durch ihren Reichtum ein Vorrecht zu haben; sie sind von Jugend auf daran gewöhnt worden, und in der Regel nıcht geistesstark genug, um sich über alle Vorurteile hinauszusetzen. [. . . I Ich habe jetzt mit den besten unter den Geldaristokraten verkehrt; es sind die letzten, mit welchen ich freundlichen Umgang pflege. Krieg zwischen mir und ihnen. “46

Ein (nicht überliefertes) Schreiben von ihm lag dem Aufsichtsrat auf seiner ersten Sitzung am 14. Dezember 1841 vor. Im Protokoll lesen wir hierüber: „Auf ein von Herrn Heß an die Geranten und den Aufsichtsrath gerichtetes Schreiben vom heutigen Tage wurde erwidert, daß eine Entscheldung über die von ihm gestellten Anträge dem Aufsichtsrathe nicht zustehe. Die beiden Geranten trugen ferner vor, daß sie beabsichtigten, vorläufig auf die Dauer eines Jahres Herrn Dr. B. Rave dahier und Herrn Heß bei der neuen Zeitung als Mitarbeiter zu beschäftigen, und zwar Ersteren, weil er als zeitiger Concessionair der Zeitung dem Unternehmen nicht wohl entbehrlich sey, Letztern, weil in der General-Versammlung der Wunsch geäußert und beifällig aufgenommen wurde, daß Herr Heß bei dem Unternehmen als Mitarbeiter angestellt werde, und weil derselbe außerdem für den Beginn des Unternehmens wirksam gewesen. 
Der Aufsichtsrath fand die Anstellung dieser beiden Herren dem Gedeihen der Zeitung entsprechend. "47

Chefredakteur wurde schließlich Dr. Gustav Höfken, der stark unter dem Einfluß der ökonomischen Anschauungen von List stand. ${ }^{48} \mathrm{He} B$ lehnte verärgert die ihm angebotene Stelle eines Mitredakteurs ab, auf Zureden Jungs nahm er sie aber schließlich doch, zu vorteilhaften Bedingungen, an. ${ }^{49}$

Es wurde entschieden, daß Heß den französischen, Höfken den deutschen und Rave den englischen Artıkel übernehmen sollten. ${ }^{49 a}$

Nachdem der Oberpräsident der Rheinprovinz, von Bodelschwingh, mittels Reskript vom 13. Dezember Renards Gesuch vom 19. November positiv entschieden und ihm die durch Verzichtleistung erledigte Konzession zur Herausgabe der Rheinischen Allgemeinen Zeitung unter Vorbehalt des jederzeitigen Widerrufs übertragen und gleichzeitig die beabsichtigte Vergrößerung des Formats und die Umänderung des Titels in Rheinische Zeitung für Politik, Handel und Gewerbe genehmıgt hatte ${ }^{50}$, erschien die erste Nummer der Rheinischen Zeitung am 1. Januar $1842 .^{51}$

In den anfänglichen Auseinandersetzungen zwischen den leitenden Männern der Rheinischen Zeitung spiegelten sich verschiedene Richtungen innerhalb der bürgerlichen Opposition wider. Höfken wollte vorwiegend die ökonomischen Interessen der Bourgeosie und das Einigungsstreben des deutschen Volkes zur Geltung bringen. In seiner Zusage betreffs der Übernahme der Leitung des Blattes schrieb er unter anderem: „Die Fortbildung des Deutschen Zollvereins, die Entwicklung des deutschen Handels und der Handelspolitik, die Befreiung des deutschen Volksbewußtseins von Allem, was die Eınıgung hemmt - das wäre heute wohl für ein deutsches Blatt die höchste Aufgabe." ${ }^{25}$ Dagegen war Jung der Ansicht, daß das Blatt in erster Linie politischoppositionelle Forderungen vertreten solle und $\mathrm{da} B$,,der von den Jung-Hegelianern in den Hallıschen Jahrbüchern begonnene Kampf der Philosophie gegen Absolutısmus und Kirchentum an den Rhein verpflanzt werden müsse". ${ }^{53}$ Auch $\mathrm{HeB}$, der den französischen Artikel redigierte, war mit der Tendenz Höfkens nicht einverstanden und verließ bereits am 2. Januar seine Stelle. ${ }^{54}$ Zum offenen Bruch zwischen Höfken und Jung kam es, als dieser auf Aufnahme eines Artikels von Bruno Bauer gegen Schellıng bestand, während jener als Schellıngıaner die Veröffentlichung ablehnte. Höfken trat am 18. Januar zurück. ${ }^{55}$ Nach Höfkens Weggang besorgten Rave und Heß die Redaktion. ${ }^{56}$ Verantwortlicher Redakteur wurde schließlich, auf Empfehlung von Marx, Adolf Rutenberg, den die preußische Regierung für einen gefährlichen Revolutionär hielt. ${ }^{57} \mathrm{Er}$ traf am 3. Februar in Köln ein ${ }^{57 a}$ und übernahm wenig später die Redaktion ${ }^{57 \mathrm{~b}}$, was sofort auf den Einspruch der Behörden stieß. ${ }^{57 \mathrm{c}}$ Rutenberg belastete die Zeitung politisch, da durch seine Anstellung die argwöhnische Aufmerksamkeit der preußischen Regierung verstärkt auf die Rheinische Zeitung gelenkt wurde, und sachlich, da er den Aufgaben nicht gewachsen war. ${ }^{58} \mathrm{Er}$ wurde bald nur noch zu untergeordneten Redaktionsarbeiten herangezogen, indes die Cogeranten sowie Rave und $\mathrm{He} ß$ die Zeitung leiteten. Nach Höfkens Weggang nahm die Rheinische Zeitung einen schärferen Ton an, der auf die zunehmende Mitarbeit radikaler Junghegelianer zurïckzuführen war. Die neue Tendenz erregte sogleich das Mißfallen der Regierung; bereits am 11. März erließ sie eine Verbotsverfügung für den 1. April 1842. Indessen wurde das Blatt durch das Eingreifen des Oberpräsidenten der Provinz, von Bodelschwingh, gerettet, der ein zu großes Aufsehen fürchtete und der Regierung gegenüber versicherte, eine Änderung in der politischen Tendenz der Zeitung zu erwirken. ${ }^{58 a}$ 
Für die verschärfte oppositionelle Tendenz des Blattes machte die Regierung Rutenberg verantwortlich, und sie beharrte auf seine Entfernung. Diese erfolgte Mitte November $1842 .^{59}$ Der Regierung gegenüber wurde Dr. Rave als verantwortlicher Redakteur benannt. ${ }^{60}$ Tatsächlich jedoch wurde zu dieser Zeit das Blatt von Marx geleitet, der dem Unternehmen von Anfang an beratend zur Seite gestanden hatte und seit Mai 1842 Mitarbeiter der Zeitung war. Marx war im Oktober 1842 nach Köln übergesiedelt und hatte Mitte dieses Monats, noch während der offiziellen Anstellung Rutenbergs, die Redaktion übernommen. ${ }^{60 a}$ Zwar trat er nach außen hin nicht als Chefredakteur in Erscheinung, doch sickerte bald durch, daß er der führende Kopf des Blattes sei. $^{60 b}$

Die Zeitung wurde das Organ der entschiedenen liberalen und demokratischen Kräfte Deutschlands und brachte deren politische, ökonomische und soziale Bestrebungen am konsequentesten zum Ausdruck: allgemeines Wahlrecht, Öffentlichkeit der Regierungshandlungen und der Gerichte, Gewissens- und Pressefreiheit; öffentliche Rechnungslegung über Einnahmen und Ausgaben des Staates, Schaffung von Handelsgerichten, Erlaß von Aktıengesetzen, Ausbau des Eisenbahnwesens, Ausbau und Stärkung des Zollvereins, Senkung der Abgaben, Minderung oder Beseitigung indirekter Steuern auf notwendige Lebensmittel, progressive Besteuerung. Dies waren die offenen, erklärten Forderungen des Blattes. In versteckter Form und zwischen den Zeilen wurde zudem für die Revolution und die durch sie zu schaffende demokratısche Republik agitiert. ${ }^{60}$ Und die sozialistischen bzw. kommunistischen Mitarbeiter des Blattes, vor allem Heß, August Becker und Sebastian Seiler ${ }^{60 d}$, sorgten dafür, daß die auch von liberalen und demokratıschen Autoren behandelten - sozialen Fragen vom Standpunkt der untersten Volksklasse erörtert und sozialistische Tendenzen eingeschmuggelt wurden.

Heß hat annähernd 150 Beiträge - Aufsätze, Korrespondenzen, Rezensionen - in der Rheinischen Zeitung veröffentlicht. ${ }^{61}$ Soweit die behandelten Gegenstände es erlaubten, stellte er die soziale Frage in den Vordergrund ; und in dem Rahmen der durch Zensur und die liberale bzw. demokratische Einstellung der Geranten gesteckten Grenzen ließ er sozialistische Ansichten zu Wort kommen. Das letztere wurde ihm insofern erleichtert, als ihm die Redaktion des französıschen Artikels oblag. Eine korrekte Berichterstattung über das westliche Nachbarland mußte auch die dort verbreiteten sozialistischen Lehren und Publikationen berücksichtigen. So konnte Heß referierend mitteilen, was er als eigene Meinung nicht zum Ausdruck bringen durfte. Über diese Taktik schrieb er später, „daß während der ganzen Zeit des Bestehens genannter Zeitung die philosophische Bewegungspartei sich noch feindlich zum radikalen Sozialismus verhielt und dieser recht eigentlich in die Rheinische Zeitung eingeschwärzt wurde".62

Hinsichtlich der sozialen Frage erklärt $\mathrm{HeB}$ u. a., daß deren Lösung dıe zentrale Aufgabe des 19. Jahrhunderts sei; weder die Französische Revolution noch die konstitutionelle Monarchie hätten sie bewältigen können. ${ }^{63}$

Die Unfähigkeit des Staates, die Freiheit des Individuums zu gewährleisten bei gleichzeitiger gesetzmäßiger Ordnung der Gemeinschaft, zeigt Heß bei der Erörterung der Zentralisationsfrage. ${ }^{64}$ Im Gegensatz zur bestehenden Gesellschaftsordnung gebe es in der wahren Gesellschaft keinen Gegensatz zwischen Individuum und Gemeinschaft. Der wahre Mensch lebe in Übereınstımmung mit dem Gattungswesen; dieses beruhe auf der Harmonıe von Individuum und Gemeinschaft.

Neben den schon erwähnten ökonomıschen und sozialen Gründen für eine sozıalistısche 
Gesellschaft werden hier anthropologisch-humanistische geltend gemacht, die von Feuerbach übernommen sind. HeB meint, der Staat müsse eine „Volkserziehungsanstalt" sein $^{64 a}$ (eine Anschauung, die der Demokrat Marx als „Bevormundungstheorie“" bezeichnet $^{\text {(4) }}$ ) und die Aufgabe wahrnehmen, die Entwicklung, die humane Bildung positiv zu fördern und jedes dieser Entwicklung sich in den Weg legende Hemmnis zu entfernen. Durch die Freiheit werde das erstere und durch das Gesetz das letztere bewirkt.

Diese beiden Pole des Staatslebens müßten scharf gesondert werden, wenn nicht die Freiheit in egoistische Willkür und das Gesetz in nivellierenden Despotismus übergehen sollen. $\mathrm{HeB}$ meint, das strikte Auseinanderhalten der beiden Pole ermögliche die Harmonie im Staatsleben.

Heß' Aufsatz über die Zentralisationsfrage stieß auf scharfen Einspruch von Marx. Anders als $\mathrm{HeB}$ war Marx nicht Sozialist, sondern noch revolutionärer Demokrat. Aber gerade seine Einstellung als revolutionärer Demokrat ließ ihn, obwohl er noch nicht den Zusammenhang von Ökonomie und Politik, von Gesellschaft und Staat ergründet hatte, die Bedeutung der politischen Macht bei der Umgestaltung der Gesellschaft einsehen und erkennen, daß sie als entscheidender Faktor in Rechnung zu stellen ist. So wandte er sich in einem (erst postum veröffentlichten) Artikelfragment gegen die abstrakte Behandlung politischer Fragen durch Heß. Statt von konkreten Tatsachen auszugehen, habe Heß, so schrieb Marx, die Zentralisationsfrage auf abstrakte und utopische Weise behandelt, indem er das reale Weltbild durch ein imaginäres ersetzt und den Konflikt zwischen Individuum und Staat durch die Fiktion von einem ,Volk der Gerechten" zu schlichten versucht habe. ${ }^{65}$

Die Auffassung, daß keine politische Reform den Gegensatz von „Pauperismus“ und „Geldaristokratie" zu beseitigen vermag, äußerte $\mathrm{HeB}$ in schärfster Form in einem Aufsatz, der sich auf die Lage der Arbeiter in England bezog. ${ }^{66}$

Wenige Wochen vor Ausbruch des großen Chartistenstreiks, in dem die Arbeiter der größten englischen Fabrikstädte sich erhoben, verweist $\mathrm{HeB}$ unter Bezugnahme auf englische Zeitungen auf die gefährlichen Symptome der in England herrschenden sozialen Krankheit. Das Mißverhältnis der Reichen zu den Armen, der Gegensatz von Geldaristokratie und Pauperismus, diese Verhältnisse, aus denen alle unsere gesellschaftlichen Leiden leicht zu erklären sein dürften, hätten in England eir,e Zuspitzung erfahren, die eine Katastrophe befürchten lasse. Klar sei, daß politische Reformen hier nicht helfen könnten, da das Übel sozialer Natur sei; die Beziehung zwischen den sozialen Verhältnissen und der Regierungsform oder dem politischen Leben überhaupt sei zu indirekt, als daß von dieser Seite her ein Heilmittel erwartet werden könne. Es gelte, die sozialen Zustände zu verändern, die infolge der Konzentration und Zentralisation der Industrie und des Handels entstanden seien. Zwar benutzt Heß die Begriffe „Konzentration" und ,Zentralisation" nicht, aber er gibt annähernd phänomenologisch wieder, was wir heute darunter verstehen.

Von entscheidendem Nachteil für Heß' Theorienbildung ist, daß er von diesen offen zutage liegenden sozial-ökonomischen Verhältnissen aus nicht zu deren ökonomischen Grundlagen vordringt. Anders als wenig später Marx wird $\mathrm{Heß}$ durch die Konfrontation mit der sozialen Frage nicht zum Studium der Ökoriomie angeregt. Heß geht nicht den für den Aufbau einer wissenschaftlichen Theorie notwendigen Weg der Induktion, was in vorliegendem Falle bedeutet hätte, die historische Bewegung der Produktion zu studieren, woran sich, wie Marx' Beispiel zeigen sollte, die Erkenntnis des Be- 
dingungsverhältnisses: Ökonomik - gesellschaftliche Verhältnisse - Politik - Ideologie, angeschlossen hätte.

HeB' Art der Erfassung der gesellschaftlichen Verhältnısse war verbunden mit einer Unterschätzung und Außerachtlassung der Erfordernisse des politischen Kampfes, die auch in späteren Schriften von $\mathrm{He}$ hervortreten und die charakteristisch für die Vertreter des ,wahren“ Sozialismus werden sollten.

Anders als in der Europäischen Triarchie, in der er die Religion dem Staat untergeordnet wissen wollte, verlangt $\mathrm{Heß}$ nun eine strenge Trennung von Staat und Religıon. $\mathrm{Zu}$ diesem Thema hat die Rheinische Zeitung mehrfach Stellung genommen, nachdem wegen ihrer radikalen Kritik an Religion, Kirche und Staat von anderen Blättern, u. a. der Kölnischen Zeitung, die Forderung erhoben war, religiöse und philosophische Ansichten dürften in Zeitungen weder verbreitet noch bekämpft werden. Eine Antwort von Marx - die schärfste und brillanteste Auseinandersetzung, die über diesen Gegenstand in der Rheinischen Zeitung erschien - veröffentlichte die Zeitung am 10., 12. und 14. Juli 1842. ${ }^{66 a}$ Gleich darauf äußerte Heß sich zu dem Thema. ${ }^{66 \mathrm{~b}}$ Sein Aufsatz ist ein matter Abglanz des Marxschen und lehnt sich zum Teil an diesen an, speziell hinsichtlich der Forderung, den Staat auf Vernunft und Öffentlichkeit zu gründen. $\mathrm{HeB}$ stellt fest, $\mathrm{da}$ die Rheinische eine politische Zeitung sei und jede religiöse und theologische Frage außerhalb ihres Bereiches liege. Der Philosophie jedoch, insofern sie die allgemein menschliche Vernunft sei, könne sie sich nicht entschlagen, was aber auch der Staat nicht könne, wenn anders er nicht auf Unvernunft fußen wolle. Die Gegner der Rheinischen Zeitung hätten Wissenschaft (Philosophie) und Glauben, Religion und Staat identifizieren wollen und werfen nun mit Rückendeckung von Polizei und Zensur der sich auf die Philosophie stützenden Zeitung vor, sie bekämpfe die Religion und den christlichen Staat. Hier handele es sich um eine unselige Vermengung der Begriffe, die schwinde, wenn Religion und Kirche nicht in die Belange des Staates eingriffen und der Staat sich von konfessionellen Bindungen freihielte. Demgegenüber sei in Wirklichkeit die Theorie vom christlichen Staate sehr verbreitet; um so mehr sei es daher Beruf der Presse, jener Theorie die Vernunft entgegenzustellen.

Wie Marx, wenn auch nicht annähernd mit der gleichen dialektischen Schärfe, bekämpft Heß Religion und Kirche und den christlichen Staat. Die Religion wird als Unvernunft erklärt, und an den Staat wird die Forderung gerichtet, die Vernunft zu seiner Grundlage zu machen.

In zahlreichen Artikeln kommt Heß versteckt oder - wenn es sich um auswärtige Vorgänge handelt - offen auf den Kommunismus zu sprechen. In seinem Die politischen Parteien in Deutschland ${ }^{67}$ betitelten Aufsatz stellt er fest, daß die ,ganze Organisation oder vielmehr Desorganisation unseres socialen Lebens" eine "Reform" erheische. ${ }^{67 a}$ Welcher Art die Reform sein müsse, verschweigt $\mathrm{HeB}$, indes versucht er des Lesers Überlegungen geschickt in die gewünschten Bahnen zu lenken. Der Pauperismus habe in jüngster Zeit die Aufmerksamkeit auf sich gezogen und den Bestrebungen der Zeit eine ganze neue und eigentümliche Richtung gegeben. Es sei eine Ungerechtigkeit und ein Unglück, daß die arme, unmündige Volksklasse wenig von den Früchten der Zivilisation erhalte. Alle freien Staatsverfassungen, von der französischen Republik an bis herab zu den Republiken des Altertums seien an dieser Klippe gescheitert. An der prinzipiellen Begründung jener Bestrebungen, die auf die Beseitigung des Gegensatzes von Pauperismus und Geldaristokratie und die Schaffung 
der Einheit im Staate zielten, werde in diesem Jahrhundert gearbeitet. Soviel fühle man bereits, daß die bisher freisinnigsten Bestrebungen unzureichend gewesen, um mit dem Problem fertig zu werden.

Weiter konnte Heß kaum gehen; er mußte es dem Leser überlassen, die Konsequenzen aus dem Gesagten zu ziehen.

Geringere Verschleierungsmanöver hatte $\mathrm{He} ß$ aufzubieten, wenn er lediglich als Berichterstatter auftrat. So druckte er ein in der Pariser Tageszeitung La Presse veröffentlichtes Manifest der sich „Rationalisten“ nennenden Anhänger Colins' ab. ${ }^{68}$ In seinen die Grenzen des Zensurmöglichen fast überschreitenden Schlußbetrachtungen bemerkt $\mathrm{HeB}$, aus dem mitgeteilten Manifest der französischen Kommunisten sei ersichtlich, daß diese nicht gerade rohe und ungebildete Proletarier unter ihren Anhängern zählten und ihnen das Bewußtsein über das, was sie wollten, und über ihr Verhältnis zum Bestehenden nicht abgesprochen werden könne. Der Kommunismus sei, wie es scheine, das Produkt aller jener Sozialtheorien, die unter dem Namen SaintSimonismus, Fourierismus und anderen unter den Gebildeten wie unter dem Volke Anhänger hätten. Wie groß aber auch die Zahl seiner Anhänger sein möge - er sei ,jedenfalls eine historische Erscheinung, die wohl gewürdigt zu werden verdient" . 68 a

Im September resümierte $\mathrm{Heß}$ in einer kurzen Notiz, Die Regierungsform des kommunistischen Prinzips ${ }^{69}$, die Grundgedanken eines im Telegraph erschienenen Artikels $^{69 a}$, den dieser aus der von Weitling redigierten Zeitschrift Die Junge Generation ${ }^{69 b}$ übernommen hatte. Die Kommunisten um Weitling (von dem Heß offenbar noch nichts wußte, denn er übernimmt aus dem Telegraph die falsche Schreibung ,Weitzling") würden alle Regierungsformen, von der monarchischen bis zur republikanischen, für den ,Zustand der Gemeinschaft" ablehnen. In der kommunistischen Gesellschaft werde die Herrschaft durch die Wissenschaft ausgeübt werden.

Im Dezember 1842 übersiedelte Heß im Auftrag der Rheinischen Zeitung, deren Geranten einen eigenen Pariser Korrespondenten wünschten, nach Paris. ${ }^{70}$ Diese Aufgabe mag $\mathrm{He} ß$ besonders gereizt haben, da sie ihn in ein Land führte, dessen Bündnis mit Deutschland ihm am Herzen lag. ${ }^{71}$

Frankreichs Hauptstadt war zu jener Zeit ein Zentrum der sozialistischen Bewegung auf dem Kontinent. Die kapitalistische Entwicklung war in Frankreich vorangeschrittener als in Deutschland, und es gab ein zahlreicheres Proletariat, in dem eine revolutionäre Tradition lebendig war. Paris war zudem, neben der Schweiz und London, ein Sammelpunkt von Emigranten aus vielen europäischen Ländern und der Ort, an dem sich eine selbständige deutsche Arbeiterbewegung zu bilden begann. Deutsche wandernde Handwerker hatten hier den kommunistischen „Bund der Gerechten“ geschaffen, dessen Gründungsstatut aus dem Juli 1838 datierte ${ }^{72}$. Der Bund stand lange Jahre unter der Leitung des aus Magdeburg stammenden Schneiders Wilhelm Weitling. ${ }^{72 a}$ Zwar war der Bund nach seiner Teilnahme an dem von Blanqui im Mai 1839 organisierten Aufstand gegen die Regierung des Bürgerkönigs Louis Philippe verfolgt worden, doch existierte er weiter in Form einer geheimen Verbindung, an deren Spitze Hermann Ewerbeck und German Mäurer ${ }^{72 b}$ standen. Heß unterhielt rege Beziehungen zu den Führern des Bundes und französischer Arbeitervereine, trat aber keinem bei. ${ }^{72 c}$

In seinen Korrespondenzen für die Rheinische Zeitung ${ }^{72 \mathrm{~d}}$ besprach er Ereignisse der französischen Innen- und Außenpolitik, wobei er solche Themen bevorzugte, die seinen sozialistischen Propagandabestrebungen und seinem Anliegen entgegenkamen, zu einer deutsch-französischen Verständigung beizutragen. 
Über den Widerhall, den der französische Sozialismus vor allem durch die Artikel von $\mathrm{He} B$, aber auch durch andere Autoren in dem Blatte fand, schrieb Marx später : ,Andererseits hatte zu jener Zeit, wo der gute Wille ,weiterzugehen' Sachkenntnis vielfach aufwog, ein schwach philosophisch gefärbtes Echo des französischen Sozialismus und Kommunismus sich in der ,Rheinischen Zeitung' hörbar gemacht." “72e

Die eineinvierteljährige Episode der Rheinischen Zeitung hatte bei $\mathrm{He} ß$ eine bedeutende geistige Wandlung gezeitigt. Unter dem Einfluß Feuerbachs und der Junghegelianer hat er sich von der Weltgeistkonzeption und den Resten religiöser Anschauungen befreit. In der ersten Phase der Rezeption Feuerbachs wurde dieser jedoch noch nicht bestimmend für HeB' Theorie. Der Beeinflussung durch Feuerbach ging einher eine durch die an der Rheinischen Zeitung mitarbeitenden Junghegelianer. Heß' Berufung auf das Selbstbewußtsein ist vermerkt worden. Aber auch die kritische Haltung der Junghegelianer, die $\mathrm{He} B$ in der Europäischen Triarchie abgelehnt hatte, weil sie nichts Positives schaffe, fand nun in ihm einen Verteidiger. Als Herwegh und Gutzkow Sommerende in Köln weilten, bei welcher Gelegenheit der Kreis der Rheinischen Zeitung ihnen einen festlichen Empfang gab, wurde u. a. über die Tendenz der Zeitung diskutiert. Gustav Mevissen, ein liberaler Industrieller und Mitarbeiter des Blattes, der an dem Gespräch teilnahm, vertrat die Ansicht, daß die Richtung der Rheinischen Zeitung zu negativ sei. Das Positive solle überall die Grundlage der Negation sein, denn die absolute Negation sei nichts anderes als die absolute Leere. Heß erwiderte: „Nein, Negation ist die Hauptsache. Man muß niederreißen, um die Dinge alle in Bewegung zu bringen. Das Negative schließt ja auch das Positive schon in sich." $72 f$

Die erste Rezeption Feuerbachs und die folgende Beeinflussung durch Junghegelianer hat für Heß' Theorienbildung nachteilige Folgen. Der Grund hierfür: Die unmittelbare Konfrontation mit politischen und gesellschaftlichen Gegebenheiten wird für ihn kein Anla B, theoretisch tiefer in gesellschaftliche Prozesse einzudringen und Feuerbachs Materialismus auf Geschichte und Gesellschaft anzuwenden. Hatte er zuvor der Entwicklung des Tat-Bewußtseins den Weltgeist als objektive Gesetzlichkeit unterlegt, so führt ihn die Überwindung dieses objektiv-idealistischen Moments dazu, die Tätigkeit des Bewußtseins, für die er keine außer ihr liegende Bestimmung mehr weiß, selbst zum Gesetz zu erheben, und zu einem Rückgriff auf die Fichtesche Philosophie. Seine theoretischen Arbeiten gegen Ende der Rheinischen Zeitung und kurz danach weisen ihn als in unmittelbarer Nachbarschaft der junghegelschen subjektiv-idealistischen Philosophie des Selbstbewußtseins stehend aus.

Gegenüber Marx nimmt $\mathrm{He} ß$ eine geradezu rückläufige Entwicklung. Anders als $\mathrm{He} B$ kommt Marx unter dem Einfluß Feuerbachs und durch die Erfahrungen an der Rheinischen Zeitung sowie durch die von der Mitarbeit an dem Blatt provozierten Studien zur sukzessiven Aufgabe der Philosophie des Selbstbewußtseins.

Die der Feuerbachschen Philosophie entlehnten Elemente integrierte Marx in sein politisches Weltbild. Dieses erweist sich seit Anfang 1842 bis zum Ende der Rheinischen Zeitung als eine Synthese von Hegelianismus, Junghegelianismus, Feuerbachianismus und der radikalen politischen Aufklärung des 18. Jahrhunderts, wobei gewisse Schwerpunktverlagerungen wahrzunehmen sind. Von Hegel bewahrt Marx die Auffassung, daß der Staat die Daseinsweise der Freiheit sein müsse. Aber anders als Hegel betrachtet Marx Staat und Freiheit nicht als Realisierung von jenseitigen Ideen, sondern als Realisierung des vom menschlichen Selbstbewußtsein nach einem geschichtlichen Prozeß schließlich als vernünftig Erkannten. Das Selbstbewußtsein wird 
nicht mehr an sich, als ,oberste Gottheit ${ }^{672 \mathrm{~g}}$, sondern als Produkt der Menschengattung gefaßt. In Heß’ Anschauungen figurierte ,Gattung““ als teleologisches Zaubermittel; Marx dagegen begriff zu dieser Zeit die Gattung nicht als gewesene oder zu realisierende ideale Menschengemeinschaft, sondern als eine faktische Gemeinschaft, die sich in Völkern repräsentiert und in einem geschichtlichen Prozeß zur Erkenntnis des Vernünftigen gekommen ist, das es zu realisieren gelte. Und die Wirklichkeit des in politischer Hinsicht vom Selbstbewußtsein als vernünftig Erkannten erblickt Marx in Anlehnung an Rousseau in einem auf Volkssouveränität beruhenden Staat, der durch eine revolutionäre Aktion des Volkes geschaffen werden müsse. ${ }^{7 \mathrm{~h}}$

Bedeutsam ist, daß Marx zu gleicher Zeit bei der Analyse politischer und ideologischer Verhältnisse bereits Elemente seiner späteren historisch-materialistischen Theorie zu entwickeln beginnt. Marx beginnt, das von Feuerbach konstatierte Bedingungsverhältnis von menschlichem Sein und Religion weiterzuentwickeln zur Erkenntnis des Bedingungsverhältnisse von Gesellschaft und Ideologie.

Ein politisches System, das nicht auf die allen Individuen gemeinsame Vernunft gegründet ist, müsse notwendig gewissen einzelnen Personen besondere Attribute zuschreiben, deren die Allgemeinheit ermangele. Da dies aber nicht aus dem wirklichen Wesen des Menschen zu erklären sei, müßten die Herrschenden ,,notwendigerweise ihre Zuflucht zum Wunderbaren und Mystischen" nehmen. ${ }^{72 \mathrm{i}}$

Die Vertiefung der Einsichten in das Bedingungsverhältnis von Gesellschaft und Ideologie sollte Marx wenig später - nach dem Untergang der Rheinischen Zeitung dazu führen, seine idealistische Staatsauffassung zu überwinden. In diesem Prozess spielte eine wesentliche Rolle die ebenfalls während der Tätigkeit an der Rheinischen Zeitung gewonnene Erkenntnis von der Existenz der auf Besitz gegründeten materiellen Interessen.

Die Analyse der Debatten des 6. Rheinischen Landtags zeigte Marx, daß die Einstellung der Landtagsdeputierten zu Fragen der Preßfreiheit und des Holzdiebstahls wechselte mit dem Stand, den der jeweilige Deputierte repräsentierte. Es war unverkennbar, daß die Deputierten nur die egoistischen Interessen des in ihren Händen befindlichen Eigentums verfochten. „Handelt der größte Teil eurer Prozesse und der größte Teil der Zivilgesetze nicht vom Besitz?“ - so fragt Marx an anderer Stelle. ${ }^{72 j}$ Das Privatinteresse sei immer feig, ,denn sein Herz, seine Seele ist ein äußerlicher Gegenstand, der immer entrissen und beschädigt werden kann, und wer zitterte nicht vor der Gefahr, Herz und Seele zu verlieren? Wie sollte der eigennützige Gesetzgeber menschlich sein, da das Unmenschliche, ein fremdes materielles Wesen, sein höchstes Wesen ist? ${ }^{\text {“72k }}$

Hier erkennen wir den ersten Ansatz eıner moralischen Kritik des Eigentums, die Marx während seines Überganges zum Kommunismus noch vertiefen sollte. In Analogie zu Feuerbachs Erklärung der christlichen Religion wird das Eigentum als ein dem Wesen des Menschen entfremdeter Gegenstand gedeutet. In seinem Aufsatz Zur Judenfrage (geschrieben im Herbst 1843) sollte Marx dieses auf Feuerbach zurückgehende philosophısch-moralische Erklärungsprinzip auch auf das Geld ausdehnen. Diese Konzeption sollte für die Theorie der ,wahren“ Sozialisten, namentlich ihres bedeutendsten Vertreters, Heß, bestimmend werden, indes Marx - als Folge seiner ökonomıschen Studien - bald zu anderen Ergebnissen kam. ${ }^{721}$

Zu gleicher Zeit, als er den Weg in Richtung auf die Erkenntnis der Rolle der in der Gesellschaft wirkenden materiellen Interessen betrat, kam er auch nicht umhin, die 
soziale Frage, die er unkritisch als bloßes Faktum schon in seiner Kindheit wahrgenommen ${ }^{72 m}$, als ein wichtiges Problem der Industriestaaten anzuerkennen. Wenn sich im Rheingebiet die soziale Frage nur erst in Gestalt ohnmächtiger Armut bemerkbar machte, so in Frankreich in Gestalt von Aufständen und sozialistischen und kommunistischen Theorien, die auch in der Presse behandelt wurden, und so in England im Sommer 1842 in schweren Auseinandersetzungen zwischen Proletariat und Bourgeoisie. Den Arbeiterunruhen und sozial-ökonomischen Problemen in England widmete die Rheinische Zeitung in zahlreichen Artikeln große Aufmerksamkeit. In dieser Zeit, spätestens Anfang Oktober 1842, machte Marx sich mit verschiedenen sozialistischen Antworten auf die soziale Frage bekannt. Sozialistische Theorien wurden ausführlich in (Marx zugänglichen) französischen und schweizerischen Presseorganen diskutiert und fanden auch in Deutschland ein literarisches Echo, u. a. in der Stadt-Aachener Zeitung, der Mannheimer Abendzeitung und dem Telegraph. Die Königsberger Zeitung berichtete schon seit den 30er Jahren ausführlich über die sozialen Bewegungen in Frankreich und England, und Anfang der 40er Jahre widmeten sich die radikalen Elbinger Anzeigen dem gleichen Thema. Die Rheinische Zeitung berichtete zwischen dem 23. September und 11. Oktober 1842 in einer Artikelserie über den Gelehrtenkongre $\beta$, der vom 28. September bis 9 . Oktober in Straßburg stattfand. ${ }^{72}$ In einer der Sektionen des Kongresses, an dem Gelehrte aus mehreren europäischen Ländern teilnahmen, u. a. die französischen Sozialisten Leroux, Considérant, Hennequin und de Pompery, wurden die soziale Lage der Besitzlosen und der Fourierismus und St.Simonismus erörtert. Im September 1842 erschien (in Leipzig bei O. Wigand) Lorenz Steins Der Socialismus und Communismus des heutigen Frankreichs. Darin wird zwar gegen den Sozialismus Stellung genommen und seine Anwendbarkeit auf Deutschland und dessen Anfälligkeit für ihn verneint; jedoch machte die Schrift das gebildete Leserpublikum mit dem französischen Sozialismus bekannt und trug dazu bei - wider den Willen des Verfassers -, den Sozialismus zu einem öffentlich diskutierwürdigen Gegenstand zu erheben.

Als Marx in der ersten Oktoberhälfte nach Köln übersiedelte und am 15. dieses Monats die Redaktion der Rheinischen Zeitung übernahm, hatte er nicht nur Kenntnis von der sich auf dem Kontinent wie in England erhobenen sozialen Frage; er hatte sich zu dieser Zeit auch bereits - aus erster oder zweiter Hand - mit den Lehren von Fourier, Proudhon, Leroux und Considérant bekannt gemacht. Dies geht aus seiner Polemik gegen die Augsburger Allgemeine Zeitung hervor, die am 16. Oktober 1842 in der Rheinischen Zeitung erschien. ${ }^{720}$ Die Allgemeine Zeitung hatte die Berichte in der Rheinischen Zeitung über den Kongreß in Straßburg sowie die Aufnahme einer in Weitlings Zeitschrift Die junge Generation erschienenen Korrespondenz aus Berlin vom 21. August über Berliner Familienhäuser ${ }^{72 p}$ zum Anlaß genommen, die Rheinische kommunistischer Tendenzen zu bezichtigen. ${ }^{72 q}$ In seiner Replik erklärt Marx ohne Umschweife, kein ,,probates Rezept“ zur Bewältigung jener Probleme zu haben, ,,an deren Bezwingung zwei Völker arbeiten“" ${ }^{72 r}$ Aber soviel steht für ihn bereits fest: „daß der Stand, der heute nichts besitzt, am Reichtum der Mittelklassen teilzunehmen verlangt, das ist ein Faktum, welches ohne das Straßburger Reden und trotz dem Augsburger Schweigen in Manchester, Paris und Lyon auf den Straßen jedem sichtbar umherläuft."72s Marx bekennt sich keineswegs zum Kommunismus; er meint jedoch, $\mathrm{da} B$ dies Problem eines gründlichen Studiums bedürfe. ${ }^{72 t}$ 
Die Kenntnisnahme sozialer Tatsachen und sozialistischer Theorien bewirkt bereits die Untergrabung seines demokratischen Staatsideals. Er ist sich dieses Umstandes nicht bewußt, aber er ahnt wohl schon die Gewissenskonflikte, in die ihn ein tieferes Eindringen in diese Problematik stürzen könne. Er schreibt: „Doch die Augsburger Zeitung hat die Gewissensangst, welche eine Rebellion der subjektiven Wünsche des Menschen gegen die objektiven Einsichten seines eigenen Verstandes hervorruft, wohl nie kennengelernt [. . .]."72u

Aus Vorstehendem wird so viel ersichtlich, daß die gesellschaftliche und LiteraturSituation zahlreiche Motive an Marx herantrug, sich mit den sozialistischen und kommunistischen Lösungsversuchen der andrängenden sozialen Frage zu beschäftigen. Dagegen lesen wir bei Silberner: „Es ist keine gewagte Annahme, daß Hess, durch seine Artikel in der ,Rheinischen Zeitung،, durch die Teilnahme an den Debatten in dem Kreise des Blattes und durch den Umgang mit Marx, diesen von der Notwendigkeit überzeugte, sich mit dem Kommunismus theoretisch zu befassen. Dieses Studium führte bekanntlich Marx nicht zu einer Kritik des Kommunismus, sondern zum Kommunismus schlechthin. So übte Hess einen schicksalhaften Einfluß auf Marx aus." ${ }^{62 \mathrm{v}}$

Was die Debatten im Kreise der Rheinischen Zeitung angeht, so handelt es sich um Diskussionen über die soziale Frage, zu denen Mitarbeiter und Aufsichtsratsmitglieder der Zeitung und ihr nahestehende Personen sich wöchentlich einmal im „Laacher Hof" in Köln trafen ${ }^{72 w}$. Heß nahm hieran bis zu seiner Übersiedlung nach Paris Anfang Dezember 1842 teil. Als Marx nach seinem Umzug nach Köln Anfang Oktober 1842 sich dem Kreise beigesellte, war er, wie aus seinem Artikel gegen die Allgemeine Zeitung hervorgeht, in bezug auf die soziale Frage und auf den französischen Sozialismus kein Neuling mehr. Engeren Umgang mit Marx konnte Heß erst seit Mitte Oktober 1842 pflegen, nachdem Marx Chefredakteur der Zeitung geworden war. Daß Heß die unmittelbare Nachbarschaft nutzte, um in seinem Sinne Marx zu beeinflussen, ist mit Sicherheit anzunehmen. Aber dieser Einfluß war nur einer von zahlreichen auf Marx einwirkenden Faktoren. Wie gering der Einfluß von Heß auf Marx war, ist schon aus der Tatsache zu ersehen, daß Marx trotz persönlichen Kontaktes mit Heß nicht Kommunist wurde. Heß ist durchaus nur eine Randerscheinung bei Marx' Entwicklung vom Demokraten zum Kommunisten. Die praktische und theoretische Konfrontation mit der sozialen Frage (mit der Marx, wie Silberner zuvor gesteht, „als Mitarbeiter und später als Chefredakteur der ,Rheinischen Zeitung“" ,sich selbständig“ $z u$ beschäftigen begann ${ }^{72 x}$ ) führte Marx zum Studium sozialistischer Lehren, dann aber vor allem zum Studium der Geschichte und der Ökonomie, und auf der hieraus gewonnenen Erkenntnis des allgemeinen Ganges der Geschichte und besonders des ökonomischen Mechanismus der bürgerlichen Gesellschaft baute er seine kommunistische Lehre auf.

Erfolg mit seiner Werbung für den Kommunismus hatte $\mathrm{Heß}$ bei Friedrich Engels. Nach einer kaufmännischen Ausbildung in Bremen (Juli 1838-März 1841) hatte Engels in Berlin als Einjährig-Freiwilliger seiner Militärdienstpflicht genügt (September 1841 bis August 1842). In Berlin hatte er an der Universität hospitiert, und hier war er mit zahlreichen Junghegelianern in freundschaftlichen Kontakt gekommen. Neben der Beschäftigung mit politischen und philosophischen Zeitfragen machte Engels sich in der preußischen Hauptstadt „,im stillen eine Zeitlang mit den englischen Zuständen“ vertraut $^{72 y}$, dies wahrscheinlich im Hinblick auf eine in Aussicht genommene Fort- 
setzung seiner kaufmännischen Ausbildung in der Zweigfirma seines Vaters in Manchester. Als revolutionärer Demokrat verließ er Berlin. Als er auf der Rückreise nach Barmen im Oktober $1842 \mathrm{HeB}$ in Köln traf, war er in philosophischer, politischer und sozialer Hinsicht schon für den Schluß vorbereitet, daß ,eine durchgreifende Revolution der sozialen Verhältnisse auf der Grundlage des Gemeineigentums jetzt einer dringenden und unvermeidlichen Notwendigkeit geworden ist ${ }^{*} .{ }^{72 x} \mathrm{Zu}$ diesem Schluß verhalf ihm offenbar Heß. An Auerbach schrieb Heß am 19. Juni 1843: „Im vorigen Jahre nämlich, als ich im Begriffe war, nach Paris zu reisen, kam er [Engels] von Berlin durch Köln; wir sprachen über die Zeitfragen und er, ein Anno I Revolutionär, schied von mir als allereifrigster Kommunist. So richte ich Verwüstungen an [. . .]."73

Wohl Heß folgend, schrieb Engels im November 1843, daß in Deutschland ,der Kommunismus eine so notwendige Konsequenz der neuhegelianischen Philosophie (war), daß keine Opposition ihn niederhalten konnte" ${ }^{\text {" }}{ }^{73}$

Im gleichen Aufsatz schrieb Engels, der „erste Kommunıst in der Partei“" sei Heß gewesen. ${ }^{73 \mathrm{~b}}$ Unter Partei wird hier die ,,philosophische Bewegungspartei“ verstanden, und auf diese bezieht sich die $\mathrm{Heß}$ zugeschriebene Prioritätsrolle. Isoliert gegeben, verschiebt dies Zitat sehr leicht die wirklichen Verhältnisse, und zwar bis zu der These, HeB sei der „Vater der deutschen Sozialdemokratie“ gewesen. ${ }^{7 \mathrm{e}}$ In dem Aufsatz spricht Engels auch von Weitling, „der als Begründer des deutschen Kommunismus anzusehen ist". ${ }^{\text {. }}$ d

Entscheidend für Engels' kommunistische Orientierung wurden die in dem entwickelten Industriestaat England von 1842 - 44 auf ihn wirkenden Einflüsse, unter denen er proletarisch-revolutionärer Kommunıst wurde. "Ich war", so schrieb Engels 1885, „,in Manchester mit der Nase darauf gestoßen worden, daß die ökonomischen Tatsachen, die in der bisherigen Geschichtsschreibung gar keine oder nur eine verachtete Rolle spielen, wenigstens in der modernen Welt eine entscheidende geschichtliche Macht sind; daß sie die Grundlage bilden für die Entstehung der heutigen Klassengegensätze; daß diese Klassengegensätze in den Ländern, wo sie vermöge der großen Industrie sich voll entwickelt haben, also namentlich in England, wieder die Grundlage der politischen Parteibildung, der Parteikämpfe und damit der gesamten politischen Geschichte sind. “73e

Als die Rheinische Zeitung durch eine Verbotsverfügung der preußischen Regierung ab 1. April $1843 \mathrm{ihr}$ Erscheinen einstellen mußte, hatte Heß die erste gewichtige Phase seiner öffentlichen Wirksamkeit durchlaufen.

In ,,der Judengasse geboren“, nur einer kümmerlichen Ausbildung teilhaftig geworden, hatte er eine glänzende geistige Entwicklung genommen. Als Mitbegründer, Mitredakteur und Mitarbeiter der Rheinischen Zeitung war er in die führenden Kreise der deutschen fortschrittlichen Publizistik aufgerückt. Er hatte sich als mutiger, auf die Herausforderungen des Tages sofort reagierender Journalist bewährt, und dies - ungeachtet seiner utopisch-idealistischen Grundhaltung - im Sinne des sozialen und politischen Fortschritts. Es ist in der Tat kein geringes Verdienst, die Rheinische Zeitung mitgestaltet zu haben, die auf dem Felde der Presse das bedeutendste Vorspiel der Revolution von $1848 / 49$ gewesen ist. 


\section{Der ,philosophische" Kommunismus}

Nach dem Aufhören der Rheinischen Zeitung widmete Heß sich ,ausschließlich der philos[ophischen] Entw[icklung] des Communismus“" ${ }^{\text {73f }}$ und fand in Julius Fröbel (1805 bis 1893) eınen bereitwilligen Verleger für seine sozıalistıschen Aufsätze. Mit Fröbel war Heß im Sommer 1841 bekannt geworden, als jener auf einer Reise Köln berührte. Wohl unter dem Einfluß von $\mathrm{HeB}^{74}$ und Weitling ${ }^{75}$ wandte er sich einem sozialen Radikalismus zu, der ihm im großen und ganzen mit dem Kommunismus übereinzustimmen schien. Tatsächlich kam Fröbel über eınen radikal-demokratischen Standpunkt nicht hinaus, indessen hatten sich in dem Auflösungsprozeß des Junghegelianismus noch keine klaren Grenzen zwischen Demokratismus, Feuerbachschem Humanismus und Kommunismus gebildet, und Fröbel konnte 1843 durchaus der Meinung sein, ım Prınzip mıt dem Kommunismus übereinzustimmen. ${ }^{76}$ Fröbel spielte zu dieser Zeit eine bedeutsame Rolle in der fortschrittlichen Bewegung, da das von ihm geleitete Literarische Comptoir von Zürich und Winterthur zahlreiche von der preußischen Zensur unterdrückte radikale Schriften herausgab.

Fröbel hatte Ende 1842 seıne Professur an der Zürıcher Universität niedergelegt, um in seiner politıschen und Herausgebertätıgkeit ungehinderter zu sein. Insbesondere handelte es sich um die Herausgabe einer radikalen deutschen Zeitschrift in der Schweiz. Sie sollte die Fortsetzung der von ihm geleiteten, offiziell von seinem Bruder Karl redigierten Zeitung Der deutsche Bote aus der Schweiz sein. Das Blatt erschien vom 5. Januar bis 1. Oktober 1842 zweimal wöchentlich in Zürich. Im Sommer 1842 plante Fröbel, die nach Deutschland gerichtete politische Aktivität zu verstärken und den Boten - als Monatsschrift, aber unter Beibehaltung des Namens - zum Organ dieser Bestrebungen zu machen. Die Redaktion sollte Herwegh übernehmen. ${ }^{77}$ Dieser unternahm $1 \mathrm{~m}$ gleichen Jahr eine Reise durch Deutschland, u. a. um Mitarbeiter für die geplante Zeitschrift zu gewinnen. In Dresden schloß Herwegh Freundschaft mit Ruge, lernte dort den aus Rußland emigrierten Michael Bakunin kennen (mit dem er dann zusammen in die Schweiz reiste). Die Reise führte Herwegh nach Berlin, wo er enttäuscht feststellen mußte, daß unter den Junghegelianern kein brauchbarer Mitarbeiter zu finden sei. Führende Köpfe dieser Bewegung hatten hier einen Verein der „Freien“ gebildet, der in anarchistischem Übermut verächtlich auf die Welt herabblickte. ${ }^{78}$ Das publizistische Vorhaben scheiterte schließlich an polizeilichen Maßnahmen Preußens und der Züricher Regierung. ${ }^{79}$

Die für die Monatsschrift gesammelten Aufsätze und Gedichte, darunter auch dreı Artikel von $\mathrm{HeB}^{79 a}$, veröffentlichte Herwegh in den Einundzwanzig Bogen aus der Schweiz, die im Julı 1843 herauskamen. ${ }^{79 b}$

Kurz vor seiner Übersiedlung nach Paris hatte $\mathrm{HeB}$ an Auerbach geschrieben, daß er für Herweghs Deutschen Boten schreibe und sich hier ,ganz frei aussprechen" könne. ${ }^{\mathbf{8 0}}$ Wahrscheinlich hat $\mathrm{He} ß$ das Manuskript mindestens eines der Artikel vor dem 18. Januar 1843 fertiggestellt und Fröbel übersandt. In einem Brief unter diesem Datum schrieb Fröbel an die Redaktion der Rheinischen Zeitung, deren Mitarbeiter er war, $\mathrm{He} B$ habe ihm mitgeteilt, daß er sich Fröbels bei der Zeitung noch gutstehendes Honorar habe auszahlen lassen ${ }^{80 a}$; es handelt sich wohl um Honorar für an Fröbel gelieferte Arbeit und bei dieser vermutlich um die Socialismus und Communismus betitelte Kritik des (bereits erwähnten) Buches von Stein, die Heß eigenen Angaben zufolge vor seiner Übersiedlung nach Paris an Fröbel geschickt hatte. ${ }^{80 b}$ Die Ent- 
stehungszeit von Die Eine und ganze Freiheit! läßt sich nicht genau bestimmen. Wenn die Reihenfolge des Abdrucks in den Einundzwanzig Bogen als Indiz gelten kann, so ist der Aufsatz bald nach dem soeben genannten entstanden. Der dritte Aufsatz Philosophie der That ist offenbar erst nach dem 16. März 1843 beendet worden; es wird darin auf eine an diesem Tage in der Rheinischen Zeitung erschienene Besprechung des Steinschen Buchs verwiesen. ${ }^{80 c}$

Die wissenschaftliche, das hieß für $\mathrm{HeB}$ : die philosophische Begründung des Kommunismus ist Gegenstand aller drei Aufsätze. Der erste, Socialismus und Communismus, ist eine Auseinandersetzung mit Steins Buch über den französischen Sozialismus und Kommunismus.

Lorenz Stein (1815-1890, 1868 geadelt $)^{80 d}$ hatte in Kiel und Jena studiert, war nach der Promotion zum Doktor der Rechte (1840) als Stipendiat der preußischen Regierung nach Paris gegangen, arbeitete an den Deutschen Jahrbüchern und der Rheinischen Zeitung mit und berichtete von Paris aus der preußischen Regierung über die französischen sozialistischen und kommunistischen Theorien und Bewegungen sowie über die dortigen Verbindungen deutscher Handwerker. ${ }^{80 e}$

In einem Bericht schrieb er: „Ich habe es mir daher zur Aufgabe gestellt, demjenigen, dem das nationale Gefühl und das innere Rechtsbewußtsein nicht hinreicht[,] um sich von Frankreich abzuwenden, und dem Wege zu folgen, den eine höhere Fügung uns führt, die innere Verkehrtheit einer jeden revolutionären Idee an dem Unsegen, mit dem der hiesige Zustand in jeder Beziehung behaftet ist, nachzuweisen, in einer Darstellung des französischen socialen Lebens und seınes Verhältnisses zur Revolution." ‘80f

Den sich selbst gestellten Auftrag führte Stein noch im gleichen Jahr aus mit dem Buch Der Socialismus und Communismus des heutigen Frankreichs. Ein Beitrag zur Zeitgeschichte. Er erörtert darin die Stellung des Proletariats in der Gesellschaft und gibt einen Überblick der Lehren der bedeutendsten französischen Sozialisten und Kommunisten und ihrer Schulen. Er erkennt, daß das Proletariat eine Klasse und etwas anderes darstellt als die Armen früherer Zeiten; es ist die „Classe derer, die weder Bildung noch Eigenthum als Basis ihrer Geltung im gesellschaftlichen Leben besitzen, und die sıch dennoch berufen fühlen, nicht ganz ohne jene Güter zu bleiben, die der Persönlichkeit erst ihren Werth verleihen. Diese Classe, ihre Berechtigung und ihr Loos ist es, die sowohl der Socialismus als der Communismus im Auge haben." ${ }^{80 g}$ Unter den Stürmen der Revolution und in den Kämpfen der jungen Republik in Paris und an den Landesgrenzen habe das Proletariat gelernt, sich als eigenen Stand zu begreifen und seine Bedeutung in allem, was Revolution heißt, zu erkennen. Der Proletarier beginne jetzt, selbständiges Wollen und eigene Zwecke zu entwickeln und wahrzunehmen, daß er bisher nur für andere gearbeitet und geblutet hat. Außerdem sei er zum Bewußtsein seiner Kraft gekommen, und die Erinnerung an das, was durch ihn geschehen ist, lasse ihn Pläne und Hoffnungen für möglich halten, deren Ausführung der physischen Macht bedürfen. Der Einsicht könne man sich nicht verschließen, daß ähnliche Entwicklungen wie in Frankreich auch in andern Ländern stattfinden können. ${ }^{80 h}$

Als konservativer Hegelianer betrachtet Stein die Gesetze und das Privateigentum als heilige ,Grundpfeiler alles Zusammenlebens. ${ }^{\mathbf{8} 0^{\circ} i}$ Das Proletariat sei im Irrtum, wenn es sein berechtigtes Streben nach Glück durch die Aufhebung des Privateigentums erreichen wolle. $^{80 \mathrm{j}}$ 
Von theoretischem Interesse ist, daß Stein die sozialistischen und kommunistischen Lehren und Bestrebungen aus der Klassenlage des Proletariats ableitet. Und von praktischer Bedeutung war, daß das Buch, bestimmt, vor Sozialismus und Kommunismus zu schrecken und in Deutschland Vorkehrungen zu veranlassen zur Verhinderung gleichartiger Entwicklungen wie in Frankreich, einen von Zensur und Polizei verfolgten Gegenstand literaturfähig und ein größeres Publikum mit ihm bekannt machte. $^{80 k}$

Ein anonymer Rezensent pries Steins Buch in der Rheinischen Zeitung als ,eine wahrhaft deutsche That". Seine Schlußfolgerung lag ganz im Sinne Steins: durch ,eine humane und gerechte Staatsökonomie hat man dem Communismus entgegen zu arbeiten. ${ }^{\text {“801 }}$ Diese Rezension ist zu Unrecht Heß zugeschrieben worden. ${ }^{80 m}$ Die Tendenz der Besprechung sowie die Tatsache, daß $\mathrm{HeB}$ bereits lange vor ihrem Erscheinen eine scharfe Kritik der Steinschen Schrift an Fröbel geschickt hatte ${ }^{80 n}$, schließen Heß ohne jeden Zweifel als Verfasser aus.

Steins Schrift eröffnete in Deutschland auf literarischem Boden die Reihe der reaktionären Angriffe gegen den Sozialismus. Indessen war diesem Buch ein ähnlicher Erfolg wie dem Bluntschli-Bericht beschieden. Es schreckte nicht nur vor dem Kommunismus, sondern brachte diesem wiederum neue Anhänger ein. Angesichts dieser Tatsache schrieb HeB anderthalb Jahre nach Erscheinen der Steinschen Schrift: „Stein hat den französischen Sozialismus bei den Deutschen, Herr Bluntschli hat den deutschen Sozialismus bei den Regierungen denunziert. Die beiden Jünger der alten Borniertheit verfehlten ihren Zweck so sehr, daß sie verhinderten, was sie bewirken wollten, nämlich die Angst vor dem Sozialismus, und bewirkten, was sie verhindern wollten, nämlich seine Verbreitung." ${ }^{800}$ Es muß Heß als großes Verdienst angerechnet werden, dem Versuch, den Sozialismus herabzusetzen und zu bekämpfen, entschieden entgegengetreten zu sein. Im Hinblick hierauf tritt die Tatsache in den Hintergrund, daß er in seiner Kritik einige interessante Feststellungen von Stein negiert. Stein, nach Mehring „,der fleißige Registrator einer bedeutsamen Literatur, aber weiter [. . .] auch nichts“ ${ }^{\text {81 }}$, hatte oberflächlich einen Zusammenhang zwischen den sozialistischen und kommunistischen Lehren und der sozialen und Klassenlage des Proletariats erkannt. Gerade gegen diese positive Erkenntnis erhebt $\mathrm{Heß}$ Einspruch. Er protestiert gegen die Zurückführung des Kommunismus auf ,das Streben des Proletariats, sich einen gleichen Genuß mit den Besitzern zu verschaffen ${ }^{c 82}$, und bemängelt, daß Stein den ,ZZusammenhang des Communismus mit dem Proletariat bis zum Überdrusse wiederholt. ${ }^{\text {"83 }}$

Heß will die kommunistischen Lehren nicht als Ausdruck von Klasseninteressen verstanden wissen. Das ist ihm zu äußerlich, zu materiell. Er versteht sie als Ausdruck „,des Prinzips der absoluten Einheit alles Lebens". ${ }^{84}$ Das Prinzip habe bereits Spinoza in seiner Ethik ausgesprochen. Auf unterschiedliche Weise sei dies „Grundprinzip der Neuzeit" von den Deutschen und Franzosen ausgebildet worden. ${ }^{84 a}$ Die Deutschen hätten mit ihrer Philosophie die Geistesfreiheit, die persönliche Freiheit oder die unendliche Berechtigung des Subjekts begründet. Dieser ProzeB habe mit Fichte begonnen, an dessen Atheismus die heutige energische und tatenlustige deutsche Philosophie anknüpfe, wenngleich sie über ihn hinausgehe. Und zwar dies mit Hegel; durch ihn sei der deutsche Geist zu der Erkenntnis gelangt, daß die Freiheit der Personen nicht in der Eigentümlichkeit des Einzelnen, sondern in dem allen Menschen Gemeinschaftlichen zu suchen sei. $^{84 \mathrm{~b}}$

Habe der deutsche Geist das Prinzip der subjektiven Freiheit, der absoluten 
Geistesfreiheit entwickelt, so der französische das der objektiven Freiheit, der absoluten sozialen Gleichheit. Analog dem Rückgriff auf Fichte in Deutschland näherten sich die heutigen Sozialtheorien Frankreichs, sofern sie praktisch ins Leben einzugreifen beginnen, wieder dem Babeufschen Kommunismus. Doch wie zwischen dem Fichteschen und dem heutigen Atheismus die ganze Dialektik der deutschen Philosophie liege, so zwischen dem Babeufschen und heutigen Kommunismus die Fülle der französischen Sozialphilosophie, repräsentiert durch St.-Simon, Fourier und Proudhon. Die große Idee Fouriers, der den Organismus der Arbeit auf die vollkommenste Freiheit der Bewegung aller Neigungen gründete, sei im heutigen Kommunismus bewahrt. Trotz der Konzessionen, die Fourier ähnlich wie Hegel dem Bestehenden machte, erhalte doch seine Hauptidee erst im Kommunismus ihre wahre Bedeutung, wie Hegels Idee der absoluten Persönlichkeit erst im Atheismus ihren rechten Sinn erhalte. ${ }^{84 c}$

Die beiden Momente - subjektive Freiheit und objektive Gleichheit - vereinigende Wahrheit sei das Prinzip der Einheit. Die Verwirklichung dieses Prinzips sei gleichbedeutend mit der Schaffung des Zustandes der Gemeinschaft. Diese erkenne in der freien Tätigkeit den wahren und einzigen Genuß, d. h. ein Gegensatz von Arbeit und Genuß existiere in ihr nicht mehr. Der Kommunismus sei längst über diese Abstraktionen von Arbeit und Genuß, mit denen Stein operiere, hinaus. Dieser Gegensatz, wie der zwischen Bourgeoisie und Proletariat, bestehe gegenwärtig unter den Bedingungen des Zustandes des getrennten Besitzes. ${ }^{84 d}$ Dieser Zustand werde durch Politik und Religion gesichert bzw. sanktioniert. Beide widersetzten sich dem Bestreben, die „Wirklichkeit dem Selbstbewußtsein gemäß zu gestalten“. ${ }^{84 e}$ Die durch das Selbstbewußtsein errungene theoretische Negation der Religion (deutsche Philosophie) und des Begriffes Staat oder Politik bzw. jeder politischen Herrschaft (französischer Kommunismus) müsse nunmehr in die Praxis überführt werden. Die Anleitung hierfür gebe die Philosophie der Tat. Als Vereinigung von französischem Kommunismus und deutscher Philosophie sei sie die Theorie, die die Etablierung von Geistesfreiheit und sozialer Gleichheit fordere und lehre. Der beides garantierende gesellschaftliche Zustand sei, so stellt $\mathrm{HeB}$ mit explizitem Bezug auf Proudhon fest, die Anarchie. ${ }^{84 \mathrm{f}}$

In den anderen zwei Aufsätzen kommt $\mathrm{Heß}$ auf die in der Kritik an Stein erörterten Hauptthemen zurück: die Einheit von geistiger und sozialer Freiheit und die Philosophie der Tat.

In dem Aufsatz Die Eine und ganze Freiheit! geht $\mathrm{He} B$ von der Feststellung aus, daß der Gedanke, die Philosophie müsse ins Leben eingreifen und Tat werden, sich in weiten Kreisen, namentlich unter jüngeren Philosophen, Bahn gebrochen habe. Dem Volke allein geistige Freiheit zu vermitteln sei fruchtlos, wenn man ihm nicht zugleich auch die wirkliche, die soziale Freiheit gebe. $\mathrm{HeB}$ betont, daß ,die geistige und sociale Freiheit mit einander stehen und fallen ${ }^{\star 85}$, wie auch die geistige und soziale Knechtschaft einander bedingen. Das Christentum sei historisch nachweisbar eine Tochter des Unglücks, und das Unglück wiederum habe die stärkste Garantie seiner Fortdauer in der Religion. Die himmlische wie die irdische Regierung unterdrückten das eigentliche Wesen des Menschen. Dies bestehe in der freien Tätigkeit. Unter den Bedingungen der geistigen und materiellen Unterdrückung werde die Einheit von Arbeit und Genuß zerstört und der Mensch in zwei Wesen geteilt, in einen arbeitenden Sklaven und ein genießendes Tier. Es sei möglich, daß das Übel, durch die mittelalterlichen Institutionen der Religion und Politik entstanden, ein solches Ausmaß annehmen wird, daß es nur 
durch Blut zu beseitigen ist. Gegen die Liberalen gewandt, die kein Interesse an vorbeugenden Maßnahmen hätten, meint $\mathrm{Heß}$, man könne dem Übel nicht früh genug vorbeugen. $^{85 a}$

In der Philosophie der That erreicht die schon seit der Europäischen Triarchie erkennbare Annäherung von $\mathrm{HeB}$ an junghegelsche Gedankengänge ihren Höhepunkt. In dem Aufsatz versucht er, die junghegelsche Philosophie des Selbstbewußtseins in eine sozialistische Tatphilosophie zu verlängern.

Er geht aus von einer Kritik des cartesischen Satzes „Ich denke, also bin ich“, in dem fälschlicherweise vom Denken auf das Sein geschlossen werde. Heß wendet ein: „Ich weiß, daß ich denke, daß3 ich geistig thätig bin oder, da es keine andere Thätigkeit gibt, $\mathrm{da} B$ ich thätig bin, nicht aber, daß ich bin. Nicht das Sein, sondern die That ist das Erste und Letzte." ${ }^{\text {86 }}$ Im Denkakt gebe es drei Momente: ein Denkendes, ein Gedachtes und die Identität beider, das Ich. Die Aussage ,,ich denke“ bedeute: das Ich stelle sich oder setze sich sich selber vor als ein Anderes, komme aber, nachdem es durch die Entdeckung seines eigenen Lebens im Spiegel außer sich gekommen, durch die Aufhebung dieser Reflexion wieder zu sich. Indem das Ich einsehe, daß das Spiegelbild sein eigenes ist, komme es zum Selbstbewußtsein. Das Ich sei mithin nicht etwas Ruhendes, es befinde sich in stetem Wechsel. Leben sei Tätigkeit. Diese charakterisiert Heß nach Fichteschem Vorbild ,als Herstellung einer Identität durch Setzen und Aufheben seines Gegentheils, Erzeugung seines Gleichen, seiner Sichselbstgleichheit, durch den Durchbruch der Schranke, in welcher Ich Nichtich, Thätigkeit ist", als "Selbsterzeugung“", deren Gesetz der Geist durch seine eigene Selbsterzeugung erkenne. ${ }^{86 a}$

Dem Selbstbewußtsein schreibt Heß eine ähnliche Entwicklung zu wie Hegel dem Weltgeist. Seine Entwicklung ist der Inhalt der Geschichte. Die Geschichte ist ,nichts Anderes als eben diese Entwickelung des Geistes“. ${ }^{86 b}$ Bevor das Selbstbewußtsein „,bei sich" sein könne - um Heß' Auffassung mit Hegelschen Worten zu illustrieren mußte es erst in Gestalt von Religion und Politik ,in Gegensatz zu sich treten".86c

Bei der Erklärung des Entstehens von Politik und Religion, d. h. von gesellschaftlichen und geistigen Unterdrückungsverhältnissen, kommt $\mathrm{Heß}$ auf die Zergliederung des Denkaktes zurück. In einem frühen Stadium wäre das Selbstbewußtsein noch nicht imstande gewesen, das Denkende und das Gedachte als Identität zu begreifen. Das Gedachte habe es sich als etwas Äußerliches, von ihm Unabhängiges vorgestellt und ihm den Charakter des Allgemeinen verliehen. Indes ruhe das Allgemeine allein im Individuum, es bestehe im selbstbewußten Geist oder im freien Menschen. Da dies Individuum noch nicht herausgebildet gewesen, sei das Individuelle als Besonderes und das vom Denkenden abgetrennte Gedachte als Allgemeines, als „Gott, Priester, Papst, Kirche, Staat, Monarch“ etc., erschienen. ${ }^{86 d}$ Religion und Politik seien „Übergänge von der Bewußtlosigkeit zum Selbstbewußtsein des Geistes“"86e; ihr Wesen bestehe darin, daß sie das Leben der wirklichen Individuen von einem Abstraktum, von einem „Allgemeinen“, das in Wirklichkeit nur im Individuum ruht, absorbieren lassen.

Das Privateigentum ist nach $\mathrm{He} ß$ ebenfalls eine Folge des noch unausgebildeten Selbstbewußtseins. Da das Selbstbewußtsein sich in seiner Tätigkeit noch nicht als Identität wisse, erscheine das Objekt der Tätigkeit ,noch als ein wirklich Anderes, und das Subjekt, um zum Genusse seiner Selbst, seines Lebens, seiner Thätigkeit zu gelangen, muß das von ihm getrennte Objekt als sein Eigenthum fest halten". ${ }^{86 \mathrm{f}}$ Weil der Geist seine Arbeit nicht als seine freie Tat begreife und als ein materiell Anderes 
erfasse, sei nicht die Tat das Entscheidende, sondern das Resultat, das Getane, das der Geist zu behalten versucht. Sein Anderssein, das Geschaffene, erfasse er als sein Fürsichsein, als sein Wesen. Heß schreibt: „Das materielle Eigenthum ist das zur fixen Idee gewordene Fürsichsein des Geistes. " $86 \mathrm{~g}$

Der geistige und politische Dualismus bilde jetzt die Schranke der freien Selbstbestimmung, nach deren Beseitigung die geistige und soziale Freiheit verwirklicht werde. Den Vorrang weist $\mathrm{HeB}$ der geistigen Freiheit zu: „Die soziale Freiheit ist entweder eine Folge der Geistesfreiheit, oder sie ist bodenlos und schlägt um so gewisser in ihr Gegentheil um, je revolutionärer sie sich gegen die bestehenden $\mathrm{Zu}$ stände [. . .] verhält. “86h

Die soziale Gleichheit sei die notwendige Folge der Erkenntnis des Selbstbewußtseins, daß sein wirkliches Eigentum die Tat ist und nicht deren materieller Widerschein, das materielle Eigentum. ${ }^{86 i}$

Die völlig freie Tätigkeit - das Wesen des Menschen - sei unverträglich mit der Religion wie mit dem Privateigentum, weil diese eine Schranke der freien Selbstbestimmung bilden. Daher müsse der Atheismus mit dem Kommunismus zur Errichtung der Anarchie vereinigt werden, welche letztere jegliche Staatsform negiert, die alle von der Monarchie bis zur Republik - nur Mittel der sozialen Ungleichheit seien.

Charakteristisch für $\mathrm{He}^{\prime}$ ' Aufsätze in den Einundzwanzig Bogen ist, daß die Theorie sich zunehmend von der Wirklichkeit entfernt. Anders als Marx erhält HeB durch die unmittelbare Konfrontation mit politischen und sozialen Fragen während der Mitarbeit an der Rheinischen Zeitung keine fruchtbaren Impulse, keine Anregung, in die gesellschaftlichen Verhältnisse theoretisch tiefer einzudringen. Die früher noch erkennbar gewesenen soziologisch-ökonomischen Anläufe werden nicht weiter verfolgt, sie verschwinden oder verflüchtigen sich in metaphysische Kategorien. Heß' Gesellschaftsanalyse beschränkt sich wesentlich auf die Feststellung, daß in der bisherigen Geschichte Arbeit und Genuß getrennt waren, daß das Privateigentum eine ,fixe Idee“ sei und daß durch Politik und Religion soziale und geistige Knechtschaftsverhältnisse etabliert wurden. Man vergleiche diese Sätze mit den Darlegungen Galls oder Gersteins über den Zusammenhang von Produktion, Industrie, gesellschaftlichen Klassen und Klassenkampf. $\mathrm{Zu}$ schweigen von den bedeutenden soziologischen Erkenntnissen St.-Simons oder Fouriers, die beide von Heß häufig herangezogen, aber nicht einmal angemessen rezipiert werden. Die gesellschaftlichen Verhältnisse zu analysieren scheint Heß gar nicht notwendig, sie sind einfach schlecht. Freilich will er in einer umfassenden Geschichtsphilosophie die Herkunft der schlechten Zustände erklären und aus dieser Erklärung die Notwendigkeit der künftigen kommunistischen Gesellschaft ableiten. Doch abermals geht er nicht den für den Aufbau einer wissenschaftlichen Theorie notwendigen Weg des induktiven Forschens; Vergangenheit, Gegenwart und Zukunft werden dogmatischen Bestimmungen unterworfen und nicht in einen den tatsächlichen Verlauf wiedergebenden kausalen Zusammenhang gebracht.

Die Geschichte wird in einen geistigen Prozeß verwandelt, die verschiedenen gesellschaftlichen Verhältnisse gelten als abhängig von dem jeweiligen Entwicklungsstand des Selbstbewußtseins.

Heß' Bestreben geht dahin, die kommunistische Gesellschaft als eine Notwendigkeit nachzuweisen. In seiner ersten, von Cieszkowski übernommenen Konzeption der Philosophie der Tat hatte er diesen Nachweis auf den objektiven Weltgeist Hegels basiert. Der Weltgeist wolle die Harmonie, wir erkennen seinen Willen und vollziehen 
in freier Tat das Notwendige, wir überführen das von der Philosophie Erkannte in die Wirklichkeit. Die Lektüre von Feuerbachs Wesen des Christenthums sowie der Eınfluß von Junghegelianern führen $\mathrm{He} B$ dazu, die Weltgeistkonzeption aufzugeben. Die vormals in der Bewegung des Weltgeistes verbürgte objektive Geschichtsgesetzlichkeit entfällt. Für seine kommunistische Zukunftsaussage braucht $\mathrm{HeB}$ jedoch einen objektiven Grund. Er verlegt diesen, die wirkliche Geschichte ignorierend, in das Subjekt. In dem Maße, wie Marx durch seine Erfahrungen an der Rheinischen Zeitung von der Philosophie des Selbstbewußtsems abrückt und Feuerbachs These von der Bedingtheit des Bewußtseins vom Sein historisch und soziologisch auszubauen beginnt, wird Heß ein Anhänger eben dieser Philosophie des Selbstbewußtseins. Die entwicklungsfähigen Elemente der Feuerbachschen Philosophie bleiben bei Heß unfruchtbar. Feuerbach geht vom leibhaftigen Menschen mit seinen Bedürfnissen aus, $\mathrm{Heß}$ vom Selbstbewußtsein ; für jenen ist der Mensch bedıngt durch seine gesellschaftliche Daseinsweise, für diesen durch individuelle Denkakte; für Feuerbach resultiert die Religion aus einem Mangel, er faßt sie als ein gesellschaftliches Bewußtsein auf, für Heß in diesem Falle Feuerbachsche und Fichtesche Elemente kombinierend - resultiert sie aus einem individuellen Denkfehler, er faßt sie als Fixierung des Gedachten in Trennung vom Denkenden auf. Die vormals im Namen des Weltgeistes gestellte Forderung nach kommunistischer Umgestaltung der Gesellschaft wird jetzt im Namen des Selbstbewußtseins erhoben. Beiden Tatkonzeptionen ist die Aufforderung gemeinsam, Erkanntes in die Tat umzusetzen. Heß' in den Einundzwanzig Bogen geäußerte Tatphilosophie enthält indes eın neues Element: die Tat ist überhaupt das Wesen des Menschen. Heß kombinıert die Philosophie des Selbstbewußtseins mit dem Fichteschen Grundgedanken, demzufolge das autonome Individuum die Freiheit als unbedingte, von allem unabhängige Selbsttat realisiert. Er kommt zu dem Resultat: das Selbstbewußtsein durchläuft einen Entwicklungsprozeß, seine Entwicklung macht den Inhait der Geschichte aus. Es selbst besteht in Tätigkeit, Denken. Diese Geistestat ist ein beständiges, auf immer höherer Stufe vorgehendes Setzen und Aufheben eines Nichtich, eines vom Denkenden unterschiedenen Gedachten. Auf der höchsten Entwicklungsstufe erkennt das Selbstbewußtseın dıe Identıtät von Denkendem und Gedachtem. Jetzt wird die Geistestat freie Geistestat.

Die freıe Geistestat erklärt $\mathrm{Heß}$ als das Wesen des Individuums. Und in dieser dogmatischen Wesensunterstellung hat er jetzt wieder eıne objektive Basis für die Errichtung der kommunistischen Gesellschaft gefunden: diese ist nichts anderes als die notwendige Entsprechung des erlangten Bewußtseinszustandes. Dieser subjektiv-idealistıschen Geschichtsauffassung entspricht die anarchistische Ausdeutung des Kommunismus, als deren Väter Babeuf und Proudhon bezeıchnet werden. Die kommunistısche Gesellschaft ist für $\mathrm{Heß}$ keıne kollektıve Gemeınschaft auf der Grundlage der vergesellschafteten Produktion. Sie ist eine Gesellschaft von auf sich bezogenen Individuen, die jegliche politısche und geistıge Herrschaft und das Eigentum negieren und sich in der Selbstzweck gewordenen freen Geistestätigkeit genießen. Arbeit und Genuß werden, so stellt Heß unter Berufung auf Fourier fest, in dieser Gesellschaft zum ersten Mal vereint sein.

Heß' Phılosophıe der Tat ist eine Art Neuauflage von Hegels Phänomenologie, mit dem Hauptunterschied, daß hier der Weltgeist und dort das Selbstbewußtsein das Substrat der Geschichte bilden. Daneben ermangelt Heß nicht nur der unıversellen Tatsachenkenntnis des großen Phılosophen, auch bleıbt er unermeßlich weit zurück 
hinter dessen tiefen Einsichten von der Bedeutung der wirklichen Produktion für die Herausbildung und Entwicklung des Menschen, von dem gesellschaftlichen Charakter des Menschen und von dem Bedingungsverhältnıs von Produktion, Arbeitsteilung und sozialen Schichtungen. Die profane menschliche Arbeit, die Hegel in die Philosophie einführte, kommt in Heß' umfangreıchem Aufsatz über die Philosophie der That widersinnig genug - nicht vor. Heß hat es nur mit der geistigen Tätigkeit zu tun. ${ }^{87}$

Ein ähnliches Thema wie in den Einundzwanzig Bogen handelte $\mathrm{He} B$ in dem (erst postum veröffentlichten) Aufsatz Was wir wollen. ${ }^{88}$ Er versuchte hierin die Frage zu beantworten, wie die reale Freiheit, die er als freie Selbsttat auffaßte, verwirklicht werden könne.

Die Voraussetzung für die reale Freiheit sieht Heß im individuellen Selbstbewußtsein, das erst jedes Individuum zu wirklicher Freiheit fähig mache. ${ }^{89}$ Es komme darauf an, das Selbstbewußtsein der jetzt unfreien Menschen zu entwickeln, bis es aus sich die frese Selbsttat entläßt. Zugleich versucht $\mathrm{Heß}$, seine These von der Herkunft des Kommunismus aus der Philosophie zu begründen; er stellt drei Entwicklungsetappen fest: die Althegelianer begnügten sich damit, im Geiste frei zu sein; die Junghegelianer durchbrachen diese Schranke, um die freie Tat zu verwirklichen, doch erreichten sie nur eine halbe, unentschiedene Freiheit, insofern sie sich als selbstbewußte Kritiker von den nicht selbstbewußten Individuen der Masse absonderten. Jetzt sei die Zeit gekommen, wo auch in diesen das Bewußtsein der realen Freiheit entwickelt werden müsse. Die Hauptbedingung dazu sei, daß ihnen die Bildungsmittel zugänglich gemacht werden, die ihnen bei der jetzigen ,Zufälligkeit“ ${ }^{90}$ der Verteilung unerreıchbar seien. Daher müsse zunächst die Aufhebung der gegenwärtıgen Verteilung der Bildungsmittel erfolgen und danach die Negation des materiellen Eigentums, das mit dem Begriff des unabhängıg und frei sich bestimmenden selbsttätigen Geistes unvereinbar sei. Als ideale Gesellschaft denkt er sich eine Organisation kleiner sozialer Einheiten. ${ }^{91}$

$\mathrm{HeB}$ ging nicht von den wirklichen, ökonomisch-sozialen Voraussetzungen der ,Unfreiheit" aus, sondern von Bewußtseinstatsachen. Die Geschichte erschien als ein geistiger Befreiungsprozeß, wobei die Beseitigung des Privateigentums nur als Beseitigung einer Bildungsschranke gefaßt war.

Der Aufsatz läßt eine weitere Annäherung an die subjektivistische Philosophie der Junghegelianer erkennen. Heß bemerkte die Verwandtschaft und fühlte sich veranlaßt, auf die Grenze hinzuweisen, die ihn von Bruno Bauer trenne. Dieser sei bei der Tatsache des Gegensatzes zwischen den zum Selbstbewußtsein gelangten Individuen und der geistlosen Masse stehengeblieben, während er, Heß, diese geistlose Masse der Bildung zuführen und ihr ebenfalls zum Bewußtsein ihres Wesens verhelfen wolle.

Von diesem subjektiv-idealistischen Standpunkt aus schrieb Heß im Frühling 1843 eine Kritık von Weitlings Garantien der Harmonie und Freiheit, die im Dezember 1842 erschienen waren. Die (bisher nicht aufgefundene) Besprechung las Heß einigen seiner Pariser Freunden vor. Sie sollte als Broschüre bei Fröbel herauskommen, erschien jedoch nicht. Ewerbeck schrieb am 15. Ma1 1843 an Weitling: „Seine lange Kritık Deiner Harmonie erscheint bei Fröbel als Broschüre (für ein ganz geringes) und darin sagt er die Fehler Deines Buches: 1. Du gehst vom Gleichheitsprinzip einseitig aus und läßt das Freiheitsprinzip bei Seite; 2. Du läßt die Tugend, will sagen die freiste, selbstthätige Geistesbewegung aus dem Spiele; 3. Du unterscheidest nicht bloß, sondern du schneidest gleichsam mitten durch den Geist durch, indem du Arbeit rechts, Genuß links hinstellst. Wobei die Arbeit stets als gezwungen erscheint, was um 
alles in der Welt zu verhüten ist. Das Übrige lies du selber, die Kritik ist sehr lieblich gegen dich und ziemlich verständlich. “92

Im gleichen Brief bemängelt Ewerbeck Heß’ Neigung zu Abstraktionen: „Heß ist sehr wirksam für die Bekehrung der sehr Gebildeten; aber er spricht in Begriffen, also nicht in Anschauungen, mithin für die nicht sehr Gebildeten unvernehmbar. So geht es bis jetzt allen deutschen Philosophen. Er sieht's ein und verspricht Besserung. Er hat auch manche Barockheiten, z. B. will er durchaus nur Atheismus und Anarchie predigen, mit diesen Ausdrücken, wobei man sich natürlich nichts Untugendhaftes zu denken hat; Atheismus d. h. Läugnung eines bestimmten, dieses, jenes Gottes, durch welche Läugnung man hindurch zur Wahrheit gehen soll. Unter Anarchie versteht man heute, wie Napoleon schon, wildes Rasen ohne Gouvernement, es heißt: Ohne Herrscher sein, was also gut wie schlecht sein kann. Bis jetzt aber sehe ich die Zweckmäßigkeit solcher Worte und Wortverdrehungen nicht ein; das ist um Aufsehen zu machen. Die junge deutsche philos[ophische] Schule hat (wie der Deutsche denn die Maßlogik liebt) mehr oder doch ebenso sehr diese Ausschweifung in der Theorie lieb, wie die Jakobiner die Übertreibung in der Praxis. Überhaupt sind ja alle solche Namen ein wahres Hindernis, denn sie werden sogleich Steine des Anstoßes, Scheidewände, Stichwörter.“93 Indes räumt Ewerbeck ein: „Aber diese seine Schwächen abgerechnet, ist $\mathrm{HeB}$ sehr tüchtig“" 94

Heß' Kritik scheint Weitling verstimmt zu haben; Ewerbeck sah sich veranlaßt, zwischen beiden zu vermitteln. Am 25. Mai 1843 schrieb er an Weitling: „Schlage dir nur aus dem Sinn, daß Doktor HeB dir Leids anthun will. Er tadelt dein Werk mit Recht, mit Unrecht; wie's geht, aber was er einigen hier vorlas, ist nicht beleidigend; du irrst. "95

In Paris hat Heß nicht die Impulse empfangen, wie wenig später Marx. Wie er nicht den Weg ökonomischer und historischer Studien ging, um Einsicht in die bewegenden Kräfte der Gesellschaft zu erhalten, so halfen ihm auch Anschauung und Erfahrung nicht weiter. Was für Marx' Entwicklung von entscheidender Bedeutung sein sollte, die Kenntnisnahme des französischen Proletariats, das bereits als große gesellschaftliche Klasse auftrat, befruchtete Heß' Denken ebensowenig wie die aus der Literatur gewonnene Kenntnis englischer Verhältnisse. Die kleinbürgerliche Vorstellung, im Proletariat eine arme, hilfsbedürftige Masse zu sehen, hinderte ihn, von der Erkenntnis der in der bürgerlichen Gesellschaft stattfindenden Polarisation von arm und reich fortzuschreiten zu grundlegenden Einsichten in das Wesen des Klassenkampfes. Sein „philosophischer" Kommunismus gehört indes zu den frühesten Versuchen, die moderne deutsche Philosophie dem Sozialismus dienstbar zu machen. Biedermann schrieb 1846: „Der Erste, [. . .] welcher in neuerer Zeit die Konsequenzen der deutschen Filosofie nach der Seite des Sozialismus hin mit Bewußtsein und Entschiedenheit zu ziehen versuchte, war Moritz Hess. “95a Zwei Jahre zuvor hatte Marx, als er von metaphysischphilosophischen Positionen sich zu lösen und die historisch-materialistische Theorie herauszuarbeiten im Begriff stand, die Heßschen Aufsätze in den Einundzwanzig Bogen auf ähnliche Weise gewürdigt. In Marx' 1844 entstandenen Ökonomisch-philosophischen Manuskripten lesen wir: „Es versteht sich von selbst, daß ich außer den französischen und englischen Sozialisten auch deutsche sozialistische Arbeiten benutzt habe. Die inhaltsvollen und originalen deutschen Arbeiten für diese Wissenschaft reduzieren sich indes außer Weitlings Schriften - auf die in den ,21 Bogen' gelieferten Aufsätze von $\mathrm{He \beta}$ und auf Engels' ,Umrisse zur Kritik der Nationalökonomie in den ,Deutsch-Französischen 
Jahrbüchern" wo ich ebenfalls die ersten Elemente der vorliegenden Arbeit in ganz allgemeiner Weise angedeutet habe. "96

Heß' Theorie ging nicht über eine teleologische Konstruktion hinaus. Und in dieser wurden gerade die bedeutendsten entwicklungsfähigsten Bestandteile der modernen deutschen Philosophie - die von Marx aufgegriffen wurden - vernachlässigt, so Hegels Widerspruchsdialektik, Hegels Auffassung von der Rolle der wirklichen menschlichen Arbeit in der Geschichte, Feuerbachs materialistische These von der Abhängigkeit des Bewußtseins vom Sein.

\section{Korrespondenzen für dıe „Kölnısche Zeitung“}

Das Verbot der Rheinischen Zeitung ließ Heß fast ohne Einnahmen in Paris. Er verließ am 14. Mai 1843 die französische Metropole, um nach Köln zurückzukehren. In einem Brief Ewerbecks an Weitling vom 15. Mai 1843 heißt es: „Heß wird, da er in Deutschland keıner Zeitung sich verkaufen mag und die rheınische, an der er schrieb, todt ist, zu Fröbel gehen, welcher ihm dieser Tage schrieb [. . .] Dieser Heß ist gestern nach Köln zurück."97 In Köln traf $\mathrm{Heß}$ mit Ruge zusammen, der ihn zur Mitarbeit an einer radikalen Zeitschrift einlud, die mit finanzieller Unterstützung Fröbels herausgegeben werden sollte. ${ }^{98}$

Der mit Jahreswechsel in Sachsen und Preußen einsetzenden verschärften Knebelung fortschrittlicher Presseerzeugnisse waren auch Ruges Deutsche Jahrbücher zum Opfer gefallen. Die letzte Nummer (24) dieser Zeitschrift erschien am 28. Januar 1843.98a Die Leipziger Allgemeine Zeitung wurde Ende 1842 in Preußen verboten. ${ }^{986}$ Eine Gruppe oppositioneller Philosophen und Schriftsteller war entschlossen, den Kampf gegen die absolutistischen und halbabsolutistıschen Regimes in Deutschland mittels eines im Ausland zu gründenden Presseorgans fortzusetzen. Die Initiative hierzu ergriffen Ruge und Marx, die als führende Köpfe der radikalen deutschen Publizistik galten. $^{98 c}$

Marx reiste im Mai 1843 nach Dresden, um mit Ruge die Vorbereitung der geplanten Zeitschrift zu besprechen. ${ }^{98 d}$

Deutschland schied für ein solches Unternehmen aus, und auch die Schweiz kam nicht in Frage, nachdem dort seit der Verhaftung Weitlings die radikale Bewegung immer mehr der Verfolgung ausgesetzt war. Anfang Juli hatte Fröbel die Leitung des Schweizerischen Republikaners niederlegen müssen. Ebensowenig wie Marx und Ruge dachte er daran zu kapitulieren. Ihrer aller Wunsch traf sich in dem Projekt einer Zeitschrift im Ausland. Man schwankte anfangs zwischen Straßburg und Paris, entschied sich dann für Paris, wo sich - nach Schätzung von Ruge ${ }^{98 e}-85000$ Deutsche aufhielten und wo man für die geplanten Deutsch-Französischen Jahrbücher den günstigsten Boden zu finden hoffte.

Heß nahm Ruges Anerbieten um so lieber an, als das deutsch-französische Bündnis, das Ziel des Unternehmens, von je sein Anliegen war. Außerdem mußte er befürchten, wegen seiner Mitarbeit an der Rheinischen Zeitung und an den Einundzwanzig Bogen aus der Schweiz polizeilich verfolgt zu werden. ${ }^{99}$

Vor seiner Abreise nach Paris konnte er mit einem Redakteur der Kölnischen Zeitung, Hermann Püttmann ${ }^{100}$, ein Abkommen treffen, das seine Anstellung als Pariser Korrespondent dieses Blattes festlegte. Püttmann war ein alter Bekannter von Heß, 
er hatte an der Rheinischen Zeitung mitgearbeitet; von Heß wurde er auf die Bahn des ,wahren" Sozialismus gelenkt.

Anfang August fuhren Heß und Ruge nach Brüssel, das vorübergehend auch als Verlagsort der geplanten Zeitschrift in Erwägung gezogen wurde, und dann weiter nach Paris. Hier wurden sie schon bald nach ihrer Ankunft von der preuBischen Regierung der besonderen Aufmerksamkeit des deutschen Gesandten in Paris empfohlen. ${ }^{101}$ Dieser berichtete am 26. September 1843 an den preußischen Außenminister über Ruge und Heß: ,Der Dr. Arnold Ruge befindet sich seit einiger Zeit hier, studirt die Französischen Zustände und soll kein Communist [..] sein [..] er kennt den Dr. Heß schon seit längerer Zeit und verkehrt mit ihm, ohne jedoch dessen Ansichten in den meisten Puncten zu theilen."102, ,[...] $\mathrm{Heß}$ war bereits früher hier und Correspondent der vormaligen Rheinischen Zeitung, er ist einer der Chefs der Pariser Communisten und unter ihnen der fähigste Kopf [ . . .]." ${ }^{103}$

Das Zustandekommen der Deutsch-Französischen Jahrbücher, deren erstes Heft bereits Im November 1843 erscheinen sollte ${ }^{103 a}$, verzögerte sich bis Anfang 1844. $\mathrm{He} ß$ begann inzwischen (im August 1843), die Kölnische Zeitung mit Korrespondenzen zu beliefern. ${ }^{104}$ Sein letzter Beitrag erschien in diesem Blatt am 27. Dezember 1843. Die Berichte über französische Tagesereignisse verband er geschickt mit Informationen über die sozialistischen und kommunistischen Bewegungen in Frankreich. Der Minister des Innern von Arnim wies Ende Oktober den Regierungspräsidenten von Gerlach auf die gefährliche Tendenz der Korrespondenzen in der Kölnischen Zeitung hin und forderte ,,allerentschiedenste " Maßnahmen. ${ }^{105}$

Von besonderem Interesse ist die in seiner Korrespondenz vom 2. September wiedergegebene Dankadresse in Paris lebender deutscher Kommunisten an Dr. Bluntschli. Bluntschli hatte wenıge Wochen nach der Verhaftung Weitlings (Juni 1843) bei diesem aufgefundene Papiere, Briefe etc. in dem (bereits mehrfach zitierten) Kommissionalbericht veröffentlicht in der Absicht, die kommunistische Bewegung zu diffamieren. Bluntschli erreichte z. T. das Gegenteil des Angestrebten. Sein Buch trug dazu bel, kommunistische Ideen zu verbreiten, und der Bund der Gerechten verdankte der Publıkation einen beträchtlichen Mitgliederzuwachs. ${ }^{106}$ In der Adresse heißt es u. a.: „Sie haben Sich durch die erwähnte Schrift, wenn auch wider Ihren Willen, um die Sache des Communismus große Verdienste erworben. [. . . In Betrachtung nun, daß öffentliche Verfolgungen gegen das Princip nur für dasselbe Propaganda machen, votiren wir Ihnen im Pleno unseres Ausschusses einen feierlichen Dank für Ihre Publication.“107

Einem Bericht des preußischen Gesandten in Paris zufolge hat Heß die Adresse „Namens“ der Pariser Kommunisten ,,an Dr. Bluntschli zu Zürich redigirt“. 107a Über die Autorschaft sagt Heß in seiner Korrespondenz: „Schließlich will ich Ihnen noch eine Art von Actenstück mittheilen, welches kürzlich von Seiten der hier wohnenden deutschen Socialisten und Communisten an Hrn. Bluntschli abgegangen ist [. . ]."107b

Exakter als in der Kölnischen Zeitung reproduzierte $\mathrm{He} B$ die Adresse in Nummer 216 der Mannheimer Abendzeitung vom 15. September 1843 (S. 161f). ${ }^{107 c}$ Hier ist sie unterzeichnet: „Die Ihnen unbekannten Mitglieder des Ausschusses. Gegeben zu Paris am 29. August 1843. Der gewöhnliche Schreiber." Offenbar ist also nicht Heß der Verfasser der Adresse gewesen, sondern ein Ausschuß des Bundes der Gerechten in Paris.

Auch der Bund der Gerechten in London übersandte Bluntschli ein spöttısches Dankschreıben, das zusammen mit Auszügen eines Briefes der Autoren von August 
Becker in einer anonymen Korrespondenz in der Mannheimer Abendzeitung mitgeteilt wurde. ${ }^{107 \mathrm{~d}}$

\section{Philosophie und Proletariat \\ „Entfremdung“ bei Feuerbach, Marx, Heß}

Stand Heß' Denken zur Zeit seines ersten großen Versuchs einer ,,philosophischen“ Begründung des Sozialismus unter dem Einfluß von Fichte und Feuerbach, so trat in seiner weiteren Entwicklung die Anlehnung an Fichte zugunsten einer stärkeren Aufnahme Feuerbachscher Gedanken merklich zurück. Der neuerliche Einfluß Feuerbachs, der sich auch auf andere fortgeschrittene Denker des philosophischen Radikalismus erstreckte, ging von Feuerbachs Vorläufigen Thesen zur Reformation der Philosophie und Grundsätzen der Philosophie der Zukunft aus. Die Thesen waren bereits 1842 entstanden, erschienen jedoch wegen Zensurwidrigkeiten erst im Februar 1843, und zwar in den von Ruge im Verlag des Literarischen Comptoirs herausgegebenen Anekdota zur neuesten deutschen Philosophie und Publicistik. ${ }^{107 \mathrm{e}}$ Dieses zweibändige Werk war, wie später die Einundzwanzig Bogen, eine Sammlung von Artikeln, die aus Zensurgründen in Deutschland nicht veröffentlicht werden konnten. Die Grundsätze erschienen als Broschüre im gleichen Verlag im Herbst 1843.

Die Thesen waren eine Ausdehnung der Kritik an der Religion auf die Kritik an der idealistischen Philosophie, in der Feuerbach die letzte Form der Theologie erkannte. Die idealistische Philosophie erklärte er wie die Religion als Ergebnis menschlicher Selbstentfremdung. Im Wesen des Christenthums hatte er gezeigt, daß die Eigenschaften Gottes in Wirklichkeit die Gattungseigenschaften des Menschen sind, der durch deren Entäußerung erst Gott schafft. Dabei werde der Mensch, das Subjekt, zum Prädikat Gottes und dieser, obwohl nur die Verselbständigung menschlicher Eigenschaften, zum Subjekt. Ähnlich wies Feuerbach in bezug auf die idealistische Philosophie nach, daB der in ihr auftretende absolute Geist ein Abstraktionsergebnis des wirklichen menschlichen Geistes ist. Diese Abstraktion werde in der "spekulativen Philosophie“ als Subjekt verselbständigt und der tatsächliche menschliche Geist in ein Prädikat dieses Subjekts verwandelt. In seiner Kritik kehrte Feuerbach die idealistische Auffassung des Verhältnisses von Subjekt und Prädikat wie von Denken und Sein um und stellte dem philosophischen Idealismus seine auf der Anerkennung des Menschen und der Natur als objektiver Realitäten beruhende materialistische Anschauung gegenüber.

In Anlehnung an die Methode der Feuerbachschen Kritik an der idealistischen Philosophie unternahm Marx noch vor seiner Übersiedlung nach Paris eine umfangreiche Kritik des Hegelschen Staatsrechts, von der ein Manuskript überliefert ist, dessen Ausarbeitung wohl im August 1843 beendet wurde. ${ }^{108}$

Marx stand vor dem Problem: Kann der demokratische Staat der elenden Lage der Besitzlosen, die seine Grundlagen immer wieder gefährdet, abhelfen, wenn doch das Interesse der Besitzenden sich immer wieder des Staates bemächtigen kann? Das Problem führte ihn auf die Frage nach dem prinzipiellen Bedingungsverhältnis von sozialen und politischen Faktoren. Sie stellte sich ihm dar als Frage nach dem Verhältnis von Gesellschaft und Staat. Und aus der Tatsache, daß er, ungeachtet der 
Radikalisierung der Hegelschen Staatsphilosophie, Hegel folgend gemeint hatte, der Staat solle das regulierende und die divergierenden Interessen in der Gesellschaft in Harmonie setzende Element sein - was ihm nun fragwürdig geworden -, erklärt sich, $\mathrm{da} B$ er dieser Problematik Herr zu werden versuchte durch eine Kritik der Hegelschen Rechts- und Staatsphilosophie. Die Radikalisierung der Hegelschen Rechts- und Staatsphilosophie hatte mit der Forderung nach Errichtung der demokratischen Republik die äußerste Grenze erreicht; aber - die Frage erhob sich für Marx - werde jene erstrebte Republik mit den genannten sozialen Problemen fertig werden? In einem Rückblick schrieb er: „Die erste Arbeit, unternommen zur Lösung der Zweifel, die mich bestürmten, war eine kritische Revision der Hegelschen Rechtsphilosophie $[$. . . ]."108a

Wie aus seinen im Juli und August 1843 entstandenen Exzerptheften hervorgeht, zog Marx auch Schriften in den Kreis der Untersuchungen, die die Entstehungsgeschichte der bürgerlichen Gesellschaft und des bürgerlichen Staates behandelten. Zugleich studierte er die bedeutenden politisch-theoretischen Schriften von Rousseau, Montesquieu und Machiavelli. Schließlich setzte er das schon während der Tätigkeit an der Rheinischen Zeitung begonnene Studium sozialistischer und kommunistischer Literatur fort. Er beschäftigte sich u. a. mit Cabet, Dézamy, Weitling, Fourier und Proudhon.

Marx kommt zu dem Ergebnis, daß die Hegelsche Staatsphilosophie auf einer ähnlichen Umkehrung der realen Verhältnisse beruhe, wie Feuerbach sie für Religion und idealistische Philosophie nachgewiesen hatte. Durch eine Verkehrung der wirklichen Beziehungen zwischen Gesellschaft und Staat werde dieser bei Hegel zu einer abstrakten Wesenheit, die als Verkörperung der absoluten Idee die Gesellschaftsordnung bestimme. Tatsächlich aber bestimme die Gesellschaft das Wesen des Staates. Durch diese Umkehrung der Verhältnisse spiele der Staat der Gesellschaft gegenüber die gleiche Rolle wie der Himmel oder Gott in bezug auf die Erde. Hatte Marx schon während der Mitarbeit an der Rheinischen Zeitung in Anlehnung an Feuerbach das religiöse Bewußtsein als Reflex gesellschaftlicher Verhältnisse gedeutet, so baut er nun, abermals in Anlehnung an Feuerbach, in bezug auf das Verhältnis von Gesellschaft und Staat weitere Elemente seiner späteren Theorie von „Basis“ und „Überbau“ auf. In einer späteren Charakterisierung dieses gesamten Erkenntnisprozesses erklärte Marx, er sei damals zu der Einsicht gelangt, ,,daß Rechtsverhältnisse wie Staatsformen weder aus sich selbst $\mathrm{zu}$ begreifen sind noch aus der sogenannten allgemeinen Entwicklung des menschlichen Geistes“"108b, daß sie vielmehr in den realen gesellschaftlichen Verhältnissen wurzeln. Des weiteren vertieft Marx seine Einsicht in die Rolle des Privateigentums in der bürgerlichen Gesellschaft. ${ }^{109}$ Aus dem Manuskript geht nicht hervor, ob er hieran bereits die Forderung nach Aufhebung des bürgerlichen Privateigentums knüpfte; in nicht eindeutig $\mathrm{zu}$ interpretierender Weise fordert er die völlige Durchsetzung des demokratischen Elements in Gesellschaft und Staat. ${ }^{109 a}$

Marx soziologische Einsichten hatten seinen radikalen Demokratismus bereits soweit untergraben, daß es nur noch eines kleinen Schrittes bedurfte, um aus ihnen kommunistische Konsequenzen zu ziehen. Diesen Schritt tat Marx unmittelbar im Anschluß an die Kritik der Hegelschen Staatsrechtsphilosophie. Dokumentiert ist er in einem kurze Zeit später (im September 1843) verfaßten Brief an Ruge. ${ }^{109 b}$ Als Folge seiner historischen Studien und unter dem gleichzeitigen Einfluß sozialistischer und kommunistischer Literatur erkennt Marx, daß der bürgerliche Staat nur die „,Herrschaft 
des Privateigentums“, nicht aber die „Herrschaft des Menschen“ sein könne. ${ }^{109 c}$ Marx erklärt sich für die „Aufhebung des Privateigentums“", für das „,sozialistische Prinzip“, das die praktische Realisierung „des wahren menschlichen Wesens“ erstrebt. ${ }^{109 d}$ Den Kommunısmus Cabets, Dézamys, Weitlings lehnt er ab, aber eben darum, weil er nur erst ,eine aparte, von seinem Gegensatz, dem Privatwesen, infizierte Erscheinung des humanistischen Prinzips" sei. ${ }^{109 e}$ Dieser Kommunismus und die Aufhebung des Privateigentums seien nicht identisch, ,und der Kommunismus hat andre sozialistische Lehren, wie die von Fourier, Proudhon etc., nicht zufällig, sondern notwendig sich gegenüber entstehn sehn". ${ }^{109 r}$

Aus dem Schreiben geht hervor, daß Marx bereits vor seiner Übersiedlung nach Parıs (im Oktober 1843) von radikal-demokratischen zu sozialistischen Positıonen übergegangen ist. Allerdings denkt er sich die Ausführung des sozialistischen Prinzips noch unabhängig von der Arbeiterbewegung und in Anlehnung an Feuerbach als Realisierung des wahren menschlichen Wesens. Dieser ,philosophische" Weg zum Kommunismus erklärt sich aus Marx' vorangegangener geistiger Entwicklung und aus der Tatsache, daß er das Proletariat als große gesellschaftliche Klasse noch nicht kennengelernt hatte. ${ }^{109 \mathrm{~g}}$

Marx aktıvierte - wie nach ihm die ,wahren" Sozialisten - auf utopisch-sozialistısche Weise Feuerbachs Humanismus und Entäußerungskonzeption. Letztere bot Marx, als er noch nicht in der Ökonomie den Schlüssel zum Verständnis der Gesellschaft gefunden hatte, die Möglichkeit zur Erklärung gesellschaftlicher Mißstände, und in Feuerbachs Humanismus fand er, bis er den Kommunismus kausal-historisch aus der Bewegung der bürgerlichen Gesellschaft abzuleiten imstande war, eine theoretische Grundlage seiner kommunistischen Bestrebungen. Noch deutlicher als in dem SeptemberBrief zeıgt sich dies in dem Aufsatz Zur Judenfrage. ${ }^{110}$ Die Arbeit wurde wohl zum größten Teil noch in Kreuznach geschrieben; die Auffassung, zu der Marx erst in Paris kam, nämlich daß das Proletariat der Totengräber der bürgerlichen Gesellschaft sein werde, 1st darin noch nicht zu finden. ${ }^{10 a}$

In der Judenfrage stellte Marx der von Feuerbach konstatierten religiösen Entfremdung die praktische, die politische und ökonomische, zur Seite. Er meinte, daß unter der Herrschaft des Christentums alle natürlichen, sittlichen und theoretischen Verhältnisse des Menschen ,,äußerlich“ geworden seien; die „,bürgerliche Gesellschaft“ habe sich ,,vollständig vom Staatsleben“" getrennt, ,,alle Gattungsbande des Menschen" zerrissen und ,den Egoismus, das eigennützige Bedürfnis an die Stelle dieser Gattungsbande" gesetzt. ${ }^{110 b}$ Die Entäußerung habe auch die praktische Tätigkeit des Menschen ergriffen und sie unter die Herrschaft eines äußerlichen Wesens, des Geldes, gestellt. „Die Veräußerung ist die Praxis der Entäußerung. Wie der Mensch, solange er religiös befangen ist, sein Wesen nur zu vergegenständlichen weiß, indem er es zu einem fremden phantastischen Wesen macht, so kann er sich unter der Herrschaft des egoistischen Bedürfnisses nur praktisch betätigen, nur praktische Gegenstände erzeugen, indem er seine Produkte, wie seine Tätigkeit, unter die Herrschaft eines fremden Wesens stellt und ihnen die Bedeutung eines fremden Wesens - des Geldes - verleiht." "1toc

Auf dem Umweg über die Entäußerungskonzeption näherte Marx sich der ökonomischen Erfassung der bürgerlichen Gesellschaft. Er hielt sich zunächst an die typische Erscheinungsform des Privateigentums, das Geld. „Das Geld ist das dem Menschen entfremdete Wesen seiner Arbeit und seines Daseins, und dies fremde Wesen beherrscht ihn, und er betet es an."110d 
Mitte Oktober 1843 übersıedelte Marx nach Paris. ${ }^{10 e} \mathrm{Heß}$ machte ihn dort mit den führenden Männern der sozialistischen Bewegung bekannt. Mit den Deutsch-Französischen Jahrbüchern kam es zum zweiten Mal zu einer Zusammenarbeit zwischen den beiden Männern. Marx war, wie aus seinem Brief an Ruge vom September $1843^{110}$ und der größtenteils, wenn nicht insgesamt noch in Deutschland verfaßten Judenfrage hervorgeht, auf ,,philosophisch“-sozialistische Positionen übergegangen. Dies unabhängig von $\mathrm{Heß}$; während seines vom Austritt aus der Redaktion der Rheinischen Zeitung bıs zur Übersiedlung nach Paris mit kurzen Unterbrechungen währenden Aufenthalts in Kreuznach unterhielt Marx keınen Kontakt mit Heß. Nicht nur durch sein ausgebreitetes Wissen ${ }^{110 g}$, auch hinsichtlich der theoretischen Voraussetzungen unterschied Marx sich $\mathrm{kraß}$ von $\mathrm{He}$. In dem Maße, wie dieser sich der subjektıv-idealistischen Philosophie des Selbstbewußtseins angenähert, hatte Marx sich von ihr entfernt. Heß' Hinwendung zu Feuerbach seit Ende 1843 scheint auf einen Einfluß von Marx zurückzugehen, der schon selt der Rheinischen Zeitung in zunehmenden Maße Elemente der Feuerbachschen Philosophre in sein Weltbild integriert hatte.

Etwa einen Monat nach Marx' Ankunft in Paris erschienen Feuerbachs Grundsätze der Philosophie der Zukunft (Zürich und Winterthur, Literarisches Comptoir), die Marx und seine Pariser Mitstreiter wohl unmittelbar nach ihrem Erscheinen zur Kenntnis nehmen konnten. ${ }^{10 \mathrm{~h}}$ Feuerbach erweiterte darin seine früheren humanistischen Auffassungen $\mathrm{zu}$ einer ethisch-sozialen Theorie, derzufolge die Auslöschung des Egoismus und der Sieg der Menschenliebe als das glückhafte Los des Menschengeschlechts dargestellt werden. Mit der Aufhebung von Religion und idealistischer Philosophie werde der Mensch sein Wesen wiedergewinnen und ein diesem entsprechendes Leben führen können, ein Leben, das durch die Liebe der Menschen zueinander bestimmt sein werde.

Feuerbachs Begriff des Gattungswesens enthält zwei gänzlich verschiedene, von ihm aber in eins gesetzte Begriffe: 1. der Mensch ist ein kollektives Wesen, 2. der Mensch ist ein altruistisches Wesen. Das gesellschaftliche Wesen des Menschen wird fälschlich identıfizıert mit einer altruistischen Bestimmung. ${ }^{110 i}$ Die theoretische Schwierıkeit bestand darin, zu begreifen, wie die Menschen - obwohl kollektive Wesen - untereinander in Gegensatz kommen konnten. Es handelt sich um das Verständnis des Verhältnisses der Gesellschaftlichkeit des Menschen - vermittelt durch die gesellschaftliche Art von Produktion und Austausch - zu der Existenz entgegengesetzter gesellschaftlicher Klassen. Da Feuerbach nicht die ökonomische Genesis der gesellschaftlichen Gegensätze erfaßte, gab er auf die Frage: Wie ist es möglich, daß der Mensch trotz seines gesellschaftlichen Wesens in Feindschaft zu seinen Mitmenschen kommen konnte? die Antwort: Der Mensch ist seines Wesens verlustig gegangen.

Feuerbach erfaßte zwar den Menschen als wirklichen Menschen, aber er begriff ihn nicht in seiner Bedingtheit als Mitglied einer historisch gewordenen Klassengesellschaft. Soweit er die Mängel dieser Gesellschaft wahrnahm, erklärte er sie nicht aus ihrer ökonomischen Grundlage, sondern aus der Entäußerung des Wesens des Menschen. Die Harmonisierung der Gesellschaft erscheint aber bei ihm dennoch nicht als willkürliches Postulat, da er in die ontologische Bestimmung des Menschen das harmonievolle Gattungswesen als Wesensbestimmung mit eingeschoben hat. Der Mangel an Einsicht in die kausale geschichtliche Verkettung bedingte diese teleologische Konstruktion. ${ }^{110 j}$

In Feuerbachs Grundsätzen fand Marx eine weitere philosophische Grundlage des 
Kommunismus. Zugleich überwand er schon bald nach der Übersiedlung nach Paris im Prinzip das utopische Element seiner kommunistischen Anschauung, wenngleich die metaphysısche Entfremdungstheorie noch ein ganzes Jahr in seinem Denken herumgeistern sollte. Jenen prinzipiellen Durchbruch erkennen wir aus Marx' in der ersten Dezemberhälfte 1843 beendetem Aufsatz Zur Kritik der Hegelschen Rechtsphilosophie. Einleitung, der ebenfalls in den Deutsch-Französischen Jahrbüchern veröffentlicht wurde. ${ }^{111}$

Zuvor hatte Marx die künftige kommunistısche Gesellschaft utopisch als Verwirklichung des wahren menschlichen Wesens angesehen; eine gesellschaftsumwälzende Kraft hatte er aber nicht angeben können. Auf eine solche traf er nun in Paris. In dieser Stadt lernte er das Proletariat als große gesellschaftliche Klasse kennen, hier wurde er sich rasch im klaren darüber, daß das Proletariat die Kraft ist, die Gesellschaft umzuwandeln: erstens, weil es eine gesellschaftliche Macht darstellt, zweitens, weil es als unterste Klasse der Gesellschaft ein ureigenstes Interesse an dieser Umwandlung hat; die Emanzipation dieser Klasse werde der Herrschaft des Privateigentums und des Privatinteresses ein Ende machen. Zum ersten Mal konstatierte Marx die welthistorische Rolle des Proletariats. Die Errichtung der kommunistischen Gesellschaft wurde mit der Arbeiterbewegung in Verbindung gebracht und an die revolutionäre Aktion des Proletariats geknüpft. Dies wurde der entscheidende Ausgangspunkt für Marx' weiteren gedanklichen Fortschritt.

Die ihn seit seiner Dissertation beschäftigende Frage des Verhältnisses von gesellschaftlicher Veränderung und Bewußtsein löst er nun im Hinblick auf die Realisierung der sozialistischen Gesellschaft in dieser noch ,,vorökonomischen" Phase vorläufig so, daß die Theorie, geschaffen von den fortschrittlichen Denkern, "materielle Gewalt" wird, wenn sie die „Massen ergreift", und daß diese Massen in einer revolutionären Aktion diese Theorie verwirklichen werden. ${ }^{11 \mathrm{a}}$

Dieser vielzitierte Satz läßt auf den ersten Blick noch junghegelsche Abkünfte erkennen: Etwa als wahr Erkanntes soll realisiert werden. Das als wahr Erkannte 1st die ,Lehre, daß der Mensch das höchste Wesen für den Menschen" sei ${ }^{111 \mathrm{~b}}$, woraus sich der kategorische Imperativ ergebe, ,alle Verhältnisse umzuwerfen, in denen der Mensch ein erniedrigtes, ein geknechtetes, ein verlassenes, ein verächtliches Wesen ist".111c Die Verweltlichtung der Philosophie werde Sache des Proletariats sein. ${ }^{111 d}$ Die junghegelsche Komponente dieser Feststellung sollte indes nicht überschätzt werden. Die Umsetzung der erkannten Wahrheit in die Wirklichkeit dachte Marx sich weder wie seine frühere junghegelschen Freunde als Anpassung der Wirklichkeit an die vom Selbstbewußtsein errungene Wahrheit mittels der theoretischen Kritik noch wie Heß und seine späteren wahrsozialistıschen Genossen als Realisierung des ,wahren“ menschlichen Wesens, die notwendig erfolgen müsse, wenn alle Menschen zum Bewußtsein ihres Wesens gekommen wären. Die erkannte Wahrheit war für Marx der intellektuelle Reflex historischer, sozialer und politischer Tatsachen. Und Tatsache war die Existenz antagonistischer Klassen und ihr Kampf gegeneinander. ${ }^{11 \text { e }}$ Wie die Französische Revolution der Kulminationspunkt des Kampfes der französischen Bourgeoisie gegen die Feudalität gewesen ${ }^{111}$, so werde die proletarische Revolution Resultat des Gegensatzes von Proletariat und Bourgeoisie sein. Jene habe die Diskrepanz zwischen der ökonomischen Herrschaft der Bourgeoisie und ihrer politischen Rechtlosigkeit beseitigt, sie habe die politische Herrschaft den Bourgeoisverhältnissen adäquat gemacht; insofern hatte sie einen politischen Charakter. ${ }^{11 \mathrm{~g}}$ Die Emanzipation des Proletariats 
allerdings könne nicht durch einen analogen politischen Akt erfolgen, nicht durch eine - die sozialen Gegensätze, die ,Pfeiler des Hauses ${ }^{* 111^{\text {th }}}$ bestehen lassende -- politische Revolution, sondern allein durch eine - das Privateigentum liquidierende ${ }^{111 i}$ und die soziale Freiheit ${ }^{111 \mathrm{j}}$ etablierende - radikale Revolution ${ }^{111 \mathrm{k}}$

Mit der Konstatierung des Klassenkampfes in der modernen Geschichte und der konsequenten Rückführung der „,sozialen“ Frage auf ihren eigentlichen Kern, die Lage und geschichtliche Rolle des Proletariats, bahnte Marx sich den Weg über den ,philosophischen“ Kommunismus und die Metaphysik des Feuerbachschen Humanismus hinaus in Richtung auf die Erfassung historischer Gesetzmäßigkeiten und die Entwicklung eines historisch begründeten, proletarisch-kommunistischen Humanismus, nämlich des wissenschaftlichen Kommunismus. Dagegen sollte die nach dem Weberaufstand sich ausbrcitende und namentlich von Hel3 getragenene Literaturbewegung des .. Wahren" Sozialismus in der Metaphysik des .,philosophischen" Kommunismus verharren. ${ }^{111}$

Die soziale Problematik hatte Marx an ökonomische Fragen herangeführt, wie aus der Judenfrage und dann aus der Kritik an der Hegelschen Rechtsphilosophie zu erkennen. Hierin resümierte er den Komplex, von dessen Ausmaßen und geschichtsphilosophischen Erkenntnismöglichkeiten er damals noch keine Vorstellung hatte, in der Feststellung: . Dạs Verhältnis der Industrie, überhatupt der Welt des Reichtums, zu der politischen Welt ist cin Hauptproblem der modernen Zeit. ${ }^{.111 \mathrm{~m}}$

Auf dies Hauptproblem war Engels einige Zeit zuvor gestoßen. Seine vorläufig reifste Behandlung finden wir in Engels' (ebenfalls in den Deutsch-Framzösischen Jahrbüchern erschienenen) Limrisis'n zur einer Kritik der Nationalökonomic'. ${ }^{12}$

Mit den von Hel3 genährten kommunistischen Illusionen nach England, dem entwickcltsten Industriestaat, gekommen (November 1842) ${ }^{12 a}$, durchbrach Engels rasch den Utopismus von Hel3.

Dank einem strikt empirischen Vorgehen, das er bald durch das Studium englischer und französischer Nationalökonomen und Sozialisten und Kommunisten ergänzte, kam Engels zu entscheidenden Einsichten bezüglich der Entstehung und des Funktionierens der bürgerlichen Gesellschaft; damit begann er zugleich, seinen kommunistischen Ansichten eine wissenschaftliche (irundlage zu geben.

Aus dem Studium der industriellen Revolution gewann Engels tiefe Einsichten in den Zusammenhang von Produktion. Entstehung von Klassen, Klassenkämplen und Ideologie. Früher als Marx auf das Studium der modernen Industrie und der Nationalökonomie gestoßen, entwickelte Engels selbständig wesentliche Elemente des historischen Materialismus: die Entwicklung der Gesellschaft und deren politischer Organisation sowie die künftige sozialistische Gesellschaft leitete er aus der Bewegung der Produktion ab. Bis zur engen Zusammenarbeit mit Marx seit 1845 war er jedoch geneigt. dieses Erklärungsprinzip allein auf England anzuwenden. In bezug auf Deutschland glaubte er, daß hier der Kommunismus als Konsequenz der Philosophie auf dem Wege der Bildung etabliert werden würde. Hierin unterlag er allerdings dem Einfluß des philosophischen Kommunismus von Heß. Diesem folgend, meinte er, die Engländer seien zur kommunistischen Doktrin praktisch gekommen, durch die rasche Zunahme des Elends, der Demoralisicrung und des Pauperismus; die Franzosen politisch. indem sic zunächst politische Freiheit und (jleichheit forderten, und, nachdem sie dies als umzureichend emplanden, ihren politischen Forderungen die nach sozialer Freiheit 
und sozialer Gleichheit hinzufügten. Die Deutschen seien philosophisch zu Kommunisten geworden, durch Schlußfolgerungen aus ersten Prinzipien. ${ }^{12 h}$

Im Denken von Engels finden wir in der Zeit von 1842- 1844 einen Widerspruch zwischen historisch-materialistischen Einsichten und philosophisch-kommunistischen Anschauungen. Er resultiert aus der Inkonsequenz, die aus dem Studium der englischen industriellen Entwicklung und der Ökonomie gewonnenen historisch-materialistischen Elemente (mit denen er weit über den philosophischen Kommunismus von HeB hinausging) zu verallgemeinern und auch auf andere Länder anzuwenden.

Die Widersprüchlichkeit zeigt sich auch noch in Engels' Aufsätzen in den DeutschFranzösischen Jahrbüchern. In Die Lage Englands schreibt เr, sich auf Feuerbach berufend: „Der Mensch hat sich nur selbst zu erkennen, alle Lebensverhältnisse an sich selbst zu messen, nach seinem Wesen zu beurteilen, die Welt nach den Forderungen seiner Natur wahrhaft menschlich einzurichten, so hat er das Rätsel unserer Zeit gelöst." ${ }^{* 12 *}$ In seinen Umrissen dagegen untersucht Engels eingehend die ökonomische Grundlage der bürgerlichen Gesellschaft und leitet daraus kausal-historisch (nicht wie die ,wahren" Sozialisten teleologisch aus dem Wesen des Menschen) die künftige kommunistische Gesellschaft ab.

In dem Aufsatz geht Engels von der Tatsache aus, daß die bürgerliche Gesellschaft durch das kapitalistische Privateigentum gekennzeichnet ist, das notwendig die Konkurrenz nach sich ziehe. Die Bewegung dieses Privateigentums in den verschiedenen Etappen seiner Entwicklung sei reflektiert in den verschiedenen Etappen der Nationalökonomie von den Merkantilisten bis zu Malthus. Auch bei der Untersuchung der ökonomischen Kategorien ist Engels' Ausgangspunkt das kapitalistische Privateigentum, das unvermeidlich mit der Konkurrenz verbunden ist. Engels betont, daß das Privateigentum die Grundlage der bürgerlichen Gesellschaft sei und daß die ökonomische Analyse von dieser Voraussetzung auszugehen habe. Die bürgerlichen Nationalökonomen hätten diese Voraussetzung ungeprüft gelassen und als selbstverständlich hingenommen, weshalb sie zu widerspruchsvollen Aussagen kommen mußten. Engels kommt es darauf an, die Widersprüche der bürgerlichen Ökonomen zu zeigen und nachzuweisen, daß diese aus der Außerachtlassung des Privateigentums und der Konkurrenz resultieren.

Auf Engels' Analyse der ökonomischen Kategorien, deretwegen Marx später den Aufsatz eine genicle Skizze nannte ${ }^{112\rfloor}$, ist in vorliegendem Zusammenhang nicht näher einzugehen. Jedoch hervorzuheben ist, daß Engels cingehend den Gegensatz von Kapital und Arbeit erörtert. Das Kapital sei von vornherein mit einem Gegensatz behaftet. Durch Arbeit schaffe es neue Gegenstände. die wiederum als Kapital in die Produktion eingehen. Es ist damit in einer ständigen Ausdehnung begriffen. Im Gegensatz dazu verschlechtere sich die Lage des Arbeiters, der kein Kapital besitzt. Dieser Gegensatz von Kapital und Arbeit sei im Kapitalismus unüberbrückbar. Die vom kapitalistischen Privateigentum untrennbare Konkurrenz habe die Folge, da $\beta$ das Kapital anarchisch angewendet wird. Die anarchische Produktion führe mit Notwendigkeit zu Wirtschaftskrisen. Eine andere Auswirkung der Konkurrenz sei die Zentralisation des Kapitals, ein Prozeß, bei dem die kleineren und schwächeren Kapitalisten durch größere vernichtet werden. Der Gegensat\% von Kapital und Arbeit und die Wirtschaftskrisen schaffen ein revolutionäres Proletariat, das die kommunistische Gesellschaft errichten werde, deren materielle Basis der hohe Entwicklungsstand der Produktionskräfte sei. 
Engels konstatiert den Zusammenhang von Privateigentum - Produktionskräfte - Konkurrenz - Marktverhältnisse - Wert - Gebrauchswert - Lohn - Krisen Klassenkampf - Revolution; er beginnt, die Dialektik von Produktionskräften und Produktionsverhältnissen zu begreifen (letztern Ausdruck benutzt er nicht, aber er beschreibt in andern Worten annähernd den später unter diesem Begriff gefaßten Sachverhalt), und er spricht von ökonomischen Gesetzen, die die Revolution erzeugen werden. ${ }^{12 \mathrm{e}}$

Engels' Aufsatz, nach dessen Erscheinen Marx und Engels in Briefwechsel traten ${ }^{12 f}$, wies Marx nachhaltig darauf hin, daß die Aufhellung der Frage nach der Abschaffung jeglicher Unterdrückung des Menschen durch den Menschen, die sich für Marx in die Frage der Emanzipation des Proletariats verwandelt hatte, das theoretische Verständnis der ökonomischen Grundlagen der bürgerlichen Gesellschaft verlangte.

Gegenüber den für die sozialistische Theoriengeschichte relevanten Aufsätzen von Marx und Engels in den Jahrbüchern ist Heß' Beitrag recht unbedeutend. Seine in der Zeitschrift veröffentlichten Briefe aus Paris, datiert den 2., 3., 4., 5. und 6. Januar 1844, zeigen die für ihn charakteristische Erkenntnismethode, nämlich von Prinzipien her zu Tatsachen vorzudringen. $\mathrm{He} ß$ untersucht die Geschichte Frankreichs seit der großen Französischen Revolution, er führt sie auf die Entwicklung des Prinzips der Freiheit und das der Gleichheit zurück. Die liberalen und demokratischen Bestrebungen in Frankreich beruhten auf dem Prinzip der Freiheit bzw. der Gleichheit. Bis zum Direktorium seien Freiheit und Gleichheit vereint und das bewegende Prinzip gewesen. Die Konstitution von 1795 habe beide Prinzipien in Gegensatz zueinander gebracht, und seit Napoleons Sturz habe die französische Nation mehrere Versuche gemacht, die beiden Revolutionsprinzipien vereint ins Leben einzuführen. So in der Julirevolution, die jedoch zeigte, daß die Verwirklichung beider Prinzipien ohne radikale Umgestaltung des sozialen Lebens unmöglich sei. Seitdem sei der Gegensatz beider Prinzipien dem Volke bewußt geworden.

Der einseitigen von der Bourgeoısie ausgeübten Herrschaft des liberalen Prinzips trete zunehmend das demokratische Prinzip entgegen, das immer mehr Massen gewinne. Jedoch sei die demokratische Partei in sich nicht einheitlich und zerfalle in zahlreiche Gruppen. Deren Hauptvertreter seien solche Demokraten, die das Privateigentum aufheben, und solche, die unter Beibehaltung des Privateigentums die Arbeit organisieren wollen. Anstatt ein Prinzip zu suchen, ,welches das ganze Leben des Menschen umfaßt' ${ }^{* 112 \mathrm{~g}}$, hätten die demokratischen Gruppierungen sich einseitigen dogmatischen Systemen verschrieben. Die deutschen Philosophen, Feuerbach ausgeschlossen, hätten die Wahrheit nicht im Menschen, sondern in einem transzendenten Wesen gefunden; ebenso hätten die Franzosen die Wahrheit nicht in der Gesellschaft, sondern in irgendeinem sozialistischen System gesucht. Wie die Deutschen in ihrem Idealismus, so hätten die Franzosen in ihrem Sozialismus nicht das eigene, positive Wesen erreicht. Das Wesen des Idealismus sei ,die lebendige, die menschliche Freiheit"; das Wesen des Sozialismus sei "dıe organısche, die menschliche Gleıchheit"."12h Die Demokraten hätten sich jedoch noch nicht über den Egoismus der Privatinteressen hinaussetzen können. Und das einzige, natürliche Gegengewicht gegen den Egoismus sei die Liebe. ${ }^{112 \mathrm{i}}$

Freiheıt und Gleıchheit bildeten in Wahrheit eine Einheit und brächten nur das „Eine Lebensprinzip der Selbstthätigkeit" zum Ausdruck. ${ }^{1{ }^{12 j}}$ Aber in der alten, unorganischen Weltanschauung fielen beide auseinander. In ihr könne sich die Freiheit nur dls Unabhängigkeit des einen vom anderen und im Gegensatz zur Gleichheit zur 
Geltung bringen. Umgekehrt widerspreche in der unorganischen Gesellschaft die jede Individualität und Selbständigkeit ausschließende Gleichheit der Freiheit. Der Gegensatz beider Prinzipien jedoch werde in der organischen Gesellschaft schwinden, in der alle Glieder ,,in-, mit- und durcheinander wirken“. ${ }^{12 k}$

Die Feuerbachsche Liebesutopie klingt in den Briefen an; die Entäußerungskonzeption dagegen, geschweige denn ihre Anwendung auf ökonomische Verhältnisse, suchen wir darin vergeblich. Aber gerade in dieser Hinsicht ist von manchen Autoren ein folgenschwerer Einfluß von $\mathrm{He} ß$ auf Marx behauptet worden.

Wir wissen, daß Marx bei dem Übergang von idealistischen und demokratischen auf materialistische und kommunistische Positionen mannigfachen Einflüssen und Anregungen ausgesetzt war und daß er sich eine Fülle theoretischer Quellen zugänglich gemacht hat. Viele dieser Einflüsse sind eindeutig belegbar, manche sind umstritten. $\mathrm{Zu}$ den umstrittenen gehört der von Moses $\mathrm{Heß}$. Was den vorliegenden Zusammenhang angeht, so wird vielfach erklärt, Heß habe die sozial-ökonomische Wendung der Feuerbachschen Entäußerungstheorie inauguriert und Marx sei ihm hierin gefolgt. ${ }^{1121}$

Anknüpfungspunkt der Behauptung ist eine Feststellung von Heß vom September 1846, er hätte ,,eine Abhandlung ,über das Geldwesen““ ,größtentheils der Redaktion der Deutsch-französischen Jahrbücher abgeliefert“, die ,nur deshalb erst anderthalb Jahr später in Püttmann's Rheinischen Jahrbüchern erschien ${ }^{112 m}$, weil Graziano's [Ruges] Jahrbücher kurz nach ihrer Gründung wieder aufhörten". 112n Darin habe er dargelegt, daß ,das Geld in der praktischen Welt dasselbe sei, was der Gott in der theoretischen ist : die jenseitige, im Metallgelde ,katholisch' verkörperte, im Papiergelde wieder ,protestantisch" verfälschte Idee des sozralen ,Werthes“ ".. ${ }^{1120}$

Da bis heute die Abfassung der in den Deutsch-Französischen Jahrbüchern veröffentlichten Aufsätze von Marx zumeist in die Zeit von Herbst 1843 bis Januar 1844 verlegt wird $^{12 p}$, war folgender Schluß naheliegend: Marx hat als Redakteur der Jahrbücher Kenntnis von dem Heßschen Manuskriptfragment Über das Geldwesen gehabt und er hat daraus die Anwendung der Feuerbachschen Entäußerungstheorie auf das Geld übernommen. Der Heß-Biograph Silberner glaubt sogar feststellen zu können: „Die Marxschen Gedanken über das Wesen des Geldes [in der Judenfrage] unterscheiden sich nur der Ausdrucksform nach von den Hess'schen. Es ist keine kühne Behauptung, daß diese Ähnlichkeiten nicht rein zufällig sind: Marx ist offensichtlich von Hess inspiriert. [...] Es möge noch hinzugefügt werden, daß der von Marx später im Kapital entwickelte Begriff des Fetischcharakters der Ware und des Geldes im Keime schon in Hess' Aufsatz über das Geldwesen aufzufinden ist. So hat ihm Hess auch zur Lösung des ,Rätsels des Geldfetısches‘ verholfen.“"112q

Wohlgemerkt: Die metaphysische Entäußerungskonzeption war ein Erkenntnisumweg bei der Erfassung historischer Gesetzmäßigkeiten und des Mechanismus der bürgerlichen Gesellschaft - wenngleich ein äußerst fruchtbarer, wie eine eingehende Analyse zeigen würde, auf die hier verzichtet werden muß. Jedenfalls wird die Originalität dieses Umwegs Marx abgesprochen und er hierin zu einem Schüler von Heß gemacht. Derlei Deutungen entstellen den wirklichen ideengeschichtlichen Zusammenhang und vernachlässigen auch feststehende Daten.

Es wurde schon darauf hingewiesen, daß Marx bereits im Herbst 1842 in einem in der Rheinischen Zeitung veröffentlichten Aufsatz eine an Feuerbachs Entäußerungskonzeption sich anlehnende moralische Kritik des bürgerlichen Eigentums gab. ${ }^{12 r}$ 
Er vertiefte diese Kritik und richtete sie in der Judenfrage auf die konzentrierteste Form des Privateigentums, auf das Geld. Marx beendete seine in den DeutschFranzösischen Jahrbüchern veröffentlichten Aufsätze spätestens am 19. Dezember 1843. An diesem Tage schrieb Ruge an Fröbel: „Marx ist fertig, meine Einleitung auch." Bis zu dieser Zeit und auch noch bis Januar 1844 finden wir in den Schriften von Heß keine Spur einer ökonomisch-sozialen Anwendung der Feuerbachschen Entäußerungstheorie. In den Briefen für die Deutsch-Französischen Jahrbücher untersuchte $\mathrm{He} B$ die Geschichte Frankreichs seit der großen Französischen Revolution; wenn er bereits zu dieser Zeit die auf das Geld angewandte Entäußerungstheorie konzipiert hätte, wäre dies bei der Analyse dieses Geschichtsabschnittes notwendigerweise zum Ausdruck gekommen. Das ist indes nicht der Fall. Mithin gehen die Ähnlichkeiten mancher Passagen in Marx' Judenfirage und Heß' Geldwesen ${ }^{121}$ auf einen Einfluß von Marx zurück. Der „Begriff des Fetischcharakters der Ware und des Geldes" ist ,im Keime" nicht im Geldwesen, sondern in der Judenfrage zu finden. Damit fällt auch die kühne Behauptung zusammen, $\mathrm{Heß}$ habe der Enträtselung des Geldfetisches vorgearbeitet.

Nicht ganz klar hat Heß sich im September 1846 hierzu geäußert; in der schon erwähnten Polemik gegen Ruge heißt es: „Übrigens haben Schriftsteller von ganz anderm Kaliber, als Graziano [Ruge], z. B. Karl Marx, den Gedanken, der unsrer Abhandlung über das Geldwesen zu Grunde liegt, längst anerkannt [. . .]."112u Angesichts des hier dargelegten Zusammenhangs bin ich geneigt, die Äußerung so zu interpretieren, daß der dem Geldwesen zugrunde liegende Gedanke schon vor Abfassung dieser Abhandlung anerkannt, d. h. konzipiert worden sei.

Eindeutiger äußerte Karl Grün ${ }^{12 v}$ sich zu diesem Punkt. Grün war mit Marx seit ihrem gleichzeitigen Studium an der Universität zu Bonn 1835/36 bekannt, in der zweiten Hälfte der vierziger Jahre wurde er einer der oberflächlichsten Vertreter des ,wahren" Sozialismus. In seiner ,Köln, den letzten März 1844" datierten Vorrede zu seinen Bausteinen schrieb er: ,[...] so sollte es einem ,Trierer' [Marx] vorbehalten sein, diese letzte Vertiefung des modernen Geistes, diese letzte Consequenz der abstrakten Wahrheit zu ziehen [...] Der, Trierer that dar, daß mit dem freien Staate in jenem Sinne, in dem Sinne der freien, von der Religion befreiten Sittlichkeit, noch nicht alles gethan sei, daß noch eine andere Religion als die gewöhnlich so benannte, den Menschen an der wirklichen Freiwerdung hindere, die Religion des Eigennutzes, die Anbetung des praktischen Gottes, des silbernen und goldenen Gottes des Geldes. Dieser praktische Gott sei für die wirkliche Freiheit dasselbe transcendente Wesen, wie der jenseitige Herr des Himmels; die Abhängigkeit vom Gelde, vom Besitzer, das Verhältniß des Nichtbesitzers zum Besitzer, sei eine neue Religion, welche mit der Emanzipation des Staates, wie man sie bisher projektirte, noch keineswegs vernichtet sei."112" Eine Zurückweisung der Grünschen Feststellung seitens Heß liegt nicht vor.

Über die auch die vorliegende Frage einschließende Erbschafts- oder Nachfolgeangelegenheit stellte Marx mit einiger Selbstkritik in der Deutschen Ideologie (1845/46) fest, daß der ,Weg zur materialistischen, nicht voraussetzungslosen, sondern die wirklichen materiellen Voraussetzungen als solche empirisch beobachtenden und darum erst wirklich kritischen Anschauung der Welt" schon ,angedeutet" war ,,in den DeutschFranzösischen Jahrbüchern, in der Einleitung zur Kritik der Hegelschen Rechtsphilosophie und Zur Judenfrage. Da dies damals noch in philosophischer Phraseologie geschah, 
so gaben die hier traditionell unterlaufenden philosophischen Ausdrücke wie ,menschliches Wesen', ,Gattung* pp. den deutschen Theoretikern die erwünschte Veranlassung, die wirkliche Entwicklung zu mißverstehen und zu glauben, es handle sich hier wieder nur um eine neue Wendung ihrer abgetragenen theoretischen Röcke. ${ }^{.112 x}$

Als das erste und einzige (Doppel-) Heft der Deutsch-Französischen Jahrbücher Ende Februar 1844 erschien $^{113}$, hatte Heß Paris bereits verlassen; der Mangel an Geldmitteln erlaubte ihm keinen weiteren Aufenthalt. Kurz darauf scheiterte die Fortsetzung des Zeitschriftenunternehmens, da Fröbel sich aus ökonomischen Gründen zurückzog ${ }^{113 a}$; aber auch die inzwischen eingetretenen ideologischen Divergenzen der beiden Redakteure - Marx war Kommunist geworden, Ruge Demokrat geblieben - hätten eine Weiterführung unter den vereinbarten personellen Auspizien ausgeschlossen. ${ }^{11.3 \mathrm{~h}}$

Es ist nicht gesichert, aber wahrscheinlich, daß $\mathrm{He} 3$ den der Redaktion der Zeitschrift bereits abgelieferten Teil seines Artikels über das Geldwesen nach Köln mitnahm, um dort die Abhandlung abzuschließen. ${ }^{113 c}$

Der Regierungspräsident von Gerlach berichtete am 27. März 1844: „Heß lebt seit seiner Rückkehr von Paris, bei seinem Vater, dem Kaufmann und Vorsteher der hiesigen israelitischen Gemeinde, David Heß, welcher in dem Ruf eines wohlhabenden, gescheuten und soliden Geschäftsmannes steht, [. . . in ziemlicher Zurückgezogenheit von der Außenwelt, und beschäftigt sich angeblich mit literarischen Arbeiten. - Sein Umgang beschränkte sich bisher auf einige Besuche bei dem vormaligen LandgerichtsReferendarius Dagobert Oppenheim; mit andern Personen, namentlich mit seinen Glaubensgenossen hat er wenig Verkehr gehabt." ${ }^{\text {113d }} \mathrm{Zu}$ den hier genannten literarischen Arbeiten gehörte wohl in der Hauptsache der Aufsatz Über das Geldwesen, der Heß offenbar noch im Sommer 1844 beschäftigte. Möglicherweise hat er den Schluß davon an Marx nach Paris geschickt, um dessen Urteil zu erfahren. Jedenfalls schrieb Marx ihm etwa Ende Juni, daß die ihm zugestellte Sendung noch ,vermenschlicht" werden müßte. ${ }^{114}$

Das Überraschende und Bemerkenswerte des Aufsatzes Über das Geldwesen wie auch anderer Arbeiten von Heß nach den Deutsch-Französischen Jahrbüchern ist die Ersetzung der in Fichteschem Sinne gefaßten Geistestat durch den Begriff der materiellen Produktion, die Begründung des Sozialismus auf Feuerbachs humanistische Philosophie und die Charakterisierung des Geldes als Resultat der Entäußerung des menschlichen Wesens. Was die letzten beiden Punkte betrifft, so stützte Heß sich ohne Zweifel auf Marx' Aufsätze in den Deutsch-Französischen Jahrbüchem ${ }^{1+i t}$ Und was die Aufgabe der subjektiv-idealistischen Tatkonzeption und die Aufnahme des Begriffs der materiellen Produktion angeht, so machte $\mathrm{Heß}$ sich offensichtlich Wilhelm Schulz' Werk Die Bellegung der Production ${ }^{15}$ und sicherlich auch Engels' Unrisse zu einer Kritik der Nationalökonomie zunutze.

Schulz’ soziologische Erkenntnisse gingen weit über die Einsichten der deutschen utopischen Sozialisten und Kommunisten hinaus, sosehr auch seine soziale und politische Zielsetzung hinter der ihren zurückblieb. In der genannten Schrift entwickelte Schulz eine historisch-materialistische Züge aufweisende Theorie, derzufolge die Menschheitsgeschichte von der Bewegung der Produktion und diese wiederum von der Entfaltung der „Productionskräfte" bestimmt sei.

Heß hat (ebenso wie Marx) die Schrift von Schulz gekannt ${ }^{116}$ und zweifellos natürlich auch Engels' Umrisse. Aber wie zuvor bei der Rezeption vorgefundenen theoretischen Materials geht $\mathrm{HeB}$ auch bei der Aufnahme und Verwertung der bei 
Marx, Schulz und Engels gefundenen Erkenntnisse und Aussagen auf eklektische Weise vor. Obwohl nachhaltig auf die Bedeutung der Ökonomie für das Verständnis der Geschichte im allgemeinen und der bürgerlichen Gesellschaft im besonderen hingewiesen, wird $\mathrm{Heß}$ nicht veranlaßt, sich eingehenden ökonomischen Studien hinzugeben. ${ }^{117}$ Zwar hatte er schon in der Heiligen Geschichte und dann immer wieder den methodisch richtigen Ansatz gemacht, von der Kenntnis der Vergangenheit und Gegenwart aus die sozialistische Zukunftsaussage abzuleiten; indes gelingt es ihm jetzt ebensowenig wie früher, aus dem Gewesenen kausal-historisch das Werdende zu folgern. Statt dessen finden wir auch in dieser seiner Entwicklungsphase das Bestreben, die künftige sozialistische Gesellschaft von ,letzten Prinzipien" abzuleiten. Diese letzten Prinzipien bietet ihm der Feuerbachsche Humanismus, den er in eine idealistisch-teleologische sozialistische Theorie umwandelt. In diese teleologische Konstruktion baut er die angelesenen, in ihrer tatsächlichen Bedeutung nicht verstandenen und zudem zugleich in metaphysische Kategorien verwandelten ökonomischen Begriffe ein.

Heß begreift die Tätigkeit als Güter produzierende Arbeit. Im Anfang der Menschengeschichte habe die Tätigkeit eine unorganisierte Form gehabt, bei der die Individuen vereinzelt, jedes auf seine eigene Faust, lebten. Auf diesem ursprünglich niederen Stand des Produktionsvermögens und des noch unausgebildeten Wesen des Menschen mußte die Tätigkeit des Menschen notwendig die Form der Sklaverei haben. Deren potenzierte Formen seien die Leibeigenschaft und die kapitalistische Gesellschaft. In dieser habe die Entäußerung des menschlichen Wesens, die im Altertum noch naiv und in der Feudalgesellschaft durch die Existenz der Stände begrenzt gewesen, theoretisch und praktisch die universellste Gestalt angenommen, theoretisch in der Religion und Philosophie, praktisch in der Herrschaft des Geldes. In der kapitalistischen Gesellschaft sei das Geld, das das Produkt der menschlichen Arbeit verkörpere, eine den Menschen äußere, fremde Macht geworden, ein Gott, den die Menschheit anbetet und von dem sie geknechtet werde. Dieser große geschichtliche Zeitraum von der ursprünglichen vereinzelten Tätigkeit bis zum voll ausgebildeten System des Egoismus (worin sich nach $\mathrm{HeB}$ die Konkurrenz und die privatkapitalistische Aneignung der Produkte darstellt) mache noch die Naturgeschichte des Menschen aus, in der er sein Wesen entwickele. Dieses Wesen sei nun ausgebildet und theoretisch erkannt; es bestehe im Zusammenwirken der Individuen der menschlichen Gattung, und die Realisierung dieses Wesens sei praktisch ermöglicht durch die infolge gesteigerter „Produktionskräfte“ bis zum Überfluß entwickelte Produktion von Gütern. Die Menschheit stehe daher an der Schwelle der zweiten Phase der Geschichte, in der mit dem Kommunismus die organische Gesellschaft ins Leben treten werde, worin der einzelne nicht egoistisch sein Interesse auf Kosten der Gattung durchsetzt, sondern worin in einem harmonischen Gattungsleben die einzelnen zum Wohle aller zusammenwirken. ${ }^{118}$

Diese unklare Konzeption hinsichtlich der Aufhebung des kapitalistischen Eigentums ist eine Abwandlung der Kompromißformel Proudhons, der das Eigentum in Gestalt des Besitzes bewahrt wissen wollte. ${ }^{119}$ Nach $\mathrm{Heß}$ soll das Privateigentum durch eine Besitzform des innigen Verbundenseins des geschaffenen Gegenstandes und des schaffenden Menschen ersetzt werden. Wenn nicht vorher die Kapitalisten in ,ekler Genußsucht ${ }^{* 120}$ untergehen oder wenn nicht Einsicht und Liebe dem menschlichen Wesen zum Siege verhelfen würden, werde der Übergang zum Kommunismus durch eine Revolution vollzogen werden, die sich aus der Verschärfung des Gegensatzes von 
Elend auf der Seite der Arbeiter und Reichtum auf der Seite der Kapitalien anhäufenden Besitzer ergeben werde. Die Herstellung der sozialistischen Gesellschaft werde sowohl das Ergebnis des Bewußtwerdens und Verwirklichens des Wesens des Menschen als auch eine Folge der Aufhebung der ökonomischen und sozialen Gegensätze der kapitalistischen Gesellschaft sein.

Das Geldwesen dokumentiert Heß' Abgehen von dem subjektiv-idealistischen Standpunkt und seine Hinwendung zum Feuerbachschen Humanismus. Aber anders als Marx, der das von Feuerbach konstatierte Sein-Bewußtsein-Verhältnis in eine historischmaterialistische These überführte und der aus dem „Gattungswesen“ das rationelle Element herauslöste und das gesellschaftliche Wesen des Menschen historisch aus der notwendig kollektiv verrichteten Produktion erklärte, bleibt $\mathrm{HeB}$ in der Teleologie Feuerbachs stecken.

Die Aufnahme der Ansichten von Schulz und Engels hinsichtlich der materiellen Produktion bleibt oberflächlich. Heß dringt nicht tiefer in den Sachverhalt ein, er gleicht das Angelesene seiner teleologischen Konstruktion an: die eigentliche, wahre Tätigkeit bestehe in liebevollem Zusammenwirken der Menschen. Die Beziehung, die er zwischen dem hohen Entwicklungsstand der Produktionskräfte und der kommunistischen Gesellschaft sieht, beinhaltet nicht die Auffassung, daß in der Entwicklung der Produktionskräfte letztlich die objektive Notwendigkeit für die Aufhebung der bürgerlichen Gesellschaft begründet ist. Wenn er die Produktionskräfte in Beziehung zum Kommunismus bringt, so treten jene nur als eine solche Möglichkeit auf, die die Bestätigung des menschlichen Wesens praktisch gestattet.

Das Geldwesen zeigt gegenüber den Beiträgen für die Einundzwanzig Bogen, worin der Kapitalısmus als Verneinung der freien Selbstbestimmung aufgefaßt und der Kommunismus aus dem Begriff der freien Tätigkeit abgeleitet war, einen bedeutenden Fortschritt, der vor allem in der Aufnahme ökonomischer Gesichtspunkte besteht. $\mathrm{HeB}$ hat jetzt die abgenutzten Begriffe von ,arm" und ,reich“ oder „Pauperismus“ und "Geldaristokratıe" überwunden und spricht von dem Gegensatz von Proletariern und Kapitalisten. Indes bleibt er auch hier in Oberflächlichkeiten und Kompromissen stecken. Marx erkennt bereits in seiner ,philosophisch"-kommunistischen Entwicklungsphase die Unüberbrückbarkeıt dieses Gegensatzes und die Tatsache, daß das im Privateigentum wurzelnde Privatinteresse eine Macht darstelle, die nur durch Macht zu brechen sei, daß das Proletariat diese Macht sei und daß nur es auf Grund seiner Stellung in der Gesellschaft ein Interesse an der Aufhebung der bürgerlichen und der Errichtung der kommunistischen Gesellschaft haben könne. Anders Heß. Das PrivatInteresse faßt er, die realen Klassengegensätze verwischend, als Egoismus. Die Herstellung der kommunistischen Gesellschaft ergibt sich für ihn entweder aus dem Bewußtwerden und Realisieren des Wesens des Menschens oder als Folge einer proletarischen Revolution, hervorgerufen durch den Gegensatz von Reichtum anhäufenden Kapitalisten und von zunehmend der Armut preisgegebenen Proletariern. Diese Parallelisierung idealistisch-moralischer mit oberflächlich erfaßten ökonomısch-sozialen Faktoren - wobel abwechselnd die eine Selte gegen die andere hervortritt - bleibt für den philosophischen Kommunismus von Heß kennzeichnend. Treffend schreibt Georg Lukács: „Für die theoretische Entwıcklung von $\mathrm{H}[\mathrm{e} ß]$ wurde es verhängnısvoll, daß er über die moralische Verurteilung des ,Egoismus', den er allerdings als notwendiges Produkt der bürgerlichen Gesellschaft darstellt und mit deren, ziemlich oberflächlich erfaßten ökonomischen Grundlagen ständig parallelisiert, nicht hinaus konnte. 
Er betrachtete ihn zwar als notwendiges Produkt der bürgerlichen Gesellschaft, aber doch nur als Erstarrtes: metaphysisch, nicht dialektisch." $" 121$

Heß' Aufsatz ist freilich ein höchst interessantes Dokument zur intellektuellen Situation jener Zeit. Er illustriert die Kompliziertheit des Überganges von der bürgerlichen zur sozialistischen Ideologie und die Schwierigkeiten der sozialistischen deutschen Theoretiker, sich den Schlingen der deutschen Philosophie zu entwinden.

In verschiedenen Entwürfen und Aufsätzen kommt $\mathrm{He} B$ im einzelnen auf die im Geldwesen behandelten Hauptthemen zurück.

Aufschlußreich für Heß' Fassung der Tätigkeit ist eine philosophisch-sozialistische Arbeit, von der drei Varianten vorliegen. ${ }^{122}$ Sie entstand wohl in der ersten Hälfte des Jahres 1844, also etwa zu der Zeit, als Marx die Grundlagen der materialistischen Geschichtsauffassung entwickelte.

In den Entwürfen versucht $\mathrm{Heß}$, Fichte und Hegel folgend, die Tätigkeit als Wesen des Menschen darzustellen; aber er begreift die Tätigkeit nicht in dem Sinne, daß sie des Menschen notwendige Daseinsweise wäre, sondern im Sinne einer ansichseienden Bestimmung. Die materielle Tätigkeit, die er wie im Geldwesen ins Auge faßt, löst er in die metaphysische Bestimmung ,Tätigkeit" auf und fragt dann nach dem Wesen der Tätigkeit. Dieses bestehe darin, daß sie sich selbst genüge und befriedige, ihren Lohn nicht außerhalb ihrer, sondern in sich selbst finde. Das seien die Qualitäten der wahren Tätigkeit, der Selbsttat. In der bürgerlichen Gesellschaft jedoch herrsche der Gegensatz von Wesen und Existenz der Tätigkeit, die Tätigkeit sei hier Lohnarbeit, ihren Wert habe sie nicht in sich selbst, sondern in etwas Äußerlichem, gegen das sie veräußert werde. Daher komme es darauf an, Wesen und Existenz in Übereinstimmung zu bringen, die wahre Tätigkeit, die Selbsttat, Wirklichkeit werden zu lassen.

Der metaphysischen Grundkonzeption entspricht das Utopische der sozialistischen Forderung. Die Gewißheit der sozialistischen Gesellschaft leitet Heß nicht aus dem Fortgang der materiellen Produktion ab, er basiert sie auf der unhistorischen Wesensbestimmung des Menschen. Da das Wesen des Menschen die Tätigkeit und das Wesen der Tätigkeit die Selbsttat sei, so sei die sozialistische Gesellschaft unumgänglich, denn sie sei nichts anderes als die Realisierung dieses Wesens.

Diese Realisierung solle vornehmlich die Erziehung leisten; der Frage der Erziehung widmet $\mathrm{He} B$ den größten Raum. Er übernimmt das bürgerliche Vorurteil, die Arbeiter bedürften zur Verbesserung ihrer Lage in erster Linie der Bildung; allerdings erweitert er es zu der Forderung, daß alle Menschen erzogen werden müßten. Er schreibt: „Es ist die Aufgabe, einen sozialen Zustand zu finden, in welchem der Einzelne den Lohn für seine sozialen Arbeiten in der Arbeit selbst hat." ${ }^{.123}$,Jeder Einzelne muß theoretisch vom Wesen des Menschen, d. h. davon durchdrungen sein, daß er nur im Zusammenwirken mit seinen Nebenmenschen menschlich leben kann, daß das wahre menschliche Leben aber nicht Anderes, als lieben ist. Er muß aber auch praktisch zu seinem bestimmten Wirkungskreis herangebildet werden und sich selbst bilden. Mit Einem Worte: es handelt sich um die vollendete Erziehung des Menschengeschlechtes." 124

Heß verwandelt die Tätigkeit aus einer historischen in eine metaphysische Kategorie und bleibt damit noch hinter Hegel zurück. Es gelingt ihm nicht, aus der materiellen Produktion den Begriff neu zu gewinnen; sein Rückgriff auf Fichte und Hegel trägt keine Früchte. ${ }^{124 a}$

Anders als bei $\mathrm{Heß}$ geht bei Marx die Auswertung vorgefundenen theoretischen 
Materials Hand in Hand mit einer induktiven Wirklichkeitserforschung. Nach dem Untergang der Deutsch-Französischen Jahrbücher widmete Marx sich mit großer Intensivität dem Studium der Ökonomie. Der Niederschlag und das Ergebnis dieser an Umfang und Tiefe geradezu erdrückenden Studien finden sich in jenen Pariser Manuskripten, die zwischen April und August 1844 entstanden sind und von den späteren Herausgebern Ökonomisch-philosophische Manuskripte betitelt wurden. ${ }^{124 \mathrm{~b}}$ Die Manuskripte offenbaren den Reichtum der Gedanken und theoretischen Quellen, die in den Marxismus eingingen. Im Hinblick auf die Herausarbeitung des dialektischen und historischen Materialismus und des wissenschaftlichen Kommunismus nimmt dieses Werk den wichtigsten Platz vor der Deutschen Ideologie ein. In ihm werden wichtige Elemente der wissenschaftlichen Weltanschauung des Proletariats entwickelt. Die Arbeit enthält die theoretische Vernichtung des philosophischen Idealismus und z. T. der bürgerlichen Nationalökonomie sowie Grundlinien von Marx' eigener ökonomischer Theorie; Marx beginnt den Nachweis von der notwendigen zeitlichen Begrenztheit der bürgerlichen Gesellschaftsordnung $\mathrm{zu}$ führen, deren innere Widersprüche zu ihrer Aufhebung treiben. Als bewegende Kraft der Geschichte erkennt Marx in den Ökonomisch-philosophischen Manuskripten die gesellschaftliche Praxis der Menschen, d. h. die produktive Tätigkeit, die Arbeit, durch die dic Menschen sich aus dem Tierreich herauslösten und durch die sie ihre Reproduktion bewerkstelligen. Auf die Rolle der praktischen Tätigkeit wurde Marx offenbar durch das Studium der Nationalökonomie hingewiesen. Der nur die Schaffung von Werten oder von Reichtum beinhaltende Arbeitsbegriff der englischen Ökonomen erweiterte sich für Marx, unter Ausschöpfung des Fruchtbaren in der Hegelschen Philosophie, zu einer gegenüber allen vorgefundenen Ansichten revolutionierenden Auffassung von der gesellschaftlichen Praxis als der bewegenden Kraft der Geschichte. Die ökonomischen Studien, von denen wohl der wesentlichste Anstoß zur Herausbildung des Praxisbegriffs ausging, führten Marx auf die Hegelsche Philosophie zurück, deren fruchtbare Elemente er nun von seinem wissenschaftlich bereicherten und revolutionären Standpunkt voll auszuwerten, deren Idealismus er aber grundlegend zu kritisieren und zu überwinden vermochte. Jene Elemente bestanden in der Auffassung der Tätigkeit als Selbsterzeugungsakt des Menschen und als bewegende Kraft der Geschichte sowie in der Darstellung dieser Bewegung als eines in Widersprüchen verlaufenden Prozesses.

Als das Große der Hegelschen Philosophie erklärt Marx in den Ökonomisch-philosophischen Manuskripten, daß in ihr Entstehung und Entwicklung des Menschen als ein durch die Arbeit vermittelter Prozeß begriffen werde, daß Hegel ,,das Wesen der Arbeit faßt und den gegenständlicien Menschen, wahren, weil wirklichen Menschen, als Resultat seiner eignen Arbeit begreift". ${ }^{24 c}$ Sich weniger auf Hegels Rechtsphilosophie als auf dessen Phänomenologie stützend ${ }^{124 d}$, meint Marx, Hegel habe den Menschen nur als Selbstbewußtsein und die Arbeit idealistisch nur als geistig abstrakte Arbeit gefaßt. Sie sei die tätige Beziehung zwischen einem vergeistigten Subjekt, dem Selbstbewußtsein, und einem vergeistigten Objekt, dem Bewußtsein. Die wirklichen Aktionen des Menschen als eines gegenständlichen, natürlichen Wesens, das durch seine praktische Tätigkeit in Wechselwirkung mit wirklichen, materiellen Gegenständen außer ihm trete und dadurch seine Herausbildung aus dem Tierreich sowie seine Weiterentwicklung bewerkstelligte, werden von Hegel nur abstrakt gefaßt. Der idealistisch gefaßte, allgemeinste Ausdruck der Arbeit sei bei Hegel die Entäußerung und deren Rücknahme. Die Entäußerung und deren stufenweise Aufhebung seien der idealisierte Ausdruck 
einer wirklichen Tat, nämlich der menschlichen Arbeit: Der Mensch entäußere seine Kraft, sie vergegenständliche sich in dem Produkt seiner Arbeit. Die produzierten Gegenstände seien das ,Andere" seiner selbst, und in diesem Anderen schaue er sein eigenes Wesen an. Indem der Mensch die Gegenstände in irgendeiner Weise konsumiere, eigne er sich die in ihnen vergegenständlichten Kräfte wieder an; die Entäußerung sei aufgehoben. Die idealistische Fassung der Arbeit bei Hegel verschleiere die realen Ausbeutungsverhältnisse, denn sie unterstelle die Tatsache, daß der Produzent in den Genuß des Produzierten komme.

Marx' Kritik an Hegels idealistischer Fassung des Arbeitsprozesses ist zugleich eine kritische Auseinandersetzung mit der idealistischen Dialektik Hegels. Marx stellt fest, daß Hegel mit der ,Dialektik der Negativität“ das bewegende und erzeugende Prinzip der Geschichte begriffen habe. ${ }^{124 \mathrm{e}}$ Doch habe Hegel die ,Negation der Negation [. . . ] als den einzig wahren Akt und Selbstbeștätigungsakt alles Seins" nur idealistisch gefaßt, er habe nur den ,abstrakten, logischen, spekulativen Ausdruck für die Bewegung der Geschichte gefunden". ${ }^{124 \mathrm{f}}$ In dem Maße, wie Marx zum Verständnis der materiellen Triebkräfte der Geschichte vordringt, revolutioniert er die Hegelsche Dialektik. Ein erstes Ergebnis ist der Hinweis, daß die bürgerliche Gesellschaft auf Grund des ihr inhärenten Widerspruchs zwischen Kapital und Arbeit ihrer eigenen Auflösung entgegentreibt.

In dieser Phase der Herausarbeitung seiner neuen Weltanschauung ist Marx' Denken entscheidend durch die materialistisch-humanistische Philosophie Feuerbachs geprägt, denn sie enthielt einige der wesentlichen Elemente, die sein Denken vorantrieben. Eines war zunächst der Materialismus Feuerbachs, auf dessen Grundthesen Marx aufbaut und die bleibend im Marxismus ,aufgehoben“" sind. Ferner bestanden diese Elemente in der hohen ethischen Auffassung des Menschen durch Feuerbach, die Marx' sozialistische Überlegungen beeinflußten und die in seine Darstellung des vollendeten kommunistischen Menschen mit einging, sowie in dessen genialer Erkenntnis, daß alle Qualitäten des Menschen durch sein kollektives Dasein gesetzt sind. Diese Erkenntnis wird von Marx besonders gewürdigt: „Feuerbachs große Tat ist: [ . . ] die Gründung des wahren Materialismus und der reellen Wissenschaft, indem Feuerbach das gesellschaftliche Verhältnis ,des Menschen zum Menschen“ ebenso zum Grundprinzip der Theorie macht [. . .]. "124g Den Feuerbachschen Begriff des Gattungswesens löste Marx allmählich in die historisch-materialistisch begründeten Begriffe des sozialen Menschen und des sozialistischen Menschen auf.

Feuerbachs humanistische Konzeption des Gattungswesens bezog sich, wie oben dargestellt, auf das, was der Mensch in der Tat ist: ein kollektives Lebewesen, sowie utopisch auf das, was er werden soll: ein altruistisches Lebewesen. Die „wahren“ Sozialisten blieben in der metaphysischen Spekulation über das, was der Mensch werden soll, weil es sein Wesen so bedingt, stecken. Marx, nach den bestimmenden Faktoren des menschlichen Lebens suchend, überwindet den metaphysischen Begriff des Gattungswesens und arbeitet am historischen Material die Erkenntnis von der historisch-gesellschaftlichen Bedingtheit des Menschen heraus. Es ist sehr interessant zu sehen, wie Marx in den Ökonomisch-philosophischen Manuskripten in enger Anlehnung an entsprechende - - jedoch die praktische Tätigkeit des Menschen nicht berücksichtigende - Überlegungen Feuerbachs im Wesen des Christenthums und in den Vorläufigen Thesen sowie den Grundsätzen aus dem Gattungswesen das rationelle Element herauslöst ${ }^{124 h}$, bis schließlich der Begriff zu rein terminologischer Hülle herabsinkt und endlich in den Thesen über Feuerbach (Frühjahr 1845) die historisch-materialistische

\section{LXXVI}


These formuliert wird: Der Mensch ist „das ensemble der gesellschaftlichen Verhältnisse". ${ }^{124 i}$ Die Aufhebung dieser Seite der Feuerbachschen Philosophie war die Folge der Erkenntnis der wirklichen Triebkräfte der Geschichte und des Eindringens in die Grundlagen der bürgerlichen Gesellschaft. Feuerbach blieb bei der metaphysischen Anschauung eines sozial undifferenzierten Kollektivs stehen, ohne wie Marx in der gesellschaftichen Praxis das vermittelnde und das die historische Wandlung des Kollektivs determinierende Element zu sehen. Mit dieser Entwicklung, die vom Gattungswesen ausging und zur Überwindung dieses Begriffs durch die Erkenntnis der geschichtlichgesellschaftlichen Bedingtheit des Menschen führte, ging einher die Überwindung der metaphysischen Konzeption einer sozialistischen Bestimmung des Menschen. Diese idealistisch-humanistische Konzeption spielt in den Ökonomisch-philosophischen $\mathrm{Ma}$ nuskripten zunächst eine dominierende Rolle, steht dann eine Weile gleichwertig neben den rationellen ökonomischen Erkenntnissen und leiht schließlich nur noch die Worte für die historisch-materialistische Darstellung der gesellschaftlichen Bewegung. Inhalt der Konzeption war die Vorstellung, daß dem Menschen ein Wesen eigne, das in der Bestimmung zu freundschaftlichem Dasein bestände, daß der Mensch dies Wesen entäußert hätte und dadurch in ein Verhältnis der Entfremdung zu seiner menschlichen und natürlichen Umwelt gekommen wäre. Diese idealistisch-teleologische Auffassung des jungen Marx verdeckt in gewissem Maße die Klassengegensätze der bürgerlichen Gesellschaft, da Proletariat und Bourgeoisie als gleichermaßen unter der Entäußerung ihres Wesens leidend gelten. Hieraus erklärt sich der Versuch bürgerlicher Theoretiker, jene idealistische Seite der Auffassung des jungen Marx als den eigentlichen, ,humanistischen“" Marxismus zur Geltung zu bringen. Die „,Mängel“ der bürgerlichen Gesellschaft werden im Anschluß an die Marxsche Entäußerungskonzeption als allgemein menschliches Malheur deklariert, das durch Bildung und gegenseitige Überredung aus der Welt geschafft werden könne, ohne daß dabei die Grundlagen der bürgerlichen Gesellschaft auch nur in Frage gestellt würden. Ziel dieser Versuche ist die Erhaltung der bürgerlichen Gesellschaft und die Entwaffnung des tatsächlichen Humanismus der entwickelten Marxschen Lehre, in der nachgewiesen wird, daß die Menschheit sich nur emanzipieren kann, indem das Proletariat sich emanzipiert, und daß die revolutionäre Emanzipation des Proletariats notwendig aus den in der bürgerlichen Gesellschaft herangereiften Widersprüchen folgt. ${ }^{124 j}$

Marx deutet die gesellschaftlichen Verhältnisse, die er noch nicht rationell erklären kann, als durch „Entäußerungen“ verursacht. Die Ausbeutungsverhältnisse, die er sehr klar erkennt - ohne sie allerdings schon in der klaren Form der Mehrwertlehre zu erfassen -, umschreibt er mit dem Begriff der ,entfremdeten Arbeit“. Ebenso gilt ihm das Privateigentum, dessen geschichtliche Bewegung er $\mathrm{z}$. T. genau verfolgt und analysiert, als Ergebnis der Entäußerung der menschlichen Arbeit. Und die revolutionäre Aufhebung der bürgerlichen Gesellschaft erscheint ihm zugleich als Aufhebung der Entäußerung des Wesens des Menschen in die diesem inadäquaten gesellschaftlichen und politischen Verhältnisse. Diese idealistischen Voraussetzungen unterhöhlt er jedoch durch das Eindringen in die Gesetzmäßigkeit der bürgerlichen Gesellschaft, so daß noch in den Manuskripten selbst Entäußerung und Wesen des Menschen durch historischmaterialistische Einsichten ergänzt oder verdrängt werden. Marx erkennt, daß die Entwicklung der bürgerlichen Gesellschaft die beiden Klassen der nichtbesitzenden Arbeiter und der besitzenden Nichtarbeiter in einen antagonistischen Widerspruch treibt, den das Proletariat durch die Errichtung der sozialistischen Gesellschaft aufheben wird. 
Als Folge dieses historischen Vorganges, der sozialistischen Revolution, wird der sozialistische Mensch in Erscheinung treten.

Die sich anbahnende Erkenntnis des Zusammenhangs der ökonomischen Bewegung der Gesellschaft mit dem sich in ihr vollziehenden Klassenkampf gehört mit zu den in den Manuskripten erreichten wesentlichen Erkenntnissen. Ebenso bedeutsam ist die in Anknüpfung an Feuerbachs These von der Bedingtheit des Bewußtseins vom Sein weiterentwickelte Ideologie-Theorie. Marx erkennt, daß Ideologien nicht aus sich selbst zu verstehen sind, sondern daß sie durch die Klassenstruktur der Gesellschaft bedıngt sind.

Aus diesen Ansätzen entwickelte Marx gemeinsam mit Engels in relativ kurzer Zeit die materialistische Geschichtstheorie. Aphoristisch umriß Marx sie bereits in seınen Thesen über Feuerbach (1845); zum ersten Mal systematisch ausgeführt erscheint sie in der großen Gemeinschaftsarbeit von Marx und Engels, der Deutschen Ideologie (1845/47). In diesem Werk wird die Geschichte durch die dialektische Entwicklung der Produktivkräfte und der Produktionsverhältnisse, werden Politik, Staat, Recht, Phılosophie usw. aus den sie bestımmenden materiellen Lebensbedıngungen der Gesellschaft erklärt. In den Grundzügen war damit eine wissenschaftliche Weltanschauung geschaffen, die eine Revolution in der Philosophie und im menschlichen Denken überhaupt hervorrufen und dem Proletariat das theoretische Rüstzeug in seinem Betreiungskampf geben sollte.

Moses $\mathrm{He} \beta$ vermochte mit dieser Entwicklung nicht Schritt zu halten. ${ }^{124 \mathrm{k}}$ Seine frühen Entwürfe in den Einundzwanzig Bogen aus der Schw'ız würdigend wie auch sein Stehenbleiben auf dieser Entwicklungsstufe kritisierend, schrieb Marx in der Deutschen Ideologie: „Sachen, die schon bei Heß ganz unbestimmt und mystisch sind, die aber im Anfange - in den ,Einundzwanzig Bogen - anzuerkennen waren und nur durch ihre ewige Wiederaufdrängung im „Bürgerbuch“, den ,Neuen Anekdotis“ und den ,Rheinischen Jahrbüchern' zu einer Zeit, wo sie berelts antıquiert waren, langweilıg und reaktionär geworden sınd - diese Sachen werden bei Herrn Grün vollends Unsinn." $" 1241$

\section{SOZIALISTISCHE AGITATION}

$$
\text { Karl Grüns , , Neue Anekdota“ }
$$

In Köln unterhielt $\mathrm{HeB}$ enge Beziehungen zu Karl Grün, der am 6. August 1843 in Köln das Bürgerrecht erworben hatte. ${ }^{125}$ Von Mitte 1843 bis Herbst 1844 war er leitender Mitarbeiter der in Wesel erscheinenden Zeitschrift Sprecher oder: RheinischW'estphälischer Anzeiger. ${ }^{126}$ Mit $\mathrm{HeB}$ wurde er vielleicht noch vor dessen Abreise nach Brüssel und Paris im August 1843, spätestens aber gleich nach dessen Rückkehr nach Köln bekannt. ${ }^{127}$

Bereits während seines Aufenthalts in Frankreich - von Anfang 1839 bis Anfang 1844 unterrichtete er am Collège zu Colmar deutsche Sprache und Literatur - hatte Grün mit dem Fourıerismus sympathisiert, und nach seiner Rückkehr nach Deutschland war es zunächst seın Plan gewesen, soziale Romane zu schreiben und Schriften Fourıers zu übersetzen. ${ }^{128}$ Mit seinen philanthropisch-sozialistischen Neigungen erlag 
er wohl rasch dem wahrsozialistischen Einfluß von Heß. Der Erfolg seiner im Geiste des wahren Sozıalismus gehaltenen Vorlesung Über wahre Bildung am 28. April 1844 in Bielefeld ${ }^{129}$ ließ ihn den Plan der Herausgabe einer Monatsschrift (Bielefelder Monatsschrift) fassen ${ }^{130}$, die er, ebenso wie schon die Wochenschrift Sprecher, ,im Sinne des Sozialismus zu leiten" gedachte. ${ }^{131}$ Die erste Nummer sollte im Juli 1844 (in der Helmich'schen Buchhandlung) erscheinen. Für das geplante Blatt schrieb Heß den Aufsatz Über die sozialistische Bewegung in Deutschland. Während der Sprecher von der Zensur ,solange ruinirt [wurde], bis selbst das Zutrauen der Abonnenten wich“132, wurde das Erscheinen der Bielefelder Monatsschrift von den Zensurbehörden überhaupt verhindert. Für den Sprecher bestimmte und von der Zensur unterdrückte sowıe die für die Bielefelder Monatsschrift vorgesehenen Artikel veröffentlichte Grün in den Neuen Anekdota. ${ }^{133}$

In dem ,Köln, im Mai 1844“ datierten Aufsatz Über die sozialistische Bewegung in Deutschland wiederholt $\mathrm{HeB}$ seine wahrsozialistische Theorie im Rahmen einer Darstellung der deutschen Arbetterbewegung. Der Aufsatz verdient besonderes Interesse, weil er zu den ersten Versuchen einer zusammenhängenden Schilderung der Entwicklung des Sozıalısmus in Deutschland gehört. Heß erörtert insbesondere die ideengeschichtlichen Beziehungen zwischen deutscher Philosophie und kommunistischer Theorie. In der unterschiedlichen Einstellung zur praktischen Tätigkeit erkennt er einen wesentlıchen Faktor des Gegensatzes zwischen idealistischer und kommunistıscher Ideologie.

Heß unterscheidet zwei Richtungen der sozialistischen Bewegung in Deutschland: den Handwerkerkommunismus, die erste und noch rohe Form des Kommunismus ${ }^{134}$, der im materiellen Elend der Arbeiter seine Wurzel, und den theoretischen Kommunismus, der in der Philosophie seinen Ausgangspunkt habe. Heß meint, der theoretische Kommunismus sei eıne alleın durch die gedankliche Konsequenz vorangetriebene Bewegung gewesen. Die philosophische Entwicklung bis zum Humanismus Feuerbachs sei jedoch in der Theorıe steckengeblieben. Es sel notwendig, die Erkenntnis von der Entfremdung des Menschen auch auf das Gebiet der Politık und des Geldes auszudehnen $^{135}$ und durch totale Aufhebung dieser Entfremdungen den Humanismus praktisch werden zu lassen. Über Feuerbach hinausgehend müsse man erkennen, daß der Humanismus die Lehre von der menschlichen Gesellschaft seı, in der die verschıedenen Indıviduen für Identısche Interessen zusammenwırken. „Das Wesen Golles. sagt Feuerbach, ist das transcendente Wesen des Menschen, und dic wahre Lehre vom göttlichem Wesen ist die Lehre vom menschlichen Wesen. Theologie ist Anthropologie - das ist wahr - aber das ist nicht die ganze Wahrheıt Dis Wesen des Menschen, muß hınzugefügt werden, ist das gesellschaftliche Wesen. das Zusammenwirken der verschıedenen Indivıduen für eınen und denselben Zweck, für ganz identısche Interessen. und die wahre Lehre vom Menschen, der wahre Humanismus, ist die Lehre von der menschlıchen Gesellschaftung, d. h. Anthropologue ist Sozulismus. "1,

In Soralismus, so schließt Heß, werde die theoretische wie praktısche Entfremdung durch Aufhcbung der Religion und Ersetzung des Privateigentums durch den organisch'n B'sut= beselligt sein und eine auf wissenschaftlichen Prinzipien beruhende Verteilung der Produkte stattfinden $\mathrm{HeB}$ fordert die Fremeit der Wissenschaft, die Deutshland sozbalistisch umzugestalten on det I age ser.

I as ebentalls $\mathrm{m}$ (rechuesen abgeh.undelte I hema des Wesens des Menschen ist Gegenstand des gegen tnde der ersten lahreshälfti ls44 entstandenen Autiatzes 
Bestimmung des Menschen, der im Juni im Sprecher erschien. Aus Zensurgründen konnte $\mathrm{He} B$ sich nur vorsichtige Formulierungen erlauben; indes bedingte sein idealistischer Standpunkt von vornherein eine verschleiernde Ausdrucksweise. Er geht wiederum nicht von historischen Tatsachen aus, um aus ihnen die künftige Entwicklung der Gesellschaft zu erschließen, sondern von einer dogmatischen Wesensbestimmung des Menschen, die er durch historische Tatsachen zu stützen sucht. Heß meint, die Bestimmung des Menschen sei, sich ,ganz zu bethätigen."137 Als einzelnes Individuum könne der Mensch sich gar nicht betätigen. Das Wesen der menschlichen Lebenstätigkeit bestehe im Zusammenwirken der Individuen. Außerhalb dieses Zusammenwirkens sei keine einzige spezifisch menschliche Tätigkeit möglich. Jedoch sei dieses Zusammenwirken bisher dem Zufall überlassen, es sei nicht ,organisirt ${ }^{* 138}$; aus diesem Umstand erwüchsen dem Zusammenwirken Hemmnisse, die den Menschen veranlaßten, sich als isoliertes Individuum zu betrachten. Diese Hemmnisse bestünden in lügenhaften Widersprüchen, blutigen Kollisionen, in Gegensätzen, die das einige Leben trennten und vernichteten, wie dem Gegensatz von Produzenten und Konsumenten.

Zur Untermauerung der Forderung nach Etablierung der organischen Gesellschaft zieht $\mathrm{Heß}$ eine Analogie zu Naturvorgängen, ein Verfahren, das später bei manchen seiner Gesinnungsgenossen Schule machen sollte.

Das organische Leben der blinden Natur beschäme das gesellschaftliche Leben der noch nicht vereinigten Menschen. „Was der Mund an Nahrungsmitteln aufnimmt, hält er nicht im Rachen fest als sein ,unveräußerliches Eigenthum;, sondern nachdem er es verarbeitet oder genossen hat, übergibt er es dem Magen; dieser verarbeitet oder consumirt es in seiner Weise und übergibt es dem Blute; das Blut leitet es weiter zu den verschiedenen organischen Wirkungskreisen, die es zu ihrer Thätigkeit bedürfen u. s. f., bis es wieder zu den Elementen übergeht, die ihrerseits von den verschiedenen organischen Wirkungskreisen absorbiert, consumirt, verarbeitet, d. h. zu organischen Productionen benutzt werden. "139

Derartige organische Wirkungskreise habe unsere Gesellschaft bisher nicht aufzuweisen; solange jedoch die Gesellschaft nicht in dieser Weise organisiert sei, trete in ihr jede individuelle Schöpfung allen anderen feindlich entgegen. Die Bestimmung des Menschen - die ,,allseitige Entfaltung seines Gattungslebens“140 — könne sich nur ,,in der organisirten Gesellschaft, im organisch ausgebildeten menschlichen Gattungsleben" realisieren. ${ }^{141}$ Die materielle Grundlage hierfür - die erleichterte Kommunikation und die Möglichkeit, daß die „Producte ohne vielen Kraft- und Zeitaufwand fast in's Unglaubliche vervielfältigt werden können"142 — sei bereits vorhanden. Nachdem der Inhalt zur Organisation der menschlichen Gesellschaft gewonnen sei, komme es darauf an, deren Form diesem Inhalt anzupassen.

Die Identifizierung des gesellschaftlichen Wesens des Menschen mit einer altruistischen Bestimmung stellt Heß vor die Frage, wie es kommt, daß das Wesen des Menschen seiner Existenz widerspricht. Der teleologischen Konstruktion, aus der diese Frage erwächst, entspricht das Metaphysische ihrer Auflösung: die Wesensbestimmung konnte nicht realisiert werden, weil die Gesellschaft bisher nicht organisiert war. Daß die Frage damit nicht gelöst, sondern nur verschoben war, bemerkt $\mathrm{He} B$ nicht.

$\mathrm{He} B$ hatte sich mit dem (Schein-)Problem bereits im Geldwesen beschäftigt. Nochmals kommt er darauf in dem Aufsatz Fortschritt und Entwicklung zurück, der ebenfalls für den Sprecher bestimmt war, aber von der Zensur gestrichen wurde. ${ }^{143}$ 
Auch hierin versucht er aus dem Widerspruch herauszukommen, der darin besteht, $\mathrm{da}$ eine Sache etwas zum Wesen hat, dem ihre Existenz diametral entgegensteht.

$\mathrm{HeB}$ geht von der Feststellung aus, daß alle Lebewesen auf der Erde zwei Phasen durchlaufen; eine Phase, in der sie entstehen, und eine, in der sie sich durch den Gattungsakt selbst erzeugen. Die erste Phase sei ,eine Entwicklung zu seinem Wesen hin“, die zweite ,eine Selbstentwicklung, Selbsterzeugung, Selbstbethätigung des Wesens““ ${ }^{144}$ Ähnlich verhalte es sich mit der ,Welt des Geistes“, der ,,Menschheit als selbstbewußte Gattung "145; sie befinde sich noch im Stadium der Entstehung. Sie sei noch nicht organisiert, sei noch keine Selbsterzeugung, kein Gattungsakt. Charakteristisch für dieses Stadium sei der Widerspruch innerhalb des Wesens der Menschen. Wie in der Erdentstehung Naturrevolutionen stattgefunden hätten, so fänden auch während der Entstehung der ,,bewußten Gattung "145a Kämpfe und Revolutionen statt. In der Entstehungsphase suche die Gattung ,ihr Leben erst zu erwerben“. ${ }^{45 b}$ Was sie zu erwerben suche, sei ihr eigenes Wesen, ihre Einheit. Das Gattungswesen, das vereinigende Medium, sei noch etwas Fernes, Fremdes, Äußerliches; es werde von den Elementen einseitig, ,von jedem Individuum egoistisch für sich erstrebt ${ }^{" 145 c}$; dies sei die Ursache für den Kampf und den $\mathrm{Haß}$ der Individuen untereinander.

Gegenwärtig stehe die Menschheit an der Schwelle ihrer zweiten Entwicklungsart. Damit der Mensch sein Wesen erlange, sei die „Organisation der Erziehung" notwendig. ${ }^{145 d}$ Und die Voraussetzung für die Betätigung dieses Wesens, das ,im Zusammenwirken der Menschen besteht", sei die „Organisazion der Arbeit". ${ }^{145 e}$

Die bewußte Gattung werde es zur Vollkommenheit, zum Gattungsakt, zur freien Selbsttätigkeit bringen. Sie werde nicht immer im Kampf und Widerspruch und $\mathrm{HaB}$, sie werde auch einmal in der Liebe leben, ,Wir stehen am Eingange, an der Pforte dieser neuen Welt der Liebe, und fordern Einlaß.“145f

Wie zuvor geht $\mathrm{He} ß$ auch in dieser Etappe seiner Entwicklung, in der er sich vor allem auf die Philosophie Feuerbachs stützt, nicht den für den Aufbau einer wissenschaftlichen Theorie notwendigen Weg der Wirklichkeitserforschung, die ihm erlaubt hätte, historisch-kausale Beziehungen festzustellen. Sein Versuch, in einer umfassenden Geschichtsphilosophie Vergangenheit, Gegenwart und Zukunft in einen gesetzmäßigen Zusammenhang zu bringen, ist daher von vornherein zum Scheitern verurteilt. Aus dem gleichen Grunde ist er auch unfähig, die rationellen Bestandteile der modernen deutschen Philosophie der sozialistischen Theorie dienstbar zu machen.

Wie Marx knüpft er an Feuerbachs Feststellung von dem gattungsmäßig, d. h. gesellschaftlich bedingten Wesen des Menschen an, bleibt aber in der fehlerhaften Identifizierung dieses Wesens mit einer altruistischen bzw. sozialistischen Bestimmung stecken, indes Marx zu gleicher Zeit in der materiellen Produktion die Grundlage des gesellschaftlichen Wesens des Menschen erkennt und die Geschichte aus der historischen Bewegung der Produktion erklärt. Und die in der Tat geniale Entdeckung Feuerbachs von der Abhängigkeit des Bewußtseins vom Sein, die Marx noch in seiner revolutionär-demokratischen Entwicklungsetappe zu der historisch-materialistischen Basis-Überbau-Theorie auszubauen beginnt, bleibt $\mathrm{He} ß$ gänzlich verschlossen.

Soweit die aus vorgefundenen Theorien entlehnten Begriffe sich zur Stützung seiner kommunistischen Zukunftsforderung eignen, verwandelt $\mathrm{He} B$ sie in ansichseiende Wesensbestimmungen. Das gesellschaftliche Wesen des Menschen wird zum ,wahren“ altruistischen Wesen, aus der Kritik des Eigentums gewinnt er das ,wahre“ Eigentum, die Tätigkeit wird zur ,wahren" Tätigkeit. Besonders hinsichtlich der praktischen 
Tätigkeit als Hebel der Herausbildung des Menschen ist Heß als Vorläufer Marx' bezeichnet worden - zu Unrecht. Heß konzipiert den Begriff ,Tätigkeit“ zuerst in seiner subjektiv-idealistischen Phase in Anlehnung an Fichte. Zu der Zeit begreift er unter diesem Begriff allein die rein geistige Tätigkeit, die tatsächliche materielle Produktion wird nicht in Erwägung gezogen. In der folgenden Etappe seiner Entwicklung, als er sich in der Hauptsache auf den Feuerbachschen Humanismus stützt, übernimmt er von Schulz und offenbar auch von Engels den Begriff der materiellen Produktion; aber er erfaßt weder wie Schulz ihre Bedeutung als geschichtsbildende Kraft noch wie Engcls ihre spezielle Form innerhalb der bürgerlichen Gesellschaft. Nur so viel an Rationellem übernimmt er, daß der Mensch notwendig tätig ist; hieraus leitet er sofort die metaphysische Wesensbestimmung ab: das Wesen des Menschen oder die "wahre" Tätigkeit ist die freie Tätigkeit, freie Tätigkeit ist nur im Kommunismus möglich, folglich ist die kommunistische Gesellschaft eine Notwendigkeit. Der in dem Aufsatz Fortschritt und Entwicklung benützte Begriff ,Selbsterzeugung“ hat nichts mit der Erkenntnis zu tun (zu der Marx eben zu dieser Zeit gelangte), daß der Mensch sich durch die Arbeit aus einem tierischen in ein menschliches Wesen verwandelt, daß er sich durch die Arbeit selbst geschaffen hat. „Selbsterzeugung“ bedeutet bei Heß in bezug auf die organische Natur die Zeugung von Nachkommen und in bezug auf die Gesellschaft die Reproduktion des Wesens des Menschen. ${ }^{145 \mathrm{~g}}$

\section{Heß' Sozialismus in ,,Fragen und Antworten“"}

Mit einem über zwei Nummern verteilten Beitrag war Heß im Dezember 1844 im Pariser Vorwärts vertreten. ${ }^{145 \mathrm{~h}}$ In Form von Fragen und Antworten wiederholte er darin seine Kritik an der bürgerlichen Gesellschaft und seine kommunistische Auffassung. Klarer als zuvor hebt er den Gedanken hervor, daß der Mensch das Erzeugnis der Natur und der menschlichen Gesellschaft sei und daß sich sein Leben nur in Natur und Gesellschaft abwickeln könne. Dieser Lebensprozeß vollziehe sich in der gegenwärtigen Gesellschaft, die durch die Herrschaft des Geldes charakterisiert sei, im Rahmen einer nichtorganisierten, gezwungenen Arbeit, die den Menschen zur Maschine und zu einem kauf- und verkaufbaren Objekt herabwürdige. Im Namen der Freiheit und der Vernunft fordert Heß eine harmonische Gesellschaft, in der dank des Gemeineigentums und der organisierten Arbeit Produktion und Verteilung gemä $B$ den menschlichen Bedürfnissen geregelt würden, wodurch im Verein mit der Erziehung die menschliche Freiheit verbürgt sein werde.

In der Schlußanmerkung gibt er in einer Synthese St.-Simonistischer und Fourieristischer Gedanken eine klare Formulierung des kommunistischen Prinzips: „Daher Arbeit nach der Fähigkeit und Genuß nach dem Bedürfniß, die Formel des vernünftigen Vereines ist." $145 \mathrm{i}$

Die Fragen und Antworten, eine Darstellungsform übrigens, wie sie später bei den Vorläufern des Kommunistischen Manifests versucht wurde, waren keine Programmschrift; sie konnten es schon deshalb nicht sein, weil es Heß bei einer Gegenüberstellung von bürgerlicher Gesellschaft und kommunistischem Ideal bewenden ließ. Indessen machte sich hier abseits der ansonsten von $\mathrm{He} B$ bevorzugten philosophischen Erörterungen die Tendenz bemerkbar, die Arbeiter über ihre Lage in der bürgerlichen Gesellschaft aufzuklären. 
Um drei Kapitel vermehrt und unter verändertem Titel veröffentlichte Heß den Aufsatz nochmals im zweiten Bande der Rheinischen Jahrbücher zur gesellschaftlichen Reform (1846). ${ }^{145 \mathrm{j}}$

Abrechnung mit dem Junghegelianismus

An der Auseinandersetzung mit den Junghegelianern beteiligte $\mathrm{HeB}$ sich mit einer Broschüre, Die letzten Philosophen, die Mitte 1845 bei Leske in Darmstadt herauskam. ${ }^{145 \mathrm{k}}$ Diese Schrift, im wesentlichen eine Kritik an Stirners Buch Der Einzige und sein Eigenthum, hatte er im Winter 1844/45, während eines engen Zusammenwirkens mit Engels verfaßt. Er hatte Gelegenheit, die Aushängebogen einzusehen, so daß er sich an die Kritik machen konnte, bevor der kritısierte Gegenstand erschienen war.

Max Stirner (Pseudonym von Johann Caspar Schmidt, 1806 bis $1856^{145}$ ) und Bruno Bauer repräsentıerten die subjektiv-idealistıschen Ausläufer der Hegelschen Philosophie. Während die Mehrzahl der ehemalıgen Junghegelıaner sıch politischen - bürgerlichen oder sozialistischen - Bewegungen angeschlossen hatte, vermochten Bauer und Stirner sich weder mit den Interessen der Bourgeoisie noch mit denen des Proletariats zu solidarisieren. So heftig sie daher auch einander befehdeten ${ }^{145 \mathrm{~m}}$, so einig waren sie in der Gegnerschaft zum Liberalismus, Demokratismus und Sozialismus. Durch sein Unvermögen, vom philosophischen zum politischen Radıkalismus überzugehen, und seinen Rückzug auf eine subjektivistisch-anarchistische Rebelliererei hatte Bauer sich weitgehend selbst in die Isolierung gedrängt ${ }^{145 n}$, und das ,durch den vernichtenden Angriff" von Marx und Engels in der Heiligen Familie über thn gefällte literarısche Urteil war - ob freudig oder widerstrebend - allgemein anerkannt worden. ${ }^{1450}$

Anders als Bauers ins Absurde geschraubte kritische Philosophie fand Stimers anarchistisch-literarische Rebellion eine, wenn auch Vorbehalte machende, geringe positive Resonanz im gebildeten Publikum. Sein Individualismus und Egoismus wurden fast durchweg als überspannt und undurchführbar abgelehnt, sein Aufbegehren gegen politısche und religiöse Unterdrückung jedoch als Unterstützung der Opposition gegen den preußischen Absolutismus gewürdigt. ${ }^{145 p}$

Stirners Einziger erschien bei Otto Wigand in Leipzig mit der Jahreszahl 1845, kam aber schon im Herbst 1844 heraus. ${ }^{145 q}$

Wie Bauer ging Stirner von der Herrschaft der Ideen aus, und er glaubte, durch deren theoretische Vernichtung die wirkliche Vernichtung dessen, was sie abspiegeln, geleistet zu haben. Stirners Forderung bestand darin, sich von allen Mächten, wie Staat, Gesellschaft usw., die wie Gott in der Religion nur selbstsüchtige Forderungen an uns stellten, freizumachen und ein von ihnen unabhängıges, freies Leben zu führen, in dem das "Ich“ dem Individuum das Höchste sei. Die Befrelung bewerkstelligte er, ındem er die wirklichen Verhältnısse als Abstraktionen auffaßte und diese für nichtig erklärte. In der Deutschen Ideologie schrieben Marx und Engels: ,Nach und nach wurde jedes herrschende Verhältnis für ein Verhältnis der Religion erklärt und in Kultus verwandelt, Kultus des Rechts, Kultus des Staats pp. Überall hatte man es nur mit Dogmen und dem Glauben an Dogmen zu tun. Die Welt wurde in immer größerer Ausdehnung kanonisıert, bıs endlich der ehrwürdige Sankt Max [d. i. Stirner] sie en bloc heiligsprechen und damit ein für allemal abfertigen konnte."145r 
Diese Scheinvernichtung wirklicher Verhältnisse durch deren Idealisierung und Aufhebung im Bewußtsein bildete den Hauptangriffspunkt der Heßschen Kritik. Er besprach sie mit Friedrich Engels, der Sommerende 1844 von England über Paris, wo seine entscheidende Begegnung mit Marx stattfand, nach Barmen zurückgekehrt war und mit $\mathrm{Heß}$ Verbindung aufgenommen hatte. Am 19. November schrieb Engels an Marx in Paris: „Du wirst von dem Stirnerschen Buch ,Der Einzige und sein Eıgenthum" gehört haben, wenn es noch nicht da ist. Wigand schickte mir die Aushängebogen, die ich mit nach Köln nahm und bei Heß ließ."145s Engels fügte noch einige kritische Bemerkungen hınzu, die zeigen, daß er den Stirnerschen Egoismus noch nicht als völlig haltlose Phrase durchschaute. Marx scheint mit dieser Kritik nıcht sehr einverstanden gewesen zu sein, denn in seinem nächsten Brief an Marx schrieb Engels: ,Was den Stırner betrifft, so bin ich durchaus mit Dir einverstanden. Als ich Dir schrieb, war ich noch zu sehr unter dem unmittelbaren Eindruck des Buchs befangen, seitdem ich es hab' liegenlassen und mehr durchdenken können, find' ich dasselbe, was Du findest."145t Heß' Fassung einer Kritik an Stirner schien Engels mit der Marxschen Auffassung übereinzustimmen. So schrieb er im gleichen Brief an Marx: „Heß [...] den $1 \mathrm{ch}$ vor vierzehn Tagen in Bonn sprach, ist nach einigen Meinungsschwankungen ebendahin gekommen wie $\mathrm{Du}$; er las mir einen Artikel über das Buch vor, den er bald drucken lassen wird, worin er, ohne Deinen Brief gelesen $\mathrm{zu}$ haben, dasselbe sagt. Ich hab' ihm Deinen Brief dagelassen, weil er noch einiges benutzen wollte [. . .]."145u Ähnlich schrieb Heß an Marx Mitte Januar: „Als Engels mir Ihren Brief zeigte, hatte ich gerade eine Beurtellung Stırners zu Ende gebracht et j'avais la satisfaction de voir, daß Sie den Einzigen ganz von demselben Gesichtspunkte aus ansehen. Er hat das Ideal der bürgerlichen Gesellschaft im Kopfe und bildet sıch ein, mit seinem idealistıschen ,Unsinn“ den Staat zu verachten [. . . ["145v

Indessen bestand zwischen beiden, Heß und Marx, nicht so sehr eine Übereinstimmung in der Einschätzung des Stirnerschen Buches als in der Auffassung, daß es notwendıg sei, öffentlich mıt den Äußerungen des extremsten Vertreters des subjektiven Idealismus abzurechnen. Marx konnte sich sicherlich mit der These der Heßkritik einverstanden erklären, die besagte, daß Stirner nur im Geiste die Verhältnisse negierte und sich einbildete, von ihnen frei zu sein, dabei jede praktische Maßnahme unterließ, sie wirklich zu verändern. Doch der Grundlage der Heßschen Erörterungen, die eine deutliche Abhängıgkeit von Feuerbach verriet, konnte er offenbar nıcht seine Zustimmung geben. ${ }^{145 w}$

Heß kritisierte in seinem Aufsatz Feuerbach, Stirner, Bauer als die ,letzten Philosophen", die von einem abstrakt-dogmatischen Standpunkt räsonierten, von dem aus sie weder die Wirklichkeit zu erfassen noch auf sie einzuwirken in der Lage seien. Jedoch verneinte er die Voraussetzungen dieser Philosophen selbst noch vom Standpunkt der abstrakten Philosophie. Er war noch in der Auffassung befangen, ,man brauche Feuerbach nur praktisch zu machen, ihn nur aufs soziale Leben anzuwenden, um die vollständige Kritik der bestehenden Gesellschaft zu geben“" ${ }^{145 x}$ So lehnte er Bauers, Stirners und Feuerbachs Philosophie ab, weil sie phantastische Abstraktionen wie „Selbstbewußtsein“, „Gattungswesen“ usw. zur Grundlage hätten, aber er lehnte sie in Gedankengängen der Feuerbachschen Philosophie ab: Es genüge nicht, den ,Unterschied zwischen den einzelnen Menschen und der Menschengattung theoretisch aufzuheben", die „Vereinzelung der Menschen" müsse praktisch beseitigt werden; „Der moderne Staat hat den Gegensatz zwischen dem Einzelnen und der Gattung wieder nur 
verschärft"; „Die Versuche, unsere Gesellschaft zu reformieren, werden so lange wiederholt, bis sie dem innern Bewußtsein entsprechen, welches wir von unserm Leben haben" usw. ${ }^{145 y}$

In seiner Kritik an Stirner betonte $\mathrm{HeB}$, daß die Wirklichkeitsveränderung nicht allein eine Sache theoretischer Entwicklung sei, doch vollzog sich seine Wirklichkeitsannäherung vor allem gerade in den metaphysischen Vorstellungen der Feuerbachschen Philosophie.

Die Uneinheitlichkeit und Verschwommenheit des Denkens von $\mathrm{He} B$, der in einer Arbeit die Erkenntnisse der vorangegangenen außer acht ließ - im Falle dieser Kritik die ökonomischen Einsichten aus dem Geldwesen -, hatte wohl auch Engels gespürt. An Marx schrieb er in dem schon erwähnten Brief vom 19. November 1844: „Heß hat in vielem, was er über Feuerb[ach] sagt, recht, aber auf der andern Seite scheint er noch einige idealistische Flausen zu haben - wenn er auf theoretische Dinge zu sprechen kommt, geht es immer in Kategorien voran, und daher kann er auch nicht populär schreiben, weil er viel zu abstrakt ist. Daher haßt er auch allen und jeden Egoismus, und predigt Menschenliebe usw., was wieder auf die christliche Aufopferung herauskommt."

\section{Die Elberfelder Versammlungen}

Heß' Arbeit an der Stırner-Krıtik geschah zu einer Zeit, als die preußische Regierung ebenso wie das deutsche Bürgertum noch unter dem Eindruck des Weberaufstandes im Sommer 1844, der ersten großen Bewegung der deutschen Arbeiter, standen. Der Aufstand offenbarte schlagartig den Gegensatz von kapitalistischer Entwicklung und steigendem Elend der Arbeiterschaft und gab der feudalen Regierung, aber auch der jungen, aufsteigendem Bourgeoisie eine Ahnung der Gefahr, die ihnen von einer durch Not aufgereizten Arbeiterschaft drohen konnte. Auch aus Sachsen, Westfalen, dem nördlichen und südlichen Rheinland berichteten die Verwaltungsbeamten von einer wachsenden Unzufriedenheit der verarmten Arbeiterbevölkerung mit den sozıalen Verhältnıssen. Diese Unzufriedenheit machte sıch u. a. in zahlreichen, um diese Zeit entstehenden politischen Zeitungen und Zeitschriften hörbar. $\mathrm{Zu}$ gleicher Zeit wurde die Regierung durch das Hereinströmen kommunistischer Gedanken aus Frankreich beunruhigt. ${ }^{146}$ In einem ersten Erschrecken sannen Regierung und industrielles wie kommerzielles Großbürgertum auf philanthropische und caritative Maßnahmen (Gründung von Hilfsund Bildungsvereinen), dank denen sie übermäßige Not lindern und Unruhen vorbeugen zu können hofften. Dieses Projekt entstand während der Gewerbeausstellung in Berlin im Herbst 1844; es fand die Zustimmung der preußischen Regierung. ${ }^{146 a}$ In Berlin konstituierte sich ein Zentralverein, und in vielen Städten Preußens und auch anderer deutscher Staaten entstanden örtliche Vereine. Keineswegs handelte es sich hierbei um eine Art Interessenorganisation der Arbeiter selbst, nicht einmal um eine Vorstufe davon, sondern um Vereinıgungen der Bourgeoisie, die zum Schutz ihrer ökonomischen Interessen die Vergabe von materiellen und intellektuellen Almosen organisieren wollte. Die Arbeiter waren in den meisten Fällen nicht in den Vereinen zugelassen. Weder der als anleitendes Organ gedachte preußische Zentralverein in Berlin noch die zahlreichen Lokalvereıne haben die erwartete Wirksamkeit erlangt. Trotz der sehr begrenzten Zielsetzung der Vereine trugen die in der Tagespresse wiedergegebenen und besprochenen Gründungsdebatten dazu beı, Teıle des Proletariats Ideologisch 
aufgeschlossen und sozialistischen Ideen zugänglich zu machen. Bald nach Beginn der Kampagne zog sich daher das Großbürgertum zurück (Hauptträger der Vereinsbewegung wurde das demokratische Kleinbürgertum), und die ebenfalls sehr rasch desillusionierten Regierungen erhoben immer wieder Einspruch gegen die Statutenentwürfe und verhängten Versammlungsverbote. ${ }^{147}$

In einem Schreiben an den Minister des Innern, von Arnim, machte der Oberpräsident von Schaper mit Sorge darauf aufmerksam, daß bei den Vereinsgründungen ,von verschiedenen Seiten" „ganz andere Zwecke" verfolgt werden, und er begründete die Notwendigkeit, die Vereine auf begrenzte Hilfsmaßnahmen festzulegen und jegliche politische Wirksamkeit auszuschließen. ${ }^{148}$ Im Herbst 1847 hörte der Berliner Zentralverein praktisch zu bestehen auf; ein Institut entschlief, so kommentierten die demokratischen Grenzboten, ,das von der patrizischen Aristokratie Berlins angeregt, von der Regierung und von dem König selbst mit Freuden begrüßt und gutgeheißen wurde, das dann plötzlich in Mißkredit gerieth, weil man anfing, in jeder Vereinigung von Bürgern einen Jacobinerclub zu wittern". 148a Nachdem das revidierte Statut des Central-Vereins in Preußen für das Wohl der arbeitenden Klassen endlich am 12. April 1848, kurz nach den Märzereignissen, die Zustimmung des Innenministers erhalten hatte, war das Hauptziel des Vereins die „Mitwirkung. zur Beruhigung der entfesselten Leidenschaften “ ${ }^{148 \mathrm{~b}}$

Besonders in der Rheinprovinz wurden auf zahlreichen Versammlungen sozialistische und kommunistische Stimmen laut. In diese Versammlungskampagne schalteten sich im Februar $1845 \mathrm{HeB}$ und Engels ein. Heß war zwecks Herausgabe einer Arbeiterzeitschrift nach dem industriell stärker entwickelten Barmen übergesiedelt und befand sich damit in unmittelbarer Nähe des bei seinen Eltern in Barmen wohnenden Engels.

Im Zweibrücker Hof in Elberfeld veranstalteten Heß, Engels und der Maler Köttgen am 8. Februar 1845 eine hauptsächlich von Bürgern besuchte Versammlung, auf der sie über die Ziele des Kommunismus sprachen. Es folgten Versammlungen am 15. und 22. Februar. ${ }^{149}$

Am 24. Februar wurde den Veranstaltern bekannt, daß die nächste Versammlung durch Polizei gesprengt und die Redner verhaftet werden sollten. Am 22. Februar erhielt der Oberbürgermeister, von Carnap, von der Düsseldorfer Regierung die Anweisung, weitere Versammlungen, nötigenfalls mit Polizeigewalt zu verhindern. So waren die Veranstalter gezwungen, auf die Fortsetzung dieser Agitation zu verzichten. ${ }^{150}$ „Wir haben's jetzt natürlich drangegeben“, schrieb Engels an Marx, „und müssen erwarten, ob man uns einklagen wird, was aber kaum zu erwarten steht, da wir schlau genug waren, keine Handhabe zu bieten, und der ganze Dreck nur in einer großartigen Blamage der Regierung endigen könnte. Ohnehin waren die Staatsanwälte und das ganze Landgericht gegenwärtig, und der Oberprokurator hat selbst mitdiskutiert. " $" 151$

Heß und Köttgen reichten gegen das Verbot eine Beschwerdeschrift ein ${ }^{152}$, die, wie nicht anders zu erwarten stand, keinerlei Erfolg hatte. Die Propagandaresultate veranlaßten $\mathrm{Heß}$ zu einer überschwenglichen Einschätzung der Erfolge. Engels berichtete darüber an Marx: „Heß ist wieder ungeheuer sanguinisch, weil alles sonst so famos abläuft und unsre Fortschritte wirklich ungeheuer sind, der gute Kerl macht sich nur immer Illusionen." 153

Die Reden von Engels und $\mathrm{He} B$ sind nach einiger Überarbeitung durch die Autoren 
in den Rheinischen Jahrbüchern zur gesellschaftlichen Reform veröffentlicht worden. ${ }^{154}$ Sie spiegeln den Grundunterschied wieder, der die beiden Männer voneinander trennte. Engels kam sofort auf bestimmte ökonomische Verhältnisse der kapitalistischen Gesellschaft zu sprechen, wie Konzentration des Kapitals, Widerspruch zwischen Produktion und Konsumtion, Produktion für einen unbekannten Markt, Wirtschaftskrisen, und er deutete, herausgefordert durch einen Diskussionsteilnehmer, die ökonomische Notwendigkeit des Kommunismus an. Das letzte war ein heikler, weil mit der Frage der Revolution verbundener Gegenstand, den Engels auch nicht konsequent behandelte.

$\mathrm{HeB}$ hat es im wesentlichen mit philosophisch verbrämten geschichtlichen Erörterungen zu tun, zum Teil sind uns diese schon aus dem Geldwesen bekannt, zum Teil bringt er aber auch in dieser für ihn typischen philosophischen Verkleidung neue und interessante Auffassungen, die offenbar auf den unmittelbaren Einfluß von Engels und den mittelbaren von Marx zurückgehen. Die Frühzeit des Menschen bezeichnet er wiederum als einen Zustand der Vereinzelung der Individuen. Allmählich entwickelte sich durch den Produktenaustausch ein ständig steigender Verkehr, der nun ein Höchstmaß erreicht hat, jedoch innerhalb der Vereinzelung, d. h. der Konkurrenz. So erfaßt der fortwährend gegen seine philosophischen Schranken ankämpfende Heß vage den der kapitalistischen Gesellschaft innewohnenden Widerspruch zwischen der gesellschaftlichen Produktion und der privatkapitalistischen Aneignung der Produkte.

Es ist wohl dem Einfluß von Engels zu danken, der einige Monate zuvor mit Marx zu einer ersten Selbstverständigung über die Grundlagen ihrer neuen materialistischen Geschichtsauffassung gekommen war, wenn $\mathrm{He} ß$ die Erkenntnis ausspricht, daß in den enorm gesteigerten Produktivkräften die objektive Grundlage des Kommunismus liege und daß die Idee des Kommunismus selbst erst auf der Grundlage des real vorhandenen Gegensatzes zwischen dem Stand der Produktivkräfte und der egoistischen, kapitalistischen Gesellschaftsordnung erwachsen konnte. Die Idee allein, beruhe sie nicht auf bestimmten historischen Gegebenheiten, vermöge keine Umgestaltung der Gesellschaft zu vollbringen.

Heß konnte sich jedoch nicht für längere Zeit auf dem Boden der Realität und der mit konkreten Faktoren rechnenden Überlegung bewegen. Über die zu errichtende Gesellschaft räsonierte er nur in allgemeinen Phrasen; der Kommunismus sei das Leben und Wirken in der Gemeinschaft; ,,Die Idee des Communismus [. . .] ist das Lebensgesetz der Liebe, angewandt auf das Socialleben. “155

Freilich sind bei der Beurteilung der Reden von $\mathrm{HeB}$ und Engels der Zuhörerkreis und die äußeren politischen Verhältnisse in Rechnung zu setzen, die vorsichtige Formulierung der Kritik am Kapitalismus und der Darstellung des Kommunismus nahelegten. Doch selbst die Berücksichtigung dieses Umstandes kann nichts an der Tatsache ändern, daß Heß seit den Deutsch-Französischen Jahrbüchern nicht mehr auf der Höhe der theoretischen Entwicklung stand. Besonders der Vergleich seiner Arbeiten mit denen von Marx zu dieser Zeit, d. h. also seines Vorwärts-Artikels oder der Letzten Philosophen mit den Ökonomisch-philosophischen Manuskripten, dem Aufsatz gegen Ruge im Vorwärts ${ }^{156}$ oder der Heiligen Familie, zeigt, daß die theoretischsozialistische Bewegung über ihn hinausgegangen war, wenn er auch im Anfang mit an ihrer Spitze gestanden hatte. Im Gegensatz zu Marx kam er nicht über einige historisch-materialistische Ansätze hinaus zur Entwicklung einer wissenschaftlichen Gesamteinsicht der geschichtlichen Entwicklung im allgemeinen und der kapitalistischen Gesellschaft im besonderen. 


\section{Propagandaschriften}

Vor und nach den Elberfelder Versammlungen bemühte $\mathrm{HeB}$ sich um das Zustandekommen einiger sozialistischer Zeitschriften: Deutsches Bürgerbuch, Gesellschaftsspiegel, Rheinische Jahrbücher zur gesellschaftlichen Reform.

Der erste Band des Deutschen Bürgerbuches, von Püttmann bei Leske in Darmstadt herausgegeben, erschien im Dezember 1844. ${ }^{156 a}$ Er enthielt Aufsätze von Heinzen, Grün, Venedey, Gedichte von Püttmann usw. und gab ein rechtes Abbild der kleinbürgerlichen Enge der deutschen Verhältnisse. Vorteilhaft hoben sich ein Aufsatz von F. W. Wolff über den schlesischen Weberaufstand (Das Elend und der Aufruhr in Schlesien) und G. Weerths Artikel Die Armen in der Senne gegen die sozialistische Schwärmerei ab.

Das Bürgerbuch war ein ,dummer Mischmasch“ (Heß ${ }^{157}$ ) verschiedener Elemente, unter denen der ,wahre" Sozialismus überwog. Hatte Heß den Verhältnissen der kapitalistischen Gesellschaft, deren ökonomische Grundzüge er teilweise und oberflächlich erfaßte, eine moralisch-,,philosophische" Interpretation gegeben, so machten Grün, Püttmann und andere Vertreter des ,wahren“" Sozialismus die Moral vollends zu einer geschichtlichen Triebkraft. Sie stützten sich auf die teleologische Konstruktion von $\mathrm{HeB}$, bei der aus der Idee der glücklichen sozialistischen Gesellschaft, der „wahren" Gesellschaft, auf deren unvermeidliche Realisierung geschlossen wurde.

Von Heß enthielt der erste Band des Bürgerbuchs zwei Aufsätze, Über die Noth in unserer Gesellschaft und deren Abhülfe ${ }^{158}$ und Beachtenswerthe Schriften für die neuesten Bestrebungen. ${ }^{159}$ Die ,feindselige und gemeingefährliche“ Tendenz dieser und der übrigen Artikel veranlaßte die Regierung zum Einschreiten. ${ }^{160}$ Der über zwanzig Bogen starke Band entging zwar der Zensur, aber nicht der Beschlagnahme durch die Polizeiorgane. ${ }^{161}$ Leske, der einige Monate später wegen der Herausgabe der Rheinischen Jahrbücher mit Verbot seiner sämtlichen Verlegungen bedroht wurde, konnte die Herausgabe des zweiten Bandes nicht mehr übernehmen. Dieser erschien 1846 bei Heinrich Hoff in Mannheim.

In dem Aufsatz Über die Noth in unserer Gesellschaft und deren Abhülfe führte Heß die im Kapitalismus inmitten des Überflusses existierende Not auf die Trennung des Menschen von den von ihm geschaffenen Produkten und auf die Konkurrenz zurück. Er gab beiläufig eine kritische Einschätzung seiner früheren, als wissenschaftliche Begründung des Kommunismus gedachten Arbeiten, wenn er feststellte, daß der aus dieser Not hervorgegangene Gedanke des Sozialismus bis jetzt nur erst ein frommer Wunsch und noch nicht theoretische Wirklichkeit sei. Das Verständnis für die zu errichtende kommunistische Gesellschaft verlange Erkenntnisse der Fortschritte der Mechanik, der materiellen Produktion und des Wesens des Menschen. Die dank der gesteigerten Produktivkräfte erreichten Fortschritte in Industrie, Handel und Verkehr machten eine Rückkehr in vorkapitalistische Gesellschaftsordnungen unmöglich; die Beseitigung der Not könne nur durch Errichtung der kommunistischen Gesellschaft bewirkt werden, in der Erziehung und Arbeit organisiert sein werden. Durch allgemeine und unentgeltliche Erziehung sowie durch Errichtung von Nationalwerkstätten solle die kapitalistische allmählich in die sozialistische Gesellschaft übergeführt werden. Sollte diese Bewegung auf Widerstand stoßen, müsse die „Kritik der Waffen“ sprechen. ${ }^{162}$

Der Aufsatz zeigt Heß' angestrengtes Bemühen, zu den Grundlagen der bürgerlichen Gesellschaft vorzustoßen. Er steht jetzt deutlich unter dem Einfluß von Marx und

\section{LXXXVIII}


inzwischen unter der persönlichen Einwirkung von Engels. Er erkennt, daß die kommunistische Theorie auf der Einsicht in die materielle Produktion der Gesellschaft begründet sein muß und daß es mit der kommunistischen Gesellschaft vor allem die Trennung der Produkte vom Produzenten aufzuheben gilt. Er vermag jedoch den Zusammenhang von Ausbeutung und Konkurrenz mit den Voraussetzungen der kapitalistischen Gesellschaft, mit dem Privateigentum an den Produktionsmitteln, nicht zu erfassen, wie Engels ihn in seinen Umrissen dargelegt hatte, daher wird er hilflos bei der Behandlung der Frage: was geschieht in der kommunistischen Gesellschaft mit dem kapitalistischen Eigentum? Es behilft sich mit unklaren philosophischen Formulierungen: „Der Socialismus hebt in Wahrheit nur den Gegensatz von Privatmensch und entäußertem Gemeinwesen, also nicht sowohl das persönliche, als vielmehr das entäußerte Eigenthum auf." ${ }^{163}$ Neben einer die Sache selbst ergreifenden Darstellung findet sich in dieser wie in anderen Arbeiten aus dieser Zeit deren Übersetzung in eine an Feuerbach orientierte philosophische Interpretation. So wird die Konkurrenz zur klassischen Gestalt des Egoismus, der Sozialismus zu einer Gesellschaftsordnung, in der der Mensch das Gattungsleben zurückgewinnt usw. Man erkennt das Ringen von Heß um eine Erfassung der von der kapitalistischen Entwicklung aufgeworfenen praktischen und theoretischen Fragen und sieht, wie er allenthalben auf seine ,philosophischen" Schranken stößt, deren Überwindung ihm nicht gelingt.

In dem zweiten Beitrag Beachtenswerthe Schriften für die neuesten Bestrebungen beschäftigt Heß sıch mit einer Kritık an einer Reihe von in Wigand's Vierteljahrsschrift (Leipzıg 1844, Bd. 1 und 2) veröffentlichten Aufsätzen. Die Heßsche Kritik ist ein kleines Seitenstück zu der Kritik an der junghegelschen Philosophie von Marx und Engels in der Heiligen Familie, die Marx gerade zum Abschluß brachte, doch lohnt es nicht, näher auf jene einzugehen, einmal wegen der Bedeutungslosigkeit der krit1sierten Schriften, zum andern, weil Heß darin einen schon bekannten Standpunkt elnnimmt.

Die erste sozialistische Zeitschrift auf deutschem Boden, die sich ausschließlich mit der Lage der Arbeiter unter dem Bourgeoisie-Regime befaßte, war der von Heß herausgegebene Gesellschaftsspiegel. Der Weberaufstand und zahlreiche Hilferufe und rebellische Äußerungen proletarischer Gruppen aus Sachsen, Berlin, Westfalen und der Rheinprovinz hatten mit einem Schlage sichtbar gemacht, daß in Deutschland ein Proletariat herangewachsen war, das unter unmenschlichen Arbetts- und Lebensbedingungen sein Dasein fristen mußte. Die schonungslose Aufdeckung dieser Lage des Proletariats war der Gegenstand der Artikel und Berichte des Gesellschaftsspiegels. Der Arbeiter der einen Stadt sollte erfahren, daß an unzähligen anderen Orten Arbeiter unter den gleichen Bedingungen lebten und daß diese Bedingungen sie zu einer großen Klasse Recht- und Besitzloser zusammenschlossen. Es war einer der ersten Schritte, den Arbeitern zum Bewußtsein ihrer eigenen Lage zu verhelfen. Damit dokumentierte die Zeitschrift eine erste Verbindung von Arbeiterklasse und kommunıstischen Theoretikern. Die Tendenz des Blattes, die sich in seinem Untertitel verriet (Organ zur Vertretung der besitzlosen Volksklassen und zur Beleuchtung der gesellschaftlichen Zustände der Gegenwart), ging ursprünglich wohl auf Engels zurück, der mit dem Gesellschaftsspiegel ein deutsches Gegenstück zu seinem Werk über die Lage der englischen Arbeiter zu schaffen wünschte, mit dessen Abfassung er gerade beschäftıgt war. ${ }^{163 a}$

Für das als ausgesprochene Arbeiterzeitschrift bestimmte Blatt schieden von vorn- 
herein umständliche philosophische Erörterungen und auch der große Umfang (mehr als zwanzig Bogen) der Sammelwerke aus, welch letzteres allerdings mit dem Nachteil verbunden war, daß die Zeitschrift der Zensur unterlag.

Mit den Vorbereitungen zur Herausgabe des Gesellschaftsspiegels begannen Heß und Engels im Januar 1845. Am 20. Januar berichtete Engels an Marx in Brüssel: „Das Neuste ist, daß Heß und ich vom 1. April an bei Thieme \& Butz in Hagen eine Monatsschrift: ,Gesellschaftsspiegel' herausgeben und darin die soziale Misère und das Bourgeoisie-Regime schildern werden. [. . .] Das Ding kann mit wenig Mühe redigiert werden, für Material, um monatlich 4 Bogen zu füllen, werden sich Mitarbeiter genug finden - wir haben wenig Arbeit dabei und können viel wirken." ${ }^{\text {164 }}$ Einen Monat später kann er Marx mitteilen : ,Unser ,Gesellschaftsspiegel“ wird prächtig, der erste Bogen ist schon zensiert und alles durch. Beiträge in Masse. $\mathrm{H}[\mathrm{e} B]$ wohnt in Barmen in der ,Stadt London" "165

Als Engels im April nach Brüssel ging, blieb die Leitung des Blattes in Händen von Heß. Es erschien nicht, wie beabsichtigt, in Hagen, sondern in Elberfeld bei Bädeker; auch verzögerte sich die Herausgabe der ersten Nummern bis Mai 1845. Bädekers Ängstlichkeit machte Heß einiges zu schaffen; an Engels berichtete er: ... Ich habe [. . . . ] meine liebe Not mit ihm, daß er den Gesellschaftsspiegel gehörig unters Volk bringe; er will nichts riskieren."166 Im gleichen Brief ersuchte er Engels, endlich seinen versprochenen Artikel zu senden ${ }^{167}$, und teilte ihm auch die ersten Erfolge des Blattes mit: „Es sind hier am Orte unter der arbeitenden Klasse bereits über 200 Exemplare vom 1 ten Hefte abgesetzt und werden wohl noch doppelt so viele (wenigstens) verkauft werden, was insofern bedeutend ist, als die armen Leute immer zu mehreren sich auf ein Exemplar abonnieren. 600 Exemplare haben wenigstens 2000 abonnierte Leser (die Wirtshausleser also abgerechnet). Indessen ist das 2te Heft noch immer bei dem Zensor." 168

Die Zensur sowie die lokalen und Berliner Regierungsbehörden wurden anderthalb Jahre lang durch den Gesellschaftsspiegel schockiert. Die Regierung urteilte, das Blatt scheine eine sehr gefährliche Zeitung zu sein; durch die ,,boshafte und perfide Zusammenstellung der Notizen“" könnten die ,urteilsunfähigen Volksklassen "169 zu falschen Ansichten und Maßnahmen angeregt werden. Auch bürgerliche Kreise wurden angesichts des Erfolges des Gesellschaftsspiegels in Besorgnis versetzt. In große Bedrängnis geriet der Verleger Bädeker, dessen bürgerlichem Philanthropismus die Tendenz des Blattes unheimlich wurde. Der Gesellschaftsspiegel erschien bis Juli 1846 , dann wurde er von den Zensurbehörden verboten. ${ }^{170}$

„Es war kein geringes Verdienst", so schrieb Mehring über diese Zeitschrift, ,das Elend des deutschen Proletariats zu entschleiern, zur Zeit, wo der offizielle Historiker des französischen Sozialismus und Kommunismus, wo Lorenz Stein sich in der abgeschmackten Behauptung gefiel, in Deutschland gebe es kein Proletariat."171

Noch während der Vorarbeiten zum Gesellschaftsspiegel betrieb Heß die Herausgabe einer zensurfreien Vierteljahresschrift, Rheinische Jahrbücher zur gesellschaftlichen Reform. Es sollte, schrieb $\mathrm{He} ß$, eine ,rein sozialistisch(e)" Zeitschrift und „kein so dummer Mischmasch wie das Püttmansche Jahrbuch" werden; „Püttmann selbst, der als Herausgeber ,unter Mitwirkung' von uns auf dem Titel figurieren wird, ist eigentlich eine stumme Person in diesem neuen Drama und wird uns diejenigen Sachen, die nicht von uns ihm zugeschickt werden, zur Durchsicht respekt. Zensur vorlegen.“172 Die Jahrbücher erschienen im Verlag von C. W. Leske. ${ }^{172 a}$ Der Verleger warb auch 
um die Mitarbeit von Marx und suchte diesen noch vor seiner Übersiedlung nach Brüssel in Paris auf. Heß seinerseits ersuchte Marx in dem (bereits zitierten) Brief vom 17. Januar 1845, an dem Blatt mitzuarbeiten. Engels hatte seine Mitarbeit bereits zugesagt und forderte gleichfalls Marx auf, Artikel zu liefern: „Ich soll Dich nochmals in Heß' Namen - auch in dem meinigen tu ich es - auffordern, dem Püttmann was für seine $1 / 4$ jahresschrift zu schicken. Wir müssen durchaus gleich im ersten Heft alle erscheinen, damit das Ding Charakter bekommt."173 Marx zeigte anfangs große Bereitschaft zu einer Mitarbeit, war dann aber weder an dem ersten noch dem zweiten Band der Jahrbücher beteiligt; andere Arbeiten nahmen ihn wohl zu sehr in Anspruch, und dann, nach Kenntnisnahme des ersten Bandes, dürfte er das Interesse verloren haben, am zweiten mitzuwirken. Von Engels enthielt der erste Band die Elberfelder Red.'ll und der zweite Fest der Nationen in London. ${ }^{174}$

Bei der Redaktion scheint nur HeB mittätig gewesen zu sein. Im Vorwort erwähnt Püttmann ihn in einer Fußnote: „Dieser Freund hat mir bei der Redaction der wissenschaftlich gehaltenen Aufsätze sehr thätigen Beistand geleistet und auch für die Zukunft eine gleiche Mitwirkung zugesichert. "175

Die Jahrbücher sollten vierteljährlich erscheinen, indessen kamen nur zwei Bände heraus, der erste 1845 (das Vorwort trägt das Datum vom Mai 1845) und der zweite ein Jahr später (Vorwort vom Juli 1846). Die Hessische Regierung verbot bei Strafe von 500 Gulden im voraus die zensurfreie Verlegung des zweiten Bandes. Außerdem erhielt Leske eine Verwarnung der preußischen Regierung, daß bei Fortsetzung der Herausgabe derartiger Schriften ein Debitsverbot des gesamten Verlages in Preußen erfolgen würde. Ferner wurde Leske gezwungen, die Buchhändler namhaft zu machen, denen er Exemplare des ersten Bandes geliefert hatte, und schließlich wurde gegen ihn noch Anklage wegen Hochverrats und Verspottung der Religion erhoben. ${ }^{176}$ Unter solchen Bedingungen verzichtete Leske auf die Herausgabe des zweiten Bandes. Püttmann, der in die Schweiz geflohen war, gab ihn in der Verlagsbuchhandlung zu Belle-Vue bei Constanz heraus.

Von Heß enthielten die Jahrbücher insgesamt vier Beiträge: der erste Band die bereits genannten Aufsätze, Über das Geldwesen und die Elberfelder Reden, der zweite Band den Aufsatz Die Verhandlungen des gesetzgebenden Staatskörpers der Republik Waadt über die soziale Frage ${ }^{6177}$ und den erweiterten, ebenfalls schon erwähnten Vorwärts-Artikel unter dem neuen Titel Kommunistisches Bekenntniß in Fragen und Antworten.

Der Aufsatz Die Verhandlungen des gesetzgebenden Staatskörpers der Republik Waadt (verfaßt in der Mitte des Jahres 1845) bezog sich auf ein Ereignis im Waadtland in der Schweiz. Hier war die Agitation des aus Frankreich in die Schweiz emigrierten Mitverschwörers von Babeuf, Buonarroti, auf günstigen Boden gefallen. Vor Weitling hatte er hier dem Kommunismus zahlreiche Anhänger gewonnen, die im Frühjahr 1845 in einer unblutigen Erhebung die alte Regierung stürzten und im Mai 1845 Versammlungen abhielten, auf denen die künftige Konstitution des Landes beraten wurde. Dabei brachte die Bourgeoisie die Führung dieser Bewegung in ihre Hände und lieferte schließlich die sozialistischen und kommunistischen Sprecher einer grausamen Verfolgung aus. ${ }^{178} \mathrm{HeB}$, der dieses Mannöver der Bourgeoisie frühzeitig durchschaute, kritisierte in seinem Aufsatz die scheinsozialistischen Phrasen der Sprecher des Bürgertums. „Armes, unwissendes Volk!“", schrieb er, „Du wirst hier, wie überall, von Schwachköpfen und Eskamoteurs bei der Nase herum geführt. “179 
Heß' Aufsatz über die Schweizer Ereignisse zeigt deutlicher noch als zuvor den Einfluß von Marx und Engels. Heß kommt zu der Feststellung, daß allein das Proletariat zu einer Umwälzung der bestehenden sozialen Verhältnisse befähigt sei. ${ }^{180}$ Dies hätte $\mathrm{He} B$ wiederum als Ausgangspunkt dienen können, den Sozialismus als eine aus der historischen Lage des Proletariats erwachsende Bestrebung zu erkennen, woran sich die Folgerung hätte schließen können, daß die Möglichkeit und Notwendigkeit der sozialistischen Gesellschaft und der Übergang vom Kapitalismus zum Sozialismus von dem aus der ökonomischen Entwicklung resultierenden Klassenkampf abzuleiten seien. Heß war jedoch unfähig zu solcher Konsequenz. Das geht sowohl aus den Verhandlungen selbst hervor als auch aus der Tatsache, da $B$ er den inzwischen offensichtlich veralteten Vorwärts-Artikel noch einmal in den Rheinischen Jahrbüchern abdrucken ließ, und ferner aus jenem der drei hinzugefügten Kapitel, das sich mit dem Übergang zur kommunistischen Gesellschaft befaßt. ${ }^{181}$ Wie schon in seinen Elberfelder Ausführungen vertrat er auch hier keinen revolutionären Standpunkt, sondern glaubte, daß die kommunistische Gesellschaft durch allmähliche Reformen errichtet werden könne. Er gab sich der Illusion hin, daß die durch Wegfall der Ausgaben für nutzlose Staatseinrichtungen und durch Erhebung von progressiven Vermögenssteuern und Erbschaftssteuern erzielten Mittel dazu dienen würden, unentgeltliche Erziehungsanstalten und gesellschaftlich verwaltete Werkstätten einzurichten. Allmählich könne auf diesem Wege Grund und Boden aufgekauft und der Kapitalismus verdrängt werden.

Er untersuchte nicht die realen Möglichkeiten der Aufbringung solcher Mittel und eines solchen Aufkaufs, auch übersah er völlig die dabei eine entscheidende Rolle spielende Machtfrage, und er fragte nicht danach, auf welche konkrete Weise denn die nutzlosen Staatseinrichtungen abgeschafft werden sollten. Das Grundproblem, die Vergesellschaftung der Produktionsmittel, löste er durch eine Theorie des Aufkaufs, der den „organischen Besitz" herstellen sollte.

Bemerkenswert war allein die Absicht, die Theorie enger mit der Praxis zu verbinden, ein Problem, das ihn schon seit der Europäischen Triarchie beschäftigte und dem er in der Philosophie der Tat eine subjektiv-idealistische, später durch den Versuch, Feuerbachs Humanismus praktisch zu machen, eine moralisch-ökonomische Lösung gegeben hatte. Indessen zeigt auch dieser Aufsatz, daß $\mathrm{He}$ noch nicht klar verstanden hatte, daß die Theorie aus der Lage des Proletariats entwickelt werden, $\mathrm{daß}$ sie ihm diese Lage bewußt machen und es zum Handeln anleiten müsse. So schreibt er : „Wir haben vor allen Dingen der heutigen Gesellschaft ihr Elend und ihre Bestimmung zu einem bessern Dasein ins Bewußtsein zu rufen, damit der Wunsch nach menschlichen Zuständen, der Wunsch, aus dieser Sklaverei, in welcher wir uns befinden, heraus zu kommen, in der Mehrzahl der Menschen rege wird."182

\section{WISSENSCHAFTLICHER SOZIALISMUS CONTRA „WAHRER“ SOZIALISMUS \\ Offene Gegensätze}

Durch die Herausgabe des Gesellschaftsspiegel kam Heß zunehmend in ein gespanntes Verhältnis zu den Behörden, die ihn seit seiner Rückkehr aus Frankreich 
beobachten ließen. Aus Vorsicht übersiedelte er Sommerende 1845 nach Brüssel, wo er bis zum Frühjahr 1846 blieb und regen Verkehr mit Marx unterhielt. ${ }^{183}$ Marx war zu dieser Zeit mit der Abfassung der Deutschen Ideologie beschäftigt; Heß sollte zu dem Werk beitragen. ${ }^{184}$ Im März oder April 1846 ging Heß, wohl um dem Verlagsort des Gesellschaftsspiegels näher zu sein, nach Verviers, wo er sich bis zum Juni des gleichen Jahres aufhielt.

Nach der Abrechnung mit den Junghegelianern und der Trennung von den radikalen Demokraten wie Ruge und Fröbel hatte inzwischen der Scheidungsprozeß zwischen Marx und Engels einerseits und den Vertretern des namentlich von Heß begründeten „wahren" Sozialismus andererseits eingesetzt. Die Verbreitung des ,wahren" Sozialismus, der in den Jahren 1844 bis 1847 eine umfangreiche Literatur hervorgebracht hat und der zwiespältig auf die entstehende deutsche Arbeiterklasse wirkte - Bekanntmachung mit sozialistischen Ideen, aber gleichzeitig Lähmung der Kampfkraft durch die utopische Liebesideologie - , forderte Marx und Engels zu energischen Aktionen heraus, damit der ,Nebel aus der proletarischen Welt gefegt“" $\left(\mathrm{Mehring}^{185}\right)$ und dem Proletariat seine historische Aufgabe bewußt gemacht wurde. In der Deutschen Ideologie schrieben Marx und Engels hierzu: ,Wenn also die theoretischen Vertreter der Proletarier irgend etwas durch ihre literarische Tätigkeit ausrichten wollen, so müssen sie vor Allem darauf dringen, daß alle Phrasen entfernt werden, die das Bewußtsein der Schärfe dieses Gegensatzes schwächen, alle Phrasen, die diesen Gegensatz vertuschen und wohl gar den Bourgeois Gelegenheit bieten, sich kraft ihrer philanthropischen Schwärmereien der Sicherheit halber den Kommunisten zu nähern. Alle diese schlechten Eigenschaften finden wir aber in den Stichwörtern der wahren Sozialisten, namentlich in dem, wahren Eigentum'. Wir wissen sehr gut, daß die kommunistische Bewegung nicht durch ein paar deutsche Phrasenmacher verdorben werden kann. Aber es ist dennoch nötig, in einem Lande wie Deutschland, wo die philosophischen Phrasen seit Jahrhunderten eine gewisse Macht hatten und wo die Abwesenheit der scharfen Klassengegensätze andrer Nationen ohnehin dem kommunistischen Bewußtsein weniger Schärfe und Entschiedenheit gibt, allen Phrasen entgegenzutreten, die das Bewußtsein über den totalen Gegensatz des Kommunismus gegen die bestehende Weltordnung noch mehr abschwächen und verwässern könnten." $" 185 a$

Die Auseinandersetzung führte zu den ersten offenen Gegensätzen zwischen Marx und Engels auf der einen und $\mathrm{HeB}$ auf der anderen Seite. Wiewohl Heß seit dem Winter $1844 / 45$ versucht hatte, sich dem Standpunkt von Marx und Engels zu nähern, war ihm doch die von ihnen entwickelte materialistische Geschichtsauffassung unverständlich geblieben. Die Aufnahme einzelner Gedanken daraus hatte ihn nicht zu einer Überwindung seiner kleinbürgerlichen und idealistischen wahrsozialistischen Einstellung, sondern nur zu einer eklektischen Verbindung der entgegengesetzten Anschauungen geführt. Marx' konsequente und scharfe Attacken gegen die Vertreter des sektiererischen und kleinbürgerlichen Sozialismus sowie gegen den Handwerkerkommunismus Weitlings hielt er für unangebracht. Er erkannte nicht die ihnen zugrunde liegen'de sachliche Notwendigkeit einer ideologischen Klärung der Frontenstellung als Vorbedingung zur Schaffung einer proletarischen Kampfpartei.

So geriet er in eine peinliche Lage, als der Brüsseler Kreis sich mit den Auffassungen von Weitling auseinanderzusetzen begann. ${ }^{185 b}$ Weitling war nach einer zwölfmonatigen Haft in Zürich im Mai 1844 aus der Schweiz vertrieben, den deutschen Behörden über- 
liefert und im August 1844 aus Preußen ausgewiesen worden. Er war dann nach England gegangen, wo deutsche, englische und französische Sozialisten ihm zu Ehren ein Begrüßungsfest veranstalteten. Indessen mußte er bald gewahr werden, daß er seinen Einfluß im Bund der Gerechten verloren hatte. ${ }^{185 c}$ Enttäuscht verließ er England und begab sich im Januar 1846 nach Brüssel, wo er bis Mai des Jahres blieb und wo er mit Marx, Engels, Weydemeyer und Seiler verkehrte. In den ersten Wochen dürften die Beziehungen durchaus freundschaftlich und herzlich gewesen sein, und Weitling nahm gewiß teil an dem gemütlichen Beisammensein der kleinen deutschen Kolonie, von dem Jenny Marx später berichtete. ${ }^{185 d}$ Doch bald kam es zu heftigen Auseinandersetzungen zwischen ihm und dem Kreis um Marx. Auf einer Sitzung eines kleinen Kreises von Genossen in Brüssel am 30. März 1846, an der außer Marx, Engels, Weitling, Weydemeyer und Gigot noch Edgar von Westphalen und der russische Liberale Annenkow teilnahmen, prallten die gegensätzlichen Standpunkte hart aufeinander. Weitling fand keinen Übergang von seinem utopischen System zum wissenschaftlichen Sozialismus. Der Bruch war vermeidlich. ${ }^{186}$ Er wurde noch vertieft, als die Brüsseler Kommunisten in einem geharnischten Zirkular gegen Hermann Kriege Stellung nahmen, ein Mitglied des Bundes der Gerechten, der im Herbst 1845 nach New York gegangen war und dort in der von ihm herausgegebenen Zeitschrift Volks-Tribun die Ideen des "wahren“ Sozialismus propagierte. In dem Beschluß des Zirkularbriefes, dem ein ausführliches Begründungsschreiben beigefügt war, hieß es, daß die „kindisch-pomphafte Weise“ der von Kriege im Volks-Tribun vertretenen Tendenz ,im höchsten Grade kompromittierend für die kommunistische Partei in Europa sowohl als in Amerika" sei, insofern Kriege ,für den literarischen Repräsentanten des deutschen Kommunismus in New York gilt. [. . .] Die phantastische Gemütsschwärmerei, die Kriege unter dem Namen ,Kommunismus' in New York predigt, muß im höchsten Grade demoralisierend auf die Arbeiter wirken, falls sie von ihnen adoptiert wird. “187

Das Zirkular wurde am 11. Mai 1846 ausgegeben und außerdem im Juliheft des Westphälischen Dampfboots veröffentlicht. ${ }^{187 a}$ Weitling sah in dem Angriff gegen Kriege einen versteckten Angriff gegen sich. In einem Brief an Kriege klagte er: „Ich stehe von dieser Seite ganz allein mit $\mathrm{HeB}$, aber $\mathrm{He} B$ ist, wie ich, in die Acht erklärt. "188

Bei der Auseinandersetzung mit dem ,wahren" Sozialismus war es unvermeidlich, daß Marx die vor allem von $\mathrm{He} ß$ entwickelte theoretische Grundlage dieser Bewegung einer scharfen Kritik unterzog, was die Feststellung Weitlings erklären mag, daß Heß ,,in die Acht erklärt" sei. Am 20. Mai 1846 schrieb Heß aus Verviers an Marx: „Gleichzeitig mit Deinem Briefe erhalte ich einen von W[ilhelm] W[eitling]. [. .] Er ist in Verzweiflung und kann zu keinem Entschluß kommen. [. . .] Sein Mißtrauen gegen Euch hat den höchsten Gipfel erreicht. Ihr habt ihn ganz toll gemacht und wundert Euch nun darüber, daß er es ist. Ich mag nichts mehr mit der ganzen Geschichte zu tun haben; es ist zum Kotzen." ${ }^{189}$ Schließlich rang Heß sich Ende Mai, allerdings mehr aus persönlichen als prinzipiellen Erwägungen, zu einer Absage an Weitling durch; zugleich sagte er sich auch von der durch Marx repräsentierten Partei los, deren Maßnahmen er nicht voll billigen konnte. Er schrieb an Marx: „Wenn Du übrigens auch recht hast, daß die Privatmisere mit den Parteistreitigkeiten nicht zusammenhängt, so sind doch beide zusammen hinreichend, mir das gemeinschaftliche Wirken in dieser Partei zu verleiden; und so wenig $\mathrm{Du}$ auch für erstere verantwortlich gemacht werden kannst da Du selbst am meisten darunter leidest und ich wahrhaftig auch viel weniger wegen meiner als gerade wegen Deiner Privatmisere unsre Partei anklage - so sehr könntest Du doch 
dazu beitragen, die letztern, nämlich die Parteistreitigkeiten zu verhindern. [. . .] Gehab Dich wohl! Mit Dir persönlich möchte ich noch recht viel verkehren; mit Deiner Partei will ich nichts mehr zu tun haben. "190 In der notwendig gewordenen Auseinandersetzung sah $\mathrm{Heß}$ nur leidige Parteistreitigkeiten, denen er bei seiner mehr auf friedliche Schlichtung als auf kämpferische Auseinandersetzung ausgerichteten Grundhaltung verständnis- und hilflos gegenüberstand. Seine Entscheidung schien er schon bald wieder zu bedauern, denn am 5. Juni 1846 schrieb er an Marx: ,Daß ich in Sachen der Partei nicht mehr mit Dir in Kommunikation stehe, daran bin ich nicht schuld. Tut auch weiter nichts zur Sache, die ohne mein Zusammenwirken mit Dir doch ,marschieren wird." 191

Immerhin veranlaßten ihn die Auseinandersetzungen mit Weitling, Kriege und auch mit Grün, der Ende 1844 nach Paris gegangen war und dort in Versammlungen und Schulungsabenden Arbeiter mit sozialistischen Phrasen verwirrte, zur Überprüfung seiner bisherigen Ansichten. Aus Köln, wohin er sich nach dem Eingehen des Gesellschaftsspiegels begeben hatte, schrieb er am 28. Juli 1846 an Marx : „, Mit Deinen Ansichten über die kommunistische Schriftstellerei, die Du neuerdings Daniels mitteiltest, bin ich vollkommen einverstanden. So notwendig im Anfange ein Anknüpfen der kommunistischen Bestrebungen an die deutsche Ideologie war, so notwendig ist jetzt die Begründung auf geschichtliche und ökonomische Voraussetzungen, sonst wird man weder mit den ,Sozialisten', noch mit den Gegnern aller Farben fertig. Ich habe mich auch jetzt ausschließlich auf ökonomische Lektüre geworfen [. . .]."192

Der Brief kündigt Heß' Entschluß an, nunmehr durch Studien auf dem Gebiet der Ökonomie und Geschichte an der Entwicklung der neuen Weltanschauung mitzuarbeiten. Das Ergebnis seiner Bemühungen sollte aus seiner nächsten Schrift hervorgehen, mit der er nach längerer Pause im Sommer 1847 hervortrat.

Diese Pause war wohl in der Tat angefüllt mit ökonomischen und geschichtlichen Studien. Außerdem entfaltete Heß im Jahre 1846 eine große Betriebsamkeit, um einige Verlagsunternehmungen zustandezubringen. Zunächst versuchte er, ein von ihm und Engels angeregtes Projekt einer Bibliothek der vorzüglichsten Schriftsteller des Auslandes auszuführen. ${ }^{193}$ Es war geplant, die ,,besten Sachen“ von Fourier, Owen, Saint-Simon, Morelly, Godwin, Bentham etc. in deutscher Übersetzung herauszugeben. In dieser Reihe wollte $\mathrm{He} B$ eine Übersetzung der Conspiration pour l'égalité dite de Babeuf veröffentlichen. ${ }^{194}$ Dieses Unternehmen scheiterte ebenso wie der Versuch, mit Unterstützung von demokratisch oder kommunistisch eingestellten Geldgebern eine Vierteljahresschrift ins Leben zu rufen. ${ }^{195}$

Nach diesen Mißerfolgen begab Heß sich im Winter 1846/47 nach Paris ${ }^{196}$, wohl in der Hoffnung, dort größeren Erfolg mit publizistischen Unternehmungen zu haben. In Paris weilte damals auch Engels, der sich vom Frühjahr 1845 bis zum Sommer 1846 bei Marx in Brüssel aufgehalten und gemeinsam mit ihm die Deutsche Ideologie verfaßt hatte. Im August 1846 war er im Auftrag des Brüsseler Kommunistischen Korrespondenzkomitees nach Paris übergesiedelt, um hier dem Einfluß von Proudhon, Grün und Genossen auf Pariser und in dieser Stadt lebende deutsche Arbeiter entgegenzutreten. ${ }^{197}$ Die ehemals guten Beziehungen zwischen Engels und $\mathrm{He}$, in dem jener einige Jahre zuvor den ,,ersten Kommunisten “ in der Partei geschätzt hatte ${ }^{198}$, zerbrachen in der zweiten Hälfte des Jahres 1846. Der tiefe prinzipielle Gegensatz, der sich zwischen den beiden Männern gebildet hatte, war nicht mehr zu überbrücken. Die Entwicklung war über $\mathrm{Heß}$ hinweggeschritten; vor dem klaren, konsequenten und 
festgefügten Gerüst der materialistischen Geschichtsauffassung mußte er nun als zurückgebliebener Utopist erscheinen; als ein solcher wurde er von Engels behandelt. ${ }^{199}$

\section{Zur Vorgeschichte des „Kommunistischen Manifests“}

Die Differenzen zwischen Marx/Engels und Heß verhinderten indessen nicht, daß dieser doch weiterhin im Bund der Gerechten mitarbeitete. ${ }^{200}$ Den in London lebenden Führern des Bundes war gegen Ende 1846 die Unzulänglichkeit der Organisation und Ideologie des Bundes bewußt geworden, und sie planten, ihn als eine straff aufgebaute Partei mit einem einheitlichen Programm zu reorganisieren. In diesem Vorhaben suchten sie Unterstützung bei den Brüsseler Kommunisten, namentlich bei Marx und Engels. Letztere zögerten angesichts der veränderten Lage im Bund und ihrer inzwischen erfolgten theoretischen Selbstverständigung nicht mehr, dem Bund beizutreten. Auf dem ersten Bundeskongreß Anfang Juni 1847 in London, an dem Engels teilnahm, fand die Umwandlung des Bundes der Gerechten in den Bund der Kommunisten statt. ${ }^{201}$ Von dem Kongreß sind drei wichtige Dokumente überliefert : Ein Rundschreiben des Kongresses an den Bund, ein Statutenentwurf und ein Programm-Entwurf. ${ }^{201 a}$ Über diese Dokumente sollte in den Gemeinden beraten und auf einem weiteren, für den Winter 1847 vorgesehenen Kongreß abgestimmt werden. Heß hielt den Programm-Entwurf für sehr verbesserungsbedürftig. Er formulierte einen neuen, ein Glaubensbekenntnis, zu dem er auch von den Pariser Bundesmitgliedern die Zustimmung erhielt. Dieser Situation sah Engels sich gegenüber, als er nach einem etwa dreimonatigen Aufenthalt in Brüssel im Oktober 1847 nach Paris zurückkehrte. Er setzte alles daran, den Entzug der Zustimmung zu dem Heßschen Entwurf, den er völlig unbrauchbar fand, zu erwirken. Heß' Entwurf liegt nicht mehr vor, jedoch läßt sein etwa zwei Jahre später entstandener Rother Kathechismus, der gleichfalls als Grundsatzschrift gedacht war, erkennen, daß Heß auch in dieser Phase außerstande war, die geschichtliche Lage des Proletariats präzise zu umreißen und eine wissenschaftliche Richtschnur für das Handeln der Kommunisten zu geben. An Marx berichtete Engels am 25. Oktober 1847: „Ich hab' gleich eine Propagandagemeinde eingerichtet und laufe fürchterlich herum und pauke. In den Kreis bin ich gleich gewählt und hab' die Korrespondenz bekommen. [...] Dem Mosi [Heß] hab' ich, ganz unter uns, einen höllischen Streich gespielt. Er hatte richtig ein gottvoll verbessertes Glaubensbekenntnis durchgesetzt. Vorigen Freitag nun nahm ich dies im Kreise vor, Frage für Frage, und war noch nicht an der Hälfte angekommen, als die Leute sich für satisfaits erklärten. Ohne alle Opposition ließ ich mich beauftragen, ein neues zu entwerfen [...]." ${ }^{\text {202 }}$

Zur Zeit dieser Gegenaktion hielt $\mathrm{HeB}$ sich in Brüssel auf, wo er Mitglied und stellvertretender Vorsitzender des von Marx und Engels nach dem ersten Bundeskongreß gegründeten Deutschen Arbeitervereins wurde. ${ }^{203}$ Außerdem wurde er Mitglied der im November 1847 in Brüssel gegründeten Demokratischen Gesellschaft für die Vereinigung aller Völker (Association Démocratique), in deren Vorstand Marx gewählt wurde. ${ }^{204}$ Als Sprecher dieser Gesellschaft reiste Marx im November 1847 nach London, um an einer von den Fraternal Democrats veranlaßten internationalen Versammlung anläßlich des Jahrestages der polnischen Revolution von 1830 teilzunehmen (Engels war ebenfalls anwesend). ${ }^{204 a}$ Die Reise führte Marx zugleich zu dem zweiten Kongreß des Bundes der Kommunisten, der vom 29. November bis 8. Dezember in London 
tagte. $^{204 b}$ Der Kongreß verabschiedete ein neues Statut ${ }^{204 c}$, bekannte sich zu dem von Marx und Engels entwickelten wissenschaftlichen Kommunismus und beauftragte die beiden mit der Abfassung einer kommunistischen Grundsatzschrift. Noch vor dem Kongreß hatten Marx und Engels sich darüber verständigt, daß die von diesem entworfenen Grundsätze des Kommunismus dem Inhalt und der Form nach neugefaßt werden müßten, weshalb sie darauf verzichteten, sie dem Kongreß zur Beschlußfassung vorzulegen. ${ }^{205}$ Ende Januar 1848 waren Marx und Engels mit der Abfassung der Grundsatzschrift fertig, die in Gedankenführung und Stil vor allem auf Marx als Verfasser weist. Ende Februar 1848 erschien in London das Manifest der Kommunistischen Partei - die bedeutendste politische Programm- und Kampfschrift des internationalen Proletariats.

\section{Die Revolution}

Mit der Annahme des Manifestes war der Kampf von Marx und Engels um die Durchsetzung ihrer Ansichten im Bund zunächst entschieden. Notwendigerweise war dieser Kampf verbunden mit dem Kampf gegen alle Spielarten des kleinbürgerlichen Sozialismus, wie er von Proudhon, Grün, Kriege etc. vertreten wurde. Für die Auseinandersetzung mit diesen Richtungen stand ihnen seit dem Frühjahr 1847 die Deutsche-Brüsseler-Zeitung zur Verfügung. ${ }^{206}$ Dieses Blatt erschien seit Anfang 1847 zweimal wöchentlich, es wurde von Adalbert von Bornstedt herausgegeben ${ }^{207}$, der nicht verhindern konnte, daß Marx und seine Freunde allmählich die Zeitung unter ihren Einfluß brachten. Marx' erster Beitrag war eine Erklärung gegen Karl Grün, worin er die Veröffentlichung einer Kritik an dessen Buch über Die sociale Bewegung in Frankreich und Belgien. Briefe und Studien (Darmstadt, C. W. Leske, 1845) ankündigte. ${ }^{208}$ Die Kritik war bereits anderthalb Jahr zuvor entstanden und bildete einen Bestandteil der Deutschen Ideologie. Veranlaßt durch eine Herausforderung Grüns veröffentlichte Marx sie im September im Westphälischen Dampfboot. ${ }^{208 a}$

Marx kommt darin auch auf das Verhältnis von Grün und $H e B$ zu sprechen: „Herrn Grüns Bescheidenheit erlaubt ihm nicht, einen einzigen Satz auszusprechen, den nicht schon ein anderer wahrer Sozialist vor ihm in den "Einundzwanzig Bogen", dem ,Bürgerbuch' und den ,Neuen Anekdotis' geoffenbart hatte. Ja, sein ganzes Buch hat keinen andren Zweck, als ein in den ,Einundzwanzig Bogen' p. 74-88 von Heß gegebenes Konstruktionsschema der französischen sozialen Bewegung auszufüllen und einem ebendaselbst p. 88 ausgesprochenen Bedürfnis zu entsprechen. ${ }^{209}$ [...] Heß synthetisiert die Entwicklung des französischen Sozialismus mit der Entwicklung der deutschen Philosophie [...] Dieser Schematismus mit der Ausführung, die Heß $\cdot$ ihm gibt, bildet den ganzen inneren Zusammenhang des Grünschen Buchs. Nur daß Herr Grün nicht verfehlt, die Heßschen Sätze belletristisch anzustreichen. “210

Das idealistische Grunddogma des ,wahren“ Sozialismus faßt Marx in folgenden Sätzen zusammen: „Ausgestattet mit dem ungetrübten Glauben an die Resultate der deutschen Philosophie, wie sie in Feuerbach niedergelegt sind, nämlich daß ,der Mensch , der ,reine, wahrhafte Mensch', das Endziel der Weltgeschichte sei, daß die Religion das entäußerte menschliche Wesen sei, daß das menschliche Wesen das menschliche Wesen und der Maßstab aller Dinge sei; ausgestattet mit den weiteren Wahrheiten des deutschen Sozialismus [...], daß auch das Geld, die Lohnarbeit pp. Entäußerungen 
des menschlichen Wesens seien, daß der deutsche Sozialismus die Verwirklichung der deutschen Philosophie und die theoretische Wahrheit des auswärtigen Sozialismus und Kommunismus sei pp. reist Herr Grün nach Brüssel und Paris mit der ganzen Selbstgefälligkeit des wahren Sozialismus. [. . . ] Herr Grün erklärt hier also die wirklichen Lebensverhältnisse der Menschen für Erscheinungen, Religion und Politik aber für die Grundlage und Wurzel dieser Erscheinungen. Man sieht an diesem abgeschmackten Satze, wie die wahren Sozialisten die ideologischen Phrasen der deutschen Philosophie gegenüber den wirklichen Darstellungen französischer Sozialisten als höhere Wahtheit geltend machen und zugleich, wie sie $\mathrm{thr}$ eigentliches Objekt, das Wesen des Menschen, mit den Resultaten der französischen Kritik der Gesellschaft zu verbinden streben. Daß, wenn Religion und Politik als Grundlage der materiellen Lebensverhältnisse gefaßt werden, Alles in letzter Instanz auf Untersuchungen über das Wesen des Menschen, d. h. über das Bewußtsein des Menschen von sich selbst ausläuft, ist ganz natürlich. “211

Vergleicht man die Kritik an Grün mit der an Heß, so kann man in bezug auf letztere eine gewisse Zurückhaltung bemerken. ${ }^{212} \mathrm{Heß}$ wird zugestanden, daß seine Arbeiten wenigstens anfangs zu würdigen gewesen seien ${ }^{213}$, was jedoch ganz und gar nicht mehr der Fall sei bei seinen Arbeiten nach den Einundzwanzig Bogen sowie bei der gesamten Literatur der übrigen Vertreter des ,wahren" Sozialismus, die von Anfang an eine rückschrittliche Bewegung verkörpere. So mag sich also Heß recht und schlecht mit der Marxschen Kritik abgefunden haben, zumal er wohl der Meinung war, den von Marx kritisierten Standpunkt inzwischen überwunden zu haben. In Brüssel schloß er sich eng an Marx an und arbeitete auch an der Deutschen-Brüsseler-Zeitung mit. Neben einer Polemik gegen Ruge ${ }^{214}$, die sich noch auf die Zeit der Deutsch-Französischen Jahrbücher bezog, veröffentlichte er in diesem Blatt einen über mehrere Fortsetzungen sich erstreckenden Aufsatz: Die Folgen einer Revolution des Proletariats. ${ }^{215}$

In dem Aufsatz lehnt $\mathrm{HeB}$ sich zum Teil stark an Auffassungen von Marx und Engels an, und es zeigt sich, daß $\mathrm{HeB}$ wiederum einen revolutionären Standpunkt einnahm. Hatte er im Kommunistischen Bekenntniß ein phantastisches Programm zur Errichtung des Kommunismus entworfen und die Machtfrage völlig ignoriert, so stellt er hier die revolutionäre Übernahme der Macht durch das Proletariat allen ,,transitorischen" Maßnahmen (Besteuerung, allmähliche Überführung der Privatindustrie in gesellschaftliches Eigentum) voran. Die Revolution, hervorgerufen durch die $\mathrm{Zu}$ spitzung der inneren Widersprüche der kapitalistischen Gesellschaft, werde das Werk der proletarischen Klasse sein, die durch die moderne Großindustrie erzeugt wurde. Ihre objektiven Voraussetzungen lägen in der auf der gesellschaftlichen Arbeit beruhenden Großindustrie, die subjektive Voraussetzung bilde das zum Bewußtsein seiner Klassenlage und seiner historischen Aufgabe gekommene Proletariat. Nach der Erringung der politischen Macht durch das Proletariat müsse zunächst die Großindustrie und dann allmählich die gesamte Privatındustrie in die Hände des Staates übergeführt werden.

Zweifellos gehört dieser Aufsatz zu den reifsten Arbeiten von Heß; dabei darf indes zweierlei nicht übersehen werden. Erstens, soweit $\mathrm{HeB}$ eine richtige Darstellung der hıstorischen Rolle des Proletariats gibt, resümiert er Marx, und zweitens bedeutet diese Darstellung nicht, daß Heß die „Angleichung“ an Marx doch endlich gelungen sei. Es ist eine Angleichung Marxscher Auffassungen an die wahrsozialistischen von $\mathrm{Heß}$; sie bestehi in einer eklektischen Verbindung beider entgegengesetzter Stand- 
punkte. Wenn Heß z. B. von der Revolution spricht, so meint er eine in Deutschland bevorstehende sozialistische Revolution, während Marx der Ansicht war, daß in Deutschland zunächst die bürgerliche Revolution auf der Tagesordnung stehe. ${ }^{216}$ $\mathrm{HeB}$ teilte seine Auffassung mit anderen ,wahren" Sozialisten, die die bürgerliche Revolution mit der scheinradikalen Begründung ablehnten, daß sie die Bourgeoisie an die Herrschaft bringe, und diese Stufe müsse übersprungen werden.

Im Manifest der Kommunistischen Partei lesen wir: „Der Kampf der deutschen, namentlich der preußischen Bourgeoisie gegen die Feudalen und das absolute Königtum, mit einem Wort, die liberale Bewegung wurde ernsthafter.

Dem ,wahren' Sozialismus war so erwünschte Gelegenheit geboten, der politischen Bewegung die sozialistischen Forderungen gegenüberzustellen, die überlieferten Anatheme gegen den Liberalismus, gegen den Repräsentativstaat, gegen die bürgerliche Konkurrenz, bürgerliche Preßfreiheit, bürgerliches Recht, bürgerliche Freiheit und Gleichheit zu schleudern und der Volksmasse vorzupredigen, wie sie bei dieser bürgerlichen Bewegung nichts $\mathrm{zu}$ gewınnen, vielmehr alles $\mathrm{zu}$ verlieren habe. [...] Er [der ,wahre" Sozialismus] diente den deutschen absoluten Regierungen mit ihrem Gefolge von Pfaffen, Schulmeistern, Krautjunkern und Bürokraten als erwünschte Vogelscheuche gegen die drohend aufstrebende Bourgeoisie. “217

Eine weitere entscheidende Schwäche des Heßschen Aufsatzes zeigt sich in der Einschätzung des Verhältnisses von radikalen Demokraten und Kommunisten. Heß meint, daß jene lediglich einem Mißverständnis zufolge Gegner des Kommunismus seien, während in Wirklichkeit ihre Ziele sıch nicht von denen der Kommunisten unterschieden. Dies lief auf eine Verkennung gegensätzlicher Klasseninteressen hinaus und läßt erkennen, wie wenig $\mathrm{HeB}$ die Marxsche Auffassung vom Klassenkampf begriffen hatte. ${ }^{218}$

Es zeigt sich, daß von einer Anpassung $H e \beta^{\prime}$ an Marx nur bedingt die Rede sein kann. Der Gegensatz zwischen Marx/Engels und Heß mußte angesichts der bevorstehenden Revolution deutlich in Erscheinung treten. Es kam, wohl im Februar 1848, zu einem völligen Bruch. Eine freundschaftliche Zusammenarbeit von Marx/Engels mit $\mathrm{HeB}$ hat es nie wieder gegeben.

Nach Ausbruch der Revolution in Deutschland verließ Heß Brüssel, wo er sich seit September 1847 aufgehalten hatte, und begab sich nach Köln, mit der Absicht, die Rheinische Zeitung wieder ins Leben zu rufen. Als der Versuch scheiterte, ging er nach Paris (Mai 1848), wo er Mitglied und zeitweilig Präsident des im Sommer 1848 gegründeten Deutschen Vereins war. ${ }^{219}$ Nach Überhandnehmen der Kommunistenverfolgungen in Frankreich übersiedelte er im April 1849 in die Schweiz; bis Ende 1851 hielt er sich abwechselnd in Genf, Basel, Straßburg und Zürich auf. In Genf ${ }^{220}$, wo er von April 1850 bis Ende 1851 weilte, leitete er die Gemeinde der vom Bund der Kommunisten abgespaltenen Fraktion von Willich und Schapper. ${ }^{221}$

In Zürich und Genf verfaßte Heß den Rothen Kathechismus für das deutsche Volk ${ }^{222}$, eine Broschüre, die im Kölner Kommunistenprozeß eine gewisse Rolle spielen sollte. ${ }^{22 a}$ Theoretisch bringt die Broschüre nichts Neues. Sie hat ganz den Charakter einer Propagandaschrift, ist in sehr einfachen, schlagwortartigen Wendungen gehalten, womit $\mathrm{HeB}$ wohl dem Verständnis der Arbeiter entgegenkommen wollte. Die Vermuiung liegt nahe, daß Heß hierin jene Fragen und Antworten eingearbeitet hat, die er 1847 als kommunistisches Glaubensbekenntnis dem Kongreß des Bundes der Kommunisten vorzulegen beabsichtigt hatte. 
Es kam Heß vor allem darauf an, den Arbeitern ihre Lage bewußt zu machen, ihnen das System der kapitalistischen Ausbeutung zu erklären. Eine ganze Reihe von - recht oberflächlichen - Fragen und Antworten ist diesem Gegenstand gewidmet. Sodann ergeht er sich in längeren Ausführungen über die Organisation der kommunistischen Gesellschaft. Der Klassenkampf wird kaum erörtert, Fragen der Strategie und Taktik der Arbeiterklasse werden völlig übergangen. Der Kathechismus hält nicht den geringsten Vergleich mit der klassischen Kampfschrift des Proletariats, dem Manifest der Kommunistischen Partei, stand und offenbart den unermeßlichen Abstand zu Marx und Engels.

\section{SKIZZE DES LEBENS VON HESS VON 1850 BIS 1875}

Der Rothe Kathechismus (mit dessen Wiederabdruck die vorliegende Ausgabe abschließt und die Einleitung zu einer kurzen Skizzierung des Lebens und Schaffens von $\mathrm{He}$ übergeht), aber mehr noch Heß' Mitwirkung in der Gruppe Willich/Schapper zeigen, daß Heß' ideologische Annäherung an Marx eine oberflächliche war und daß er seine idealistisch-schwärmerische Haltung im Grunde nicht aufgegeben hatte. Als die unterschiedliche Einstellung im Bund der Kommunisten zur Frage der Möglichkeit einer revolutionären Erhebung des Proletariats in Deutschland 1850 zur Bildung der Fraktion Willich/Schapper führte, schloß Heß sich dieser an. Diese Gruppe glaubte das Fehlen objektiver Bedingungen zu einer proletarischen Revolution durch subjektiven Eifer wettmachen zu können. Im Sinne dieser Gruppe verfaßte Heß 1851 die Broschüre Jugement dernier du vieux monde social. ${ }^{223}$

Sowohl geschichtliches Unverständnis wie das Unterliegen besserer Einsicht vor dem revolutionären Wunsch ließen $\mathrm{HeB}$ an einer „Deutschen Nationalanleihe“ teilnehmen, durch die die Revolution auf Aktien gegründet werden sollte und für die unter anderen auch Heß als Garant zeichnete. ${ }^{224}$ In dem Statut hieß es: ,Die Beschaffung der Summe von 2 Millionen Dollars zur Beförderung der bevorstehenden republikanischen Revolution wird auf dem Wege einer deutschen Revolutionsanleihe betrieben. [...] Zur Garantierung der Anleihe sollen alle diejenigen aufgefordert werden, welche durch ihre Parteistellung der öffentlichen Meinung eine Bürgschaft bieten. [...] Die Garantie besteht in der Leistung des Versprechens, in und nach der Revolution nach Kräften dahin zu wirken, daß die Anleihe als eine verzinsliche Staatsschuld zur Anerkennung gebracht werde. “225

In Genf teilte Heß das Schicksal der zahlreichen Emigranten, die vor den Verfolgungen in Deutschland Asyl in der Schweiz suchten. Anfang 1852 ging er nach Lüttich. Auch nach dort wie nach Holland, wohin er im gleichen Jahr übersiedelte, folgte ihm der Steckbrief, der ihn als gefährlichen Kommunisten brandmarkte. Im Frühjahr 1854 suchte er Zuflucht in Marseille; im Juni war er wieder in Paris, das ihm zur zweiten Heimat wurde.

Von der ersten Hälfte der fünfziger Jahre an beschäftigte $\mathrm{HeB}$ sich mit philosophischen Fragen der modernen Naturwissenschaft. Er nahm sich damit einer in der Tat aktuell gewordenen Problematik an, der er sich, mit einigen Unterbrechungen in den 60er Jahren, bis an sein Lebensende widmete. ${ }^{225 a}$ Über sein Ziel erklärte er sich im Dezember 1852: „Ich beabsichtige nämlich, meine schon früher ausgesprochenen, aber noch nicht gehörig ausgeführten Ansichten über die Geschichte der Menschheit 
naturwissenschaftlich zu begründen, indem ich das allgemeine und gleiche oder einige Gesetz nachzuweisen mich bemühe, welches in der Entwicklungsgeschichte alles Lebens waltet, sowohl des sogenannten anorganischen wie organischen und ,geistigen“.“225b

Mit seinen Bemühungen stellte $\mathrm{HeB}$ sich als vierter in die Reihe der deutschen naturwissenschaftlichen Materialisten des neunzehnten Jahrhunderts. Er teilt die metaphysischen Schwächen des Materialismus der Moleschott, Büchner und Vogt, die den Menschen nicht als soziales, sondern als Naturwesen begriffen; aber er teilt nicht deren große Verdienste als Propagandisten des Atheismus.

Hatte er früher seine sozialistischen Vorstellungen eklektisch mit Elementen der klassischen deutschen und der Philosophie Feuerbachs zusammengebracht, so nun mit Elementen des naturwissenschaftlichen Materialismus, die er in der Hauptsache von Moleschott übernahm. In Anlehnung an Moleschott entwickelte er eine mechanische „Kraft- und Stofftheorie“, die das Leben der Gesellschaft erklären und den Sozialismus wissenschaftlich begründen sollte. ${ }^{225 c}$ Anfang der 70er Jahre schrieb Heß: „Ich habe also denselben Beweis [, den Darwin für das Organische gab,] für das Kosmische und Sociale zu liefern. Die mechanische Kraft- und Stoff-Theorie liefert ihn. “225d Der gleiche Heß, der zu Beginn der 40er Jahre versucht hatte, die Hegelsche Dialektik dem Sozialismus dienstbar zu machen und die Gesellschaft auf Grund historisch-sozialer Gesetzlichkeiten zu erklären, fiel bei seinen philosophischen Verallgemeinerungen natur- und gesellschaftswissenschaftlicher Resultate weit hinter Hegel zurück, insofern er gesellschaftliche Vorgänge per analogiam zu Naturvorgängen zu erklären unternahm. In französischen und deutschen Zeitschriften veröffentlichte $\mathrm{HeB}$ eine große Zahl von Aufsätzen naturwissenschaftlichen und philosophischen Inhalts. ${ }^{226}$

Ende der 50er Jahre wandte Heß sich Fragen der Judenemanzipation zu. In seiner Schrift Rom und Jerusalem, die letzte Nationalitätsfrage (Leipzig, E. Wengler, 1862) kam er auf die Vorstellungswelt seiner Kinder- und Jünglingsjahre zurück. Eine Lösung der „Judenfrage" sah er in der Errichtung eines jüdischen sozialistischen Staates in Palästina. Die Schrift, die die zionistische Bewegung einleitete, steht tief unter dem, was $\mathrm{HeB}$ vor der Revolution geschrieben. Heß konstruiert eine außerhalb der ökonomischen und klassenmäßigen Determiniertheit der bürgerlichen Gesellschaft stehende selbständige Kraft: die Nationalität. ${ }^{227}$

Im Erscheinungsjahr des Buches wurde $\mathrm{He} B$ auswärtiges Mitglied der Berliner „Philosophischen Gesellschaft“, für deren Zeitschrift Der Gedanke er einige Artikel lieferte. ${ }^{228}$

Vorübergehend unterstützte $\mathrm{He} ß$ den Bonapartismus und veröffentlichte von Oktober 1859 bis Juni 1860 Korrespondenzen in der in Genf erscheinenden bonapartistischen $L$ 'Espérance. ${ }^{228 a}$

Als einer der ersten aus der alten Garde schloß Heß sich der in den 60er Jahren wieder erstarkenden deutschen Arbeiterbewegung an. Er bekannte sich zu Ferdinand Lassalle und war Mitglied des 1863 in Leipzig begründeten Allgemeinen Deutschen Arbeitervereins. Von Mai bis November 1863 war er Bevollmächtigter des Allgemeinen Deutschen Arbeitervereins für Köln, und in dieser Eigenschaft hielt er im Juni 1863 in Köln eine Propagandarede ${ }^{228 b}$; ein sozialistisches Programm entwickelte er in einer Rede, die er in Köln und Düsseldorf hielt und die im Juli 1863 als Broschüre veröffentlicht wurde (Rechte der Arbeit). ${ }^{229}$ Gleichfalls als Broschüre erschien eine am 15. November 1863 in Mühlheim gehaltene Rede Über social-ökonomische Reformen. ${ }^{230} \mathrm{Im}$ Dezember 1863 ging $\mathrm{HeB}$ wieder nach Paris. Bis zu seinem Austritt 
aus dem Allgemeinen Deutschen Arbeiterverein Anfang 1867 lieferte er Beiträge für den Social-Demokraten.

Heß' Austritt aus dem Allgemeinen Deutschen Arbeiterverein erfolgte, nachdem der Verein das „Erfurter Programm“ angenommen hatte, gegen das Heß wegen seines kompromißlerischen Charakters heftigen Widerspruch erhob. ${ }^{231}$

Wie Marx und Engels bekämpfte $\mathrm{HeB}$ auf dem Kongreß der 1864 in London gegründeten Internationalen Arbeiter-Assoziation den kleinbürgerlichen Sozialismus von Proudhon und Bakunin. Auf dem Brüsseler KongreB (1868) empfahl er den Arbeitern das Studium des kürzlich erschienenen ersten Bandes des Kapital von Marx. ${ }^{231 \text { a }}$

Der Sozialdemokratischen Arbeiterpartei näherte er sich 1869; 1869/70 war er Mitarbeiter ihres Organs Der Volksstaat.

Bei Beginn des deutsch-französischen Krieges wurde Heß aus Frankreich ausgewiesen. Er ging nach Brüssel und wandte sich in mehreren Aufsätzen gegen die dynastische Kriegspolitik der Hohenzollern. ${ }^{232}$

Im Leipziger Hochverratsprozeß im März 1872, in dem Bebel, Liebknecht und Hepner wegen ihrer aktiven Gegnerschaft zu dem preußischen Raubkrieg unter Anklage standen, zählte ein Aufsatz von Heß, Die soziale Revolution, zum Belastungsmaterial. Der Aufsatz war zwischen März und August 1870 im Volksstaat, dem von Liebknecht in Leipzig herausgegebenen Organ der Sozialdemokratischen Arbeiterpartei, erschienen, an welchem $\mathrm{He}$ nach seinem Bruch mit dem Herausgeber des Social-Demokraten mitarbeitete. ${ }^{233}$ Unter anderem würdigte $\mathrm{Heß}$ darin die Leistungen von Marx mit den Worten: „Was Darwin für die Ökonomie der Natur, hat Marx für die soziale Ökonomie wissenschaftlich konstatirt.“234

Nach Paris zurückgekehrt (1872), setzte $\mathrm{Heß}$ seine naturwissenschaftlichen Studien fort. Der durch viele Kämpfe und Entbehrungen früh Gealterte wollte endlich sein lange geplantes Werk abschließen, worin er das Gesetz des Werdens und Vergehens im Bereich des kosmischen und irdischen Lebens nachweisen wollte. Die gereifte Erkenntnis des alternden Mannes wollte sich in einem umfassenden Lebenswerk aussprechen, das die Krönung eines vieljährigen Schaffens sein sollte. Der Tod ereilte ihn, bevor er dieses Werk vollbringen konnte. ${ }^{235} \mathrm{HeB}$ starb am 6. April 1875. ${ }^{236}$

Namentlich die deutsche Arbeiterklasse wird Moses Heß ein ehrendes Andenken bewahren. Ungeachtet theoretischer und praktischer Irrgänge war $\mathrm{HeB}$ bis an sein Lebensende ein aufrechter, selbstloser und unbestechlicher Kämpfer für die Befreiung der Ausgebeuteten und Unterdrückten.

Ein ehrenvoller Platz innerhalb der deutschen Arbeiterbewegung gebührt Heß vor allem für sein frühes sozialistisches Wirken. Die radikale und revolutionäre vormärzliche Publizistik ist engstens mit dem Namen HeB verbunden.

Vor Marx und Engels versuchte er, die entwicklungsfähigen Keime der klassischen deutschen und der Philosophie Feuerbachs für die sozialistische Theorie fruchtbar zu machen. Sein Versuch scheiterte, er überschritt nicht die Grenzen des utopischen Sozialismus.

Eine wissenschaftliche Theorie, welchen Gegenstandsbereich sie auch erfaßt, hat, soweit möglich, die umfassendste induktive Erforschung dieses Bereichs und den daraus gewonnenen Nachweis kausaler Beziehungen zur Mindestvoraussetzung. In den ver- 
schiedenen Etappen seiner Bemühungen um eine wissenschaftliche Geschichtstheorie und eine wissenschaftliche Begründung des Kommunismus hat $\mathrm{HeB}$ sich diese Voraussetzungen nicht schaffen können. Er verstrickte sich immer wieder in teleologische Konstruktionen und später in mechanistische Erklärungsprinzipien.

Indes hat er als unermüdlicher Propagandist, Schriftsteller, Editor und Parteigänger sein Lebtag die Interessen der Arbeiter zu verfechten gesucht. Eine Zeitlang war er enger Kampfgenosse von Marx und Engels, und als diese den Kampf gegen den ,wahren" Sozialismus eröffneten, dessen theoretische Grundlage wesentlich er geschaffen, versuchte er, den von ihnen begründeten wissenschaftlichen Kommunismus sich zu eigen $\mathrm{zu}$ machen. Es ist ihm das nicht gelungen. Einem ständigen Bündnis mit Marx und Engels standen seine idealistischen und utopischen Tendenzen im Wege, die er nie ganz loswurde. Sie ließen den „ehrlichen Confusionarius“ - wie Jenny Marx ihn einmal nannte - in der Wahl seiner Mittel oft arg danebengreifen, so daß sich sein subjektiv ehrliches Streben, irregeleitet durch mangelnde Wissenschaftlichkeit und mangelnde politische Prinzipienfestigkeit, der objektiven Wirkung nach in das Gegenteil verkehren konnte. Dennoch sind Moses Heß' theoretische und propagandistische Verdienste sowie seine Teilnahme an der deutschen sozialdemokratischen Bewegung ein unvergänglicher Beitrag für den Beginn der sozialistischen Bewegung in Deutschland. 
